Running head: EVALUATION OF COMPUTER-BASED TRAINING

EVALUATION OF COMPUTER-BASED TRAINING TO TEACH STAFF TO IMPLEMENT

FREE-OPERANT PREFERENCE ASSESSMENTS

A Dissertation

presented to

the Faculty of the Graduate School

at the University of Missouri-Columbia

of the Requirements of the Degree

Doctor of Education

By

LEANNE HOPPER

Dr. Bret D. Cormier, Dissertation Supervisor

JULY 2020 
The undersigned, appointed by the dean of the Graduate School, have examined the dissertation entitled

\section{EVALUATION OF COMPUTER-BASED TRAINING TO TEACH STAFF TO IMPLEMENT FREE-OPERANT PREFERENCE ASSESSMENTS}

presented by Leanne Hopper, a candidate for the degree of Doctor of Education, and hereby certify that, in their opinion, it is worthy of acceptance,

Dr. Bret D. Cormier, Chair

Dr. Paul Watkins

Dr. Casey Clay

Dr. Melissa Odegard-Koester

Dr. David Stader 


\section{DEDICATION}

To my husband David, for being supportive and helpful when I was on my computer for hours on end and always being my number one fan. You listened to me and encouraged me at just the right times. To my children, Ashton, Kate, and Brooklyn for their patience and understanding throughout this process. I hope to show them that hard work and perseverance in setting a goal and achieving it pays off. Finally, to my parents, Dan and Melanie Wood, who instilled in me a desire for learning, motivated me to push for more than status quo, and my biggest supporters in all things great and small. 


\section{ACKNOWLEDGEMENTS}

I would like to thank the following people, without whom I would not have been able to complete this research and doctoral degree.

To my dissertation chair, Dr. Bret D. Cormier, I appreciate your guidance through each stage of this process. Thank you for your willingness to meet with me (if not in person, then video) to help me complete this dissertation.

To the members of my dissertation committee, Dr. Paul Watkins, Dr. Melissa OdegardKoester, Dr. David Stader, and Dr. Casey Clay, thank you for your willingness to serve on my committee and assist me in this process.

To Dr. Casey Clay for your guidance, feedback, and expertise in the field of applied behavior analysis. Your feedback is invaluable, and I appreciate your ongoing support.

To Kevin and Cheryl Smith, who allowed me to provide training to their staff and allow me to take the extra time needed for the steps in this research.

To my colleagues, Rachel Felter and Brandon Colbert, that provided me with support and willingness to be an integral part of my research. I appreciate your extra time and dedication to help me complete this dissertation.

To the staff that participated in this research and completed many sessions in baseline for me and worked so hard throughout the training. The consumers you work with are truly lucky to have each of you working alongside them.

To Misty Chisum and Millicent Odhiambo for being a part of the presentation training video and learning more about preference assessments than you ever imagined! 
To my Panda sisters, each of you pulled me to the finish line - literally with your love, support, nagging, and simple refusal to leave me behind in this process. It is the friends we meet along the way that help us appreciate the journey. I am so thankful to have you all with me on the journey in this doctoral program, but most importantly-life. 


\section{Table of Contents}

Acknowledgements $\quad$ ii

List of Tables $\quad$ iiv

Abstract iiiv

Section One - Introduction to Dissertation in Practice

Background of the Study 1

Statement of the Problem 4

Problem of Practice 5

Existing Gap in the Literature 6

Purpose of the Study $\quad 8$

$\begin{array}{ll}\text { Research Questions } & 10\end{array}$

$\begin{array}{lr}\text { Conceptual/Theoretical Framework(s) } & 10\end{array}$

Design of the Study - Quantitative 12

Independent \& Dependent Variables $\quad 12$

$\begin{array}{ll}\text { Setting } & 12\end{array}$

$\begin{array}{ll}\text { Participants } & 15\end{array}$

$\begin{array}{ll}\text { Data Collection Tools } & 17\end{array}$

$\begin{array}{ll}\text { Data Analysis } & 18\end{array}$

Limitations, Assumptions, and Design Controls 20

$\begin{array}{ll}\text { Definitions of Key Terms } & 21\end{array}$

$\begin{array}{ll}\text { Significance of the Study } & 25\end{array}$

$\begin{array}{ll}\text { Scholarship } & 25\end{array}$

$\begin{array}{ll}\text { Practice } & 26\end{array}$ 
$\begin{array}{ll}\text { Summary } & 26\end{array}$

$\begin{array}{ll}\text { References } & 27\end{array}$

Section Two - Practitioner for the Study

$\begin{array}{ll}\text { Introduction } & 35\end{array}$

$\begin{array}{ll}\text { History of the Organization } & 37\end{array}$

$\begin{array}{ll}\text { Organizational Analysis } & 38\end{array}$

Leadership Analysis $\quad 41$

Implications for Research in the Practitioner Setting 43

$\begin{array}{ll}\text { Summary } & 44\end{array}$

$\begin{array}{ll}\text { References } & 45\end{array}$

Section Three - Scholarly Review for the Study

$\begin{array}{ll}\text { Introduction } & 48\end{array}$

$\begin{array}{ll}\text { Overview } & 52\end{array}$

$\begin{array}{lr}\text { Conceptual Framework } & 52\end{array}$

$\begin{array}{ll}\text { Review of the Literature } & 56\end{array}$

$\begin{array}{ll}\text { Summary } & 77\end{array}$

$\begin{array}{ll}\text { References } & 79\end{array}$

Section Four - Contribution to Practice

$\begin{array}{lr}\text { Introduction } & 91\end{array}$

Conceptual/Theoretical Framework(s) 95

$\begin{array}{ll}\text { Review of Literature } & 95\end{array}$

$\begin{array}{ll}\text { Research Design } & 99\end{array}$

$\begin{array}{ll}\text { Results } & 100\end{array}$ 
$\begin{array}{ll}\text { Discussion } & 101\end{array}$

$\begin{array}{ll}\text { References } & 103\end{array}$

Section Five - Contribution to Scholarship

$\begin{array}{ll}\text { Title } & 112\end{array}$

$\begin{array}{ll}\text { Abstract } & 113\end{array}$

$\begin{array}{ll}\text { Introduction } & 114\end{array}$

$\begin{array}{ll}\text { Method } & 119\end{array}$

$\begin{array}{ll}\text { Procedure } & 125\end{array}$

Results 128

$\begin{array}{ll}\text { Discussion } & 130\end{array}$

Limitations and Future Research 133

References 136

Section Six - Scholarly Practitioner Reflection 143 


\section{List of Tables}

Figure 1. Slide nine from computer-based training for implementing the steps of the free-operant preference assessment.

Figure 2. 11-steps of the task analysis for implementing free-operant preference assessment.

Figure 3. Multiple Baseline Across Participants. Percentage of correctly performed steps of the 11-step task analysis for conducting the free-operant preference assessment

Table 4. Percentage of correct responses across participants for written pretest and post test 


\title{
EVALUATION OF COMPUTER-BASED TRAINING TO TEACH STAFF TO IMPLEMENT FREE-OPERANT PREFERENCE ASSESSMENTS
}

Leanne Hopper

\author{
Dr. Bret D. Cormier, Supervisor
}

\begin{abstract}
Computer and video technology emerging over the last few years provide more opportunities to deliver quality staff trainings while increasing efficiency and reducing costs associated with trainings. The purpose of this study is to extend previous research by evaluating the effectiveness of computer instruction training to teach entry level staff to conduct a free preference assessment to be used with adults with developmental disabilities. This study focuses on the impact of utilizing computer instruction, without a trainer present, for entry level staff's competency to (a) implement the target steps of a free-operant preference assessment, (b) score and interpret the results of the data, and (c) maintain competency of skills taught after training is complete. Results of this study demonstrate increased performance of staff's implementation of the target steps of the assessment from a baseline average of $53.6 \%$ to $96.6 \%$ after training provided via computer-based instruction alone. During generalization phase, staff trainee's average accuracy of completing target steps maintained at $96 \%$ accuracy, while maintenance accuracy was $100 \%$ accuracy across three trainees two weeks after the training. Outcomes of the current study supports the use of computer-based learning alone as being an effective mode to training staff in less than 40 minutes training time.
\end{abstract}


Running head: EVALUATION OF COMPUTER-BASED TRAINING

SECTION ONE:

INTRODUCTION TO DISSERTATION IN PRACTICE 


\section{Background}

Identifying effective training standards for staff working with individuals with developmental disabilities is a vital part of any human service organization. To provide effective strategies to clients they serve, agencies must understand the immeasurable value of quality staff training programs. However, closing the research-to-practice gap for staff trainings may be difficult, time consuming, and costly. Training staff effectively requires a substantial amount of time, money, and materials. It also creates unbillable hours and staff are often missing therapy sessions with clients. Despite initial drawbacks, it is critical for human service organizations to understand the link between effective staff training and improved organization output tied to their mission and vision.

Reid and Parsons (2003) described two outcomes effective staff training should produce: staff skill acquisition and "enhanced client's welfare" (p. 53). Training staff to implement procedures with high levels of treatment integrity leads to increased positive outcomes for those being served and contributes to developing effective teams (DaFonte \& Capizzi, 2015). Human service organizations build strong teams through effective training. Northouse (2016) describes positive outcomes from organizations with effective teams in that they demonstrate greater productivity, display effective use of resources, make better decisions, solve complex problems, create better products and services, and foster greater innovation and creativity.

Computer and video technology emerging over the last few years provide more opportunities for organizations to deliver quality trainings to their employees while increasing efficiency and reducing costs associated with trainings (Gerencser, et al., 2020). The field of behavior analysis recommends implementation of assessments and interventions to be grounded in evidence-based research, this includes staff training methods as well. A number of research 
studies demonstrate effective training utilizing technology across a number of behavior analytic interventions and assessments that include discrete trial training (Pollard, et al., 2014; Fazzio, et al., 2009; Nosik \& Williams, 2011; Nosik, et al., 2013), basic applied behavior analysis (ABA) strategies and principles (DaFonte \& Capizzi, 2015; Granpeesheh, et al., 2010; Vladescu, et al., 2012), safety skills for children with Autism Spectrum Disorder (Johnson, et al., 2005), and direct preference assessments (Deliperi, et al., 2015; Delli Bovi, et al., 2016; Lipschultz, et al., 2015; Rosales, et al., 2015; Weldy, et al., 2014).

Within the field of applied behavior analysis (ABA), one area staff training utilizing technology would be beneficial and effective is implementing direct preference assessments with clients. Motivation is a key component necessary to create engagement and learning opportunities for learners. For individuals with developmental disabilities, we are challenged to identify how to motivate one to complete tasks that can often be aversive, but are necessary and beneficial for them to complete (e.g., self-care skills, brushing teeth, following directions, independent living skills). Without motivation, it is unlikely successful implementation of behavior strategies and interventions will occur or problem behavior may increase, including self-injurious behavior, in attempts to escape the aversive event. Determining preferences of individuals with development disabilities can often be challenging due to communication deficits, inflexible and repetitive behavior patterns, and/or restricted interests (Roane, et al., 1998). Direct preference assessments is one way to help determine what motivates the learner. Previous studies have demonstrated empirically derived reinforcers, from preference assessments, are more effective than arbitrarily selected reinforcers across a variety of behavior programs (Kodak, et al., 2009; Vollmer, et al., 1994). Conducting direct preference assessments increases the likelihood of identifying the most potent reinforcers and is recommended in best 
practice guidelines (Cote, et al., 2007; Leaf, et al., 2020). It is an effective way to assess preference and identify potential reinforcers is well supported by previous empirical studies (Carr, et al., 2000; DeLeon \& Iwata, 1996; Kang, et al., 2013; Leaf, et al., 2020; Pace, et al., 1985; Piazza, et al., 2011; Roane, et al., 1998).

One direct preference assessment is the free-operant (FO) preference assessment (Roane, et al., 1998). This type of preference assessment is simple and quick to implement at only 5minutes in duration, as compared to other types of preference assessments, which range from 1530 minutes in length (Kang, et al., 2013). This assessment involves the simultaneous presentation of all stimuli to the individual and allows engagement with all items without withdrawing items at any time. Currently, there are a handful of empirical studies demonstrating positive outcomes when staff training uses technology (e.g., computer based learning or video modeling with voiceover instructions) without any additional training components to teach trainees to accurately implement the steps of direct preference assessments (Deliperi, et al., 2015; Delli Bovi, et al., 2017; Lipschultz, et al., 2015; Rosales, et al., 2015; Weldy, et al., 2014). To date, only two published studies have explored the use of technology unaided by additional supports to train staff to implement the steps specifically for the free-operant preference assessment (Rosales et al., 2015; Weldy et al., 2014).

Research supports the use of direct preference assessments and identifies benefits of doing so with individuals with developmental disabilities, however, these methods are only useful if staff are trained to competency implementing these assessments. Additional studies are needed to add to the current body of research in using technology without a trainer present (or identify if certain steps are necessary to have a trainer present) using trainees that are front line staff or direct line implementers. 
There is great importance for organizations to understand the immeasurable value of quality training programs for staff to learn the required skills to provide effective strategies to clients they serve. However, this can be challenging to close the research-to-practice gap for staff trainings, as the methods can be time consuming and costly. Training staff effectively requires a substantial amount of time, money, and materials. Additionally, training are generally unbillable hours and staff are often missing therapy sessions with clients. However, despite initial drawbacks, it is critical for human service organizations to understand the link between effective staff training and improved organization output tied to their mission and vision for the clients served.

\section{Statement of the Problem}

Staff training that focused on teaching performance skills not only improves knowledge of the subject matter, but specifically targets improving staff's ability to implement target skill sets. Hands-on trainings provided under the direction of highly skilled professionals are considered an important part of best practice staff training for the development of performance skills (Lerman, et al., 2008; Nottingham, et al., 2017). However, this type of intensive hands-on training is often time consuming and costly, making it difficult to provide the level required to fully support trainees.

Training on procedures to conduct direct preference assessments would be beneficial to professionals implementing behavioral interventions. A meta-analysis review by MaffeiAlmodovar and Sturmey (2018) on the effective use of various approaches to training behavior performance skills found only six articles specific to training individuals to implement preference assessments. To date, only two published studies have explored the use of technology unaided by additional supports to train staff to implement the steps specifically for the free- 
operant preference assessment (Rosales et al., 2015; Weldy et al., 2014). Currently, there are a handful of empirical studies demonstrating positive outcomes when staff training uses technology (e.g., computer based learning or video modeling with voiceover instructions) without any additional training components to teach trainees to accurately implement the steps of direct preference assessments (Deliperi, et al., 2015; Delli Bovi, et al., 2017; Lipschultz, et al., 2015; Rosales, et al., 2015; Weldy, et al., 2014).

\section{Problem of Practice}

Research supports the use of direct preference assessments and identifies benefits of doing so with individuals with developmental disabilities, however, these methods are only useful if staff are trained to competency in the implementation of these assessments. Graff and Karsten (2012a) surveyed 406 professionals regarding current practices related to assessing preferences of individuals with developmental disabilities across the disciplines of Applied Behavior Analysis (ABA), Psychology, and Special Education. More than half of all respondents surveyed by Graff and Karsten (2012a) reported that they were never trained to conduct direct preference assessments. Individuals that did report receiving some type of training to implement the steps of preference assessments, indicated it was gathered independently from reading published studies or training manuals $(27 \%)$, in-services training (19\%), and $12 \%$ attended a workshop on conducting direct preference assessments. This appears much lower than the recommended training guidelines for best practice (Graff \& Karsten, 2012a). Furthermore, survey results revealed that $50 \%$ of all respondents cited lack of knowledge of preference assessment procedures as a barrier to implementing them with clients (Graff \& Karsten, 2012a). 
The importance of identifying effective reinforcers when working with individuals with developmental disabilities combined with the self-reported lack of training and knowledge of preference assessments, highlights the need for additional exploration in research regarding the development of effective and efficient training programs to teach staff to implement the steps of direct preference assessments (Graff \& Karsten, 2012a; Vollmer, et al., 1994). Graff and Karsten (2012a) reported that $81.4 \%$ of surveyed professionals cited lack of time as a barrier to using preference assessment on a regular basis. Because of the ease of implementation and short duration, free-operant preference assessments can be used daily to reveal shifts in preferences (Egel, 1981).

\section{Existing Gap in the Literature}

There are some specific target areas as related to gaps in the current literature that this study would address. First, the additional contribution to the body of literature regarding direct preference assessments and staff training related to using technology without additional trainer present would be beneficial. There are currently only five published research studies using technology alone to train staff to implement the steps of preference assessments (Deliperi, et al., 2015; Delli Bovi, et al., 2017; Lipschultz, et al., 2015; Rosales, et al., 2015; Weldy, et al., 2014). Only two of those studies are specific to free-operant preference assessments (Rosales, et al., 2015; Weldy, et al., 2014). It would be advantageous to extend this line of research with additional information on conducting this type of training with this specific preference assessment.

Second, the prior knowledge and experience of the trainee receiving instruction is also an important component. Gerencser et al. (2020) reviewed three studies using video modeling with embedded instructions to train behavior therapists (Lipschultz et al., 2014; Rosales, et al., 2015; 
Weldy et al., 2014). The participants trained to implement the preference assessment steps had more prior work experience than in in the other studies using different methods. It was suggested that this could attribute to the success of the participant's training results.

Furthermore, all participants had prior knowledge implementing other behavior implementation procedures (e.g., discrete trial instruction) but had no prior experience implementing direct preference assessments (Gerencser et al., 2020). Lipschultz et al. (2015) evaluated using video modeling with embedded instructions with four clinical staff with 3 to 60 months experience working with individuals with Autism Spectrum Disorder (ASD) to implement the steps of three direct preference assessments, single stimulus (SS), multiple stimulus without replacement (MSWO), and paired stimulus (PS). Deliperi et al. (2015) evaluated the same training method with three clinical staff with 8 to 24 months experience working with individuals with ASD to teach the components of paired-stimulus (PS) assessments. Weldy et al. (2014), used group training format to train nine behavioral staff (i.e., bachelor's degree level with no formal training in conducting preference assessments) at a clinic to implement MSWO and free-operant (FO) assessments. Delli Bovi et al. (2017) trained two public school staff (i.e., vice principal and paraprofessional) to implement MSWO preference assessment. Rosales et al. (2015) trained public school teachers to implement three different preference assessments (e.g., PS, MSWO, and FO). To date, no study has evaluated the use of video modeling or computer training to train entry level clinical staff (i.e., Registered Behavior Technicians) to conduct a free-operant assessment.

Finally, staff must be able to use the information obtained within the preference assessment. The overall goal of preference assessments is to identify stimuli that will go on to function as reinforcers. It is important for staff to be able to accurately score and interpret 
assessment results. If preference assessments are incorrectly scored or interpreted, this could lead to decreased effective instructional opportunities. Only six research studies published to date have included training staff to summarize and/or interpret preference assessment data (Bishop \& Kenzer, 2012; Graff \& Karsten, 2012b; Deliperi et al., 2015; Roscoe \& Fisher, 2008; Roscoe, et al., 2006; Weldy et al., 2014). But only one of those studies included accurate scoring and interpretation of the free-operant preference assessment (Weldy et al., 2014).

\section{Purpose of the Study}

The purpose of the current study is to extend previous research by evaluating the effectiveness of computer-based training to teach staff to conduct a free-operant preference assessment to use with adults with developmental disabilities. Organizations often desire well trained staff, but are unable to identify the important components or training methods necessary or fund the support cost of training to competency. Working with adults with developmental disabilities with behavior issues can be challenging. Staff must be competent in their skills and feel supported by leadership in order to build a strong team. Direct care staff must be provided with effective training, as they are working directly with clients that may often engage in problem behavior such as aggression toward others or self-injurious behaviors. The function of these problem behaviors can often be related to escaping nonpreferred tasks or activities. By utilizing reinforcement throughout targeted interventions, we can attempt to increase motivation during aversive tasks while decreasing problem behavior. I also recognize the difficulty organizations are faced with in that upfront cost of the hands on training required to have fully trained and competent staff. As a supervisor, often middle management, I see the constraints of the organization financially, and also recognize the great need for quality training for all staff. In order to meet both needs, I believe technology can bridge that gap and satisfy both from an 
organizational level and individual staff members.

Computer based instruction is one viable instructional method current research has highlighted that can offer a way to train staff effectively and efficiently. A number of disciplines such as medicine, healthcare, and business, have found online or computer-based training to be an effective teaching modality as compared to in person teaching (U.S. Department of Education, Office of Planning, Evaluation, and Policy Development, 2009). An emerging line of research has begun to focus on maintaining effectiveness but increasing efficiency of behavior based performance staff trainings by reducing the need for the presence of a trainer throughout the training (Gerencser et al., 2020; Karsten, et al., 2011; Nottingham et al., 2017). Using technology in the form of videos and computer training has been shown to be an effective teaching modality for numerous applied behavior analytic technologies while decreasing cost and expanding training delivery (Boyle et al., 2019; Brock \& Carter, 2013; DaFonte \& Capizzi, 2015; Feldman \& Matos, 2013; McCulloch \& Noonan, 2013). The implementation of some behavior procedures are complicated and will likely always require some aspect of hands on direct staff training in the form of trainer feedback or role play in order to be effective. However, some current research supports computer-based training alone, without a trainer present, as an effective mode of teaching the implementation of direct preference assessments in as little as 30-minutes training time (Deliperi, et al., 2015; Delli Bovi, et al., 2017; Lipschultz, et al., 2015; Rosales, et al., 2015; Weldy, et al., 2014).

This study contributes to the literature by analyzing an efficient and effective staff training approach that can be used to train all entry level behavior staff (i.e., less than three months providing behavior analytic programming at a Registered Behavior Technician (RBT) or behavior implementer) working directly with adults with developmental disabilities. Training 
these front line implementers to conduct direct preference assessments can lead to increased effectiveness of skill acquisition and behavior reduction programs for clients by staff able to better identify potential reinforcers that can be used within these interventions. The use of technology to provide training and reduce the number of direct training hours with professionals while continuing to provide an effective training will offer benefits across professionals, parents, and schools.

\section{Research Questions}

The following are the three questions guiding this research:

1. What impact does utilizing computer based staff training have on direct line implementer's competency to implement target steps of a free-operant preference assessment?

2. What impact does utilizing computer based staff training have on direct line implementer's competency to score and interpret the results of free-operant assessment data?

3. Are direct line implementer's able to maintain the skill during behavior sessions at least two weeks after the training is complete?

\section{Conceptual/Theoretical Framework}

The goal of science is to achieve a thorough understanding of the specific phenomena under study. In applied behavior analysis, the focal points are socially important behaviors. Applied behavior analysis (ABA) is the application of learning principles focused on improving behaviors of social significance and determining if the observed changes are a function to the applied procedures (Baer, Wolf, \& Risley, 1968). The United States Surgeon General (1999) concluded, "Thirty years of research demonstrated the efficacy of applied behavioral methods in 
reducing inappropriate behavior and increasing communication, learning, and appropriate social behavior."

Reinforcement is an important principle in the practice of Applied Behavior Analysis used to strengthen desired behaviors (Cooper et al., 2007). The effectiveness of skill acquisition and behavior reduction interventions depend largely on the successful identification and implementation of effective reinforcers (Kodak et al., 2009). Direct care staff often struggle to identify effective reinforcers for individuals with developmental disabilities. Research shows direct preference assessments are the most effective way to use preferred stimuli to identify potential reinforcers for individuals with development disabilities (Kang, et al., 2013).

Within the field of applied behavior analysis, interventions must have a strong evidence base. This also applies to the experimental designs used to generate empirical evidence to study these various interventions and analyze their outcomes (Hitchcock, et al., 2015; Horner et al., 2005). Single-subject designs are used to evaluate the effect of a number of different interventions in applied research and are used in the fields of psychology, education, and human behavior. Single-subject experimental designs involve repeated, systematic measurement of the dependent variable before (baseline), during (treatment/intervention), and after treatment (generalization/maintenance) through manipulation of the independent variable (Kazdin, 2011). Visual analysis is particularly important within single-subject designs, as two or more conditions are compared. For example, the baseline (before treatment) and intervention (once treatment is applied) are used to establish cause-and-effect relationships between the dependent and independent variable

There are different applications within the single subject designs including A-B-A-B design, multi-element design, and multiple baseline design. Multiple baseline design can be 
measured across multiple individuals, behaviors, or settings. This current study uses the multiple baseline across participants design. Similar to the A-B-A-B design, the multiple baseline design starts in baseline and then proceeds to the intervention. However, it is not necessary to return to baseline using the multiple baseline design in order to demonstrate treatment effect (Cooper et al., 2005). This is useful when the treatment cannot be withdrawn or the intervention is irreversible due to learning effects (i.e., cannot stop reading once the subject learns to read).

\section{Design of the Study}

This study used a single subject research design, using a noncurrent multiple baseline across participants. This design was used to evaluate the effect of computer-based training on trainee's correct implementation of the steps of the free-operant (FO) preference assessment based on Roane at al., 1998 study. A baseline was established for the dependent variable for each participant (like a control condition). During the FO preference assessment, trainees were required to (a) implement the preference assessment, (b) collect and summarize the data, (c) rank items based on calculated percentage of selection.

\section{Independent and Dependent Variables}

The independent variable was the computer-based training for each trainee. Each trainee separately viewed the same 38-minute computer-based training. The training consisted of 36 individual slides and a duration of 38 minutes, including a full 5-minute preference assessment at the end of the training. The presentation ran automatically and included voice over descriptions of the content of each slide. The first portion of the training detailed the training objectives: (a) define free operant preference assessment and importance of these type of assessments, (b) accurately implement the steps of the free-operant assessment, and (c) accurately summarize the data of the results of the assessment. The slide included knowledge checks in which the trainee 
was asked to answer true or false questions or multiple choice questions about important content.

Each step of the 11-step task analysis was reviewed with video examples and practice

opportunities. For example, step five is writing the names of each item in the assessment on the data sheet in the proper location. One slide outlined example of target items used during a preference assessment and wrote the names of the items in on the slide, while instructing the participant to write the names on the blank data sheet provided to them.

Figure 1. Slide nine from computer-based training for implementing the steps of the free-operant preference assessment.

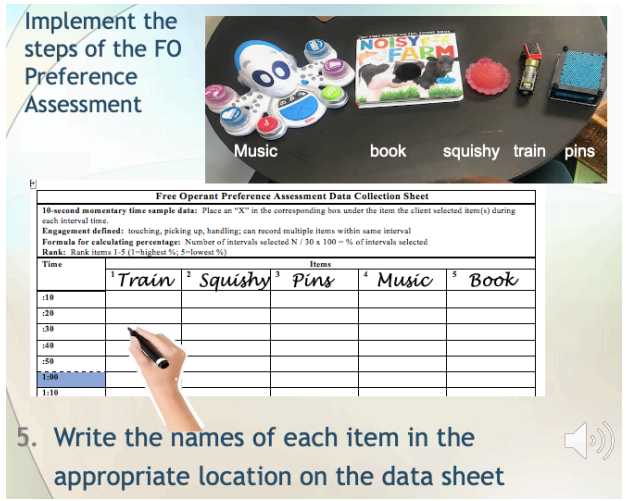

The dependent variable was the percent of correct implementation of the 11-step task analysis by the trainees (similar to those described by Weldy et al., 2014).

Figure 2. 11-steps of the task analysis for free-operant preference assessment

1. Prepares materials in location where preference assessment will be conducted (e.g., data sheet, pencil, timer, assessment items)

2. Removes distractors from location where assessment is conducted

3. Writes the names of each stimuli in the appropriate area on the data sheet

4. Directs consumer to area and presents each item separately for approximately 20 -seconds for each (or consumer stops manipulating)

5. Places all items in arched array on the table or floor in front of the consumer

6. Verbal statement to instruct the consumer to engage with any items in array

7. Press "start" on the timer to begin the session

8. Records data using the 10 -s MTS method for 5 minutes ( $90 \%$ or greater accuracy)

9. Presses stop on timer once 5 minutes has elapsed and ends the session

10. Correctly calculated the percentage of intervals each item is manipulated

11. Identifies the correct rank for each item

\section{Setting}


The practitioner setting for this study was a for-profit agency setting in a rural Midwest city. The primary researcher is a Board Certified Behavior Analyst (BCBA) that works in this agency. The computer training portion of the study took place in a small office with a desk and computer. Each trainee completed the computer-based training individually in the small office at a desk. The computer was set up on the beginning slide and the trainees were instructed initially by the primary investigator how to operate the computer to start and pause the training. Once the video began playing, the primary investigator left the room. The trainee completed the computer-based training in the room without anyone else present. Once the training video ended, the trainee came back into a conference room. The computer video training was 38minutes in duration and played on a MacBook Air computer. The slides were created in PowerPoint.

During the data collection portion, the participants were asked to watch a one-minute video of someone implementing the first eight steps of the preference assessment (see figure 2). This allowed the participant to view the implementation of the steps first (instruction and modeling steps), before practicing implementing the steps. The next slide showed the same oneminute clip and asked the participants to record data using the momentary time sampling procedure. A timer was on the screen to help identify the 10-second intervals. A completed data sheet was provided on in the training allow participants to check their responses. Additional questions were answered about how to record data if the client was engaged with more than one item during the intervals (e.g., record all engagement across all items) and if there was ever an instance of not running the assessment for a full five minutes based on item manipulation (e.g., always record full 5-minutes, even if client is not engaged with any item). Examples and practice of determining the percentages and ranking were included at the end of the training. 
The final activity was completing a full 5-minute assessment, scoring the data and figuring the percentages and rankings of the items. A completed data sheet was provided during the training to compare the participant responses to correct responses for this 5-minute session.

The sessions with a simulated client (adult playing the role of a clients) took place in a larger conference room with a long table and chairs. The trainee and adult simulated clients sat across the table from each other. The materials necessary to conduct the assessment were placed in a container on the table. Fifteen different items were alternated during the preference assessments. Five items were placed in the container, along with a timer, clipboard with FO preference assessment data sheet, and pencil at the start of each assessment. The participant was told that these five items were identified as preferred by the simulated clients for the purposes of the assessments.

During generalization and maintenance sessions with clients, the supervisors generated a list of 15-20 different preferred items specific to each client that the participant could choose from for each preference assessment. Generalization and maintenance sessions took place during a typical behavior session conducted by the participant with the clients in the session room at the agency. This room contained two to four small tables and six chairs. Two additional staff members and three to four other clients not participating in the study were present during these generalization and maintenance sessions. Materials used during these phases included at least five items identified as preferred by the specific clients at the table, a timer, pencil, and clipboard with copy of the data collection form to be completed during the assessment.

\section{Participants}


Participants (referred to as trainees) were four female staff members ranging in age from 27 to 40 years. At the beginning of the training, Rose, Madison, Layne, and Ashley had 0, 0, 12, and 0 months of experience, respectively, providing behavior-analytic services to individuals with developmental disabilities. Each of the trainees were all in process of obtaining national certification for a Registered Behavior Technician ${ }^{\mathrm{TM}}\left(\mathrm{RBT}^{\circledast}\right)$ from the Behavior Analysis Certification Board (BACB). The RBT is a paraprofessional certification in behavior analysis. RBTs assist in delivering behavior analytic services and practice under the direction of a supervisor, typically a master's-level Board Certified Behavior Analyst (BCBA). In order to be nationally certified as an RBT, the individual must complete a 40 hour training and pass a written exam.

Three of the trainees at the start of this research had completed this 40 hour training using online modules (outside of the current organization). The fourth trainee, Ashley, was certified as a RBT at the start of her training. At the completion of this study, three of the four trainees were certified as RBTs.

All trainee's average level of education was high school graduate or GED. These staff members previously worked in the position of direct care staff at the adult day program within the current organization for at least six months. Trainees reported knowledge of direct preference assessments from these training modules, but were not familiar with the terms "freeoperant preference assessment". In addition, the trainees reported no hands-on training implementing any direct preference assessment. The trainee, Layne, did report 12 months of experience implementing behavior analytic programming with a child with autism spectrum disorder (ASD). She implemented these programs under the direction of a BCBA. This 
experience ended 18 months prior to this research study. Layne reported that no training or implementation of preference assessment occurred during this time.

Participation in the study was voluntary and not a requirement for their employment. Staff participants were excluded from the research study if they met any of the following criteria: (a) score $80 \%$ or above on the written pre-test of the preference assessment training, (b) verbal report of prior experience or hands on training by a BCBA regarding implementation of direct preference assessment methods, or (c) demonstrate above $80 \%$ accuracy of implementation of direct preference assessment components during baseline sessions. All trainees were able to participate in the study and did not meet any exclusionary standards.

\section{Data Collection Tools}

Free-operant preference assessment data collection form. This data collection form was the form the trainees were taught to use during the video training session (see Appendix). The form was then used by the trainee to implement the free-operant preference assessment with the simulated client and in the maintenance phase. Data was collected on this form by the trainee using 10-s momentary time sample data for $5 \mathrm{~min}$. The form was divided into 30 intervals (10second intervals across $5 \mathrm{~min}$ ), for the trainee to collect data at the end of each 10 -second interval based on the client's engagement with items used in the preference assessment. Operational definition of engagement with items was defined as the client "touches any part of the item". A placed on "X" under the column for each stimuli the client was interacting with at the end of that interval. The interval was left blank if the client was not interacting with any items at the end of that specific interval. At the end of the $5 \mathrm{~min}$, the total number of intervals the individuals interacted with each stimuli was reported as a percentage of engagement (number of intervals interacted with item divided by the total number of intervals during the assessment 
and multiplied by 100). The total percentage of engagement for each stimuli was also used to rank the items based on percentage from 1 to 5 , with 1 being the stimuli with the highest percentage (most preferred) and 5 being the stimuli with the lowest percentage (least preferred).

Free-operant task analysis data collection form. An 11-step task analysis was used to collect data for the dependent variable (see Appendix). This task analysis contained 11 specific steps necessary to complete the preference assessment and is similar to task analyses developed in previous research (Rosales et al., 2015; Weldy et al., 2014). Observers collecting primary and secondary data related to the dependent variable, as well as treatment fidelity, used this data collection form.

Written pre- and posttests. Pretests and posttests composed of 14-multiple choice questions about the specific steps of the preference assessment were provided to each trainee and completed before (pretest) and at the end (posttest) of the computer-based training (see Appendix). This was used to gather basic knowledge of free-operant preference assessment for each trainee at baseline and after the computer training was provided. Trainees must score below $80 \%$ on the written pretest in order to participate in the study. Posttest mastery criterion of $80 \%$ or higher was necessary in order to begin sessions with a simulated client.

\section{Data Analysis}

Free-operant preference assessment data collection form. This data collection sheet was used by trainees during all free-operant preference assessment sessions throughout the study. Data from this form was used to score step eight in the free-operant task analysis form (e.g., "records data using the 10-s momentary time sampling method for 5-min with at least $90 \%$ accuracy") The data the trainee's collected during the simulated client step was compared against the script used by the simulated client. Each interval from the trainee data form that 
matched the script data form was scored as correct, while intervals that did not match the script data form was recorded as incorrect. Percentage correct was calculated by adding the total number of correct intervals by the total number of correct and incorrect intervals and multiplying by 100 (e.g., 28 intervals matched scripted data/30 total intervals divided by 100 would be $93.3 \%$ accurate). If the percent correct was $90 \%$ of above, the data recorded on the task analysis form for step nine was recorded as correct (e.g., “+”). If the percent correct was below 90\% accuracy, step nine was recorded as incorrect (e.g., “-”).

Free-operant task analysis data collection form. Once the computer training was complete (independent variable), the trainees were asked to implement the steps of the freeoperant preference assessment taught in the computer training with a simulated client (i.e., primary investigator or another staff member acting as a client). Data was collected using the 11-step task analysis during these sessions and summarized by the percent of correct implementation of these steps (similar to those described by Weldy et al., 2014).

Data were collected for each step by placing an " $\mathrm{X}$ " under the appropriate columns: "yes", "no", and "not applicable". A "X" was recorded under the "yes" column if the target step was performed correctly by trainee. An "X" was recorded under the "no" column if the target skill was not performed or performed incorrectly by staff trainee. If the step was not applicable during a particular assessment, the "X" was placed under the "not applicable" column. The percentage for correct responses was calculated for each session by dividing the number of correct responses ("yes") by the number of total opportunities to engage in a correct response ("yes" and "no") and multiplying by 100. Components scored as "not applicable" were not included in the calculations. Mastery criterion for treatment sessions with a simulated client was $90 \%$ accurate completion of steps using the free-operant preference assessment data collection 
form across two consecutive sessions.

Written pre and posttests. Pre and post tests were scored as percentage correct by totaling the number of correct responses, dividing by the total number of questions, and multiplying by 100 . Trainees must score below $80 \%$ on the written pretest in order to participate in the study. Posttest mastery criterion of $80 \%$ correct responses or higher was necessary in order to begin sessions with a simulated client.

\section{Limitations, Assumptions, and Design Controls}

This study focuses on a specific group of trainees (i.e., entry-level behavior technicians) and it limited to one agency, so the generalizability of the findings to other agencies and trainees not examined in this study is limited to those that are similar. There is limited research in regard to training staff with little experience in implementation of behavior analytic strategies or intervention. For example, Weldy et al., (2014) participants had at least one year of behavior analytic studies, implementation of behavior analytic interventions, and data collection. There was a concern that this type of training might not be an adequate training method for individuals with less experience or education in the field, such as newly hired line therapists (e.g., registered behavior technicians or behavior implementers).

As with any study, certain assumptions are present. It is expected that the participants were completing the activities during the computer-based training. Also, the most effective training methods were identified in previous research. Staff training programs relying on only verbal-skill strategies (e.g., lectures, presentation of written and visual material) can enhance targeted information, but often are ineffective for teaching learners to perform newly targeted job skills (Parsons, et al., 2011). This study used a computer-based instructional method that incorporated proven effective training methods using behavior skills training (e.g., instruction, 
modeling, practice, and feedback). Like previous research using computer based instructions (Gerencser, et al., 2020), this study utilized multiple features from other training formats such as video examples, competency questions, narrated slides, self-guided practice, and/or mastery assessments.

Certain design controls were implemented during this study. A second, independent observer collected interobserver agreement (IOA) data on a minimum of $30 \%$ of preference assessment sessions throughout the study. Mean IOA for correct implementation of the 11 target steps within the assessment was collected using the trial-by-trial method. Trial-by-trial IOA was collected by calculating the number of trial items agreement divided by the total number of trials and multiplied by 100 . Mean IOA for correct implementation of completing the data collection sheet during the preference assessment (step eight of the 11 steps) was also completed and used interval-by-interval method. This IOA was collected regarding the accuracy of the data collected by the trainee as compared to the script used during the baseline and simulated client phases (pre-completed FO assessment data form). During maintenance, this IOA was collected by a secondary observer and compared with the primary observer's data. This used a scored interval IOA, by identifying the number of intervals that agree, then divide that number of those that agree by the total number of those intervals.

Another design control used was treatment fidelity. Data was collected for at least 20\% of sessions in the study regarding the implementation of the steps in which the intervention was accurately implemented. A checklist of steps to be implemented by the trainer were used to record "yes" (if the step was completed correctly) or "no" (if the step was completed incorrectly or skipped) by a secondary observer (see Appendix). 


\section{Definition of Key Terms}

\section{Applied Behavior Analysis}

It is the science dedicated to improving human behavior by using the scientific method to analyze behavioral interventions and determining their effectiveness in improving behaviors of social significance.

\section{Behavior Analyst Certification Board (BACB)}

The Behavior Analyst Certification Board, Inc. ${ }^{\circledR}\left(\mathrm{BACB}^{\circledR}\right)$ is a nonprofit 501(c)(3) corporation established in 1998 to meet professional credentialing needs identified by behavior analysts, governments, and consumers of behavior analysis services.

\section{Board Certified Behavior Analyst (BCBA)}

A Board Certified Behavior Analyst (BCBA) is a person with a certification in applied behavior analysis. BCBAs receive this certification through the Behavior Analyst Certification Board (BACB).

\section{Computer-based instruction}

Computer based instruction utilized multiple features from other training formats such as video examples, competency questions, narrated slides, self-guided practice, and/or mastery assessments.

\section{Free-operant preference assessment}

Free-operant preference assessment is a way to identify potential reinforcers. One observes what the individuals interacts with in an unrestricted manner. The total duration of the time that the person engages with each item or stimulus is recorded. The longer that the individual engages with the stimulus, the stronger the case that the item is preferred. This method can be contrived (contrived free-operant observation), where the environment is seeded 
with hypothetically reinforcing items, or conducted in a natural environment (naturalistic freeoperant observation) such as a small room.

\section{Interobserver agreement (IOA)}

Interobserver agreement (IOA) refers to the degree to which two or more independent observers report the same observed values after measuring the same events. Interobserver agreement increases the confidence that the target behavior was clearly defined and confirm that change in data is due to change in behavior and not in data collection.

\section{Interval interobserver agreement (IOA)}

In scored interval IOA, one must determine the number of intervals that have a "yes", then divide that number of those that agree by the total number of those intervals.

\section{Momentary time sampling}

Recorder notes whether the behavior happens at the moment each interval ends.

\section{Multiple baseline across participants}

This single subject experimental design uses multiple participants in the study and staggering when the intervention is applied. At first baseline data is taken on all participants, and then participants are given treatment over time.

\section{Positive reinforcement}

Positive reinforcement involves adding something to increase response, such as going on a bike ride with a child after she cleans up her room.

\section{Preference assessment}

A preference assessment is conducted to identify potential reinforcers.

\section{Registered Behavior Technician (RBT)}

The Registered Behavior Technician ${ }^{\mathrm{TM}}\left(\mathrm{RBT}^{\circledR}\right)$ is a paraprofessional certification in 
behavior analysis. RBTs assist in delivering behavior analysis services and practice under the direction and close supervision of an RBT Supervisor and/or an RBT Requirements Coordinator, who are responsible for all work RBTs perform.

\section{Reinforcement}

Reinforcement is a term used in operant conditioning to refer to anything that increases the likelihood that a response will occur. Reinforcement is defined by the effect that it has on behavior-it increases or strengthens the response.

\section{Single subject/case experimental design}

Single-case experimental designs (SCED) are experimental designs aiming at testing the effect of an intervention using a small number of patients (typically one to three), using repeated measurements, sequential ( \pm randomized) introduction of an intervention and method-specific data analysis, including visual analysis and specific statistics.

\section{Social Validity}

Social validity refers to the acceptability of and satisfaction with intervention procedures, usually assessed by soliciting opinions from the people who receive and implement them.

\section{Task Analysis}

A task analysis links a series of behaviors to create a more complex behavior chain.

\section{Treatment fidelity}

Treatment fidelity reflects the extent to which an intervention is accurately implemented. Treatment integrity, implementation accuracy, and procedural accuracy are all terms that essentially describe the assessment of how well a treatment was implemented as designed. 
Treatment fidelity is important because it is impossible to know how to proceed if a treatment does not work for a given client when the treatment was not accurately delivered.

\section{Trial-by-trial interobserver agreement (IOA)}

This type of IOA is calculated by the number of trial items agreement divided by the number of trials and multiplied by 100 .

\section{Video modeling}

Video Modeling is a visual teaching method that occurs by watching a video of someone modeling a targeted behavior or skill and then imitating the behavior/skill watched.

\section{Significance of the Study}

\section{Scholarship}

There are some specific target areas as related to gaps in the current literature that this study addresses. Currently, there are currently only five published research studies using technology alone to train staff to implement the steps of preference assessments. Only two of those studies are specific to free-operant preference assessments. It would be advantageous to extend this line of research with additional information on conducting this type of training with this specific preference assessment. Second, the prior knowledge and experience of the trainee receiving instruction is also an important component. To date, no study has evaluated the use of video modeling or computer-based training to train entry level clinical staff (i.e., Registered Behavior Technicians) to conduct the steps of a free-operant assessment. Finally, it is important for staff to be able to accurately score and interpret assessment results. If preference assessments are incorrectly scored or interpreted, this could lead to decreased effective instructional opportunities. Only six research studies published to date have included training staff to 
summarize and/or interpret preference assessment data (Bishop \& Kenzer, 2012; Graff \&

Karsten, 2012b; Deliperi et al., 2015; Roscoe \& Fisher, 2008; Roscoe, et al., 2006; Weldy et al., 2014). But only one of those studies included accurate scoring and interpretation of the freeoperant preference assessment (Weldy et al., 2014).

\section{Practice}

This study will contribute to research-to-practice by analyzing an efficient and effective staff training approach that can be used to train all entry level behavior staff (i.e., less than three months providing behavior analytic programming at a Registered Behavior Technician (RBT) or behavior implementer) working directly with adults with developmental disabilities. Training these front line implementers to conduct direct preference assessments can lead to increased effectiveness of skill acquisition and behavior reduction programs for clients, by staff being able to better identify potential reinforcers that can be used within these interventions.

The use of technology to provide quality training while also reducing the necessary number of direct training hours with professionals encourages supervisors and organizations to provide highly effective trainings. The training provided in the study has the capabilities of being extended to train a wider range of individuals in a variety of different capacities. For example, this training and materials can be accessed online to train entry level staff in schools, organizations, and clinics in a systematic, empirically validated method. Furthermore, parents could be extended into the target audience and this type of training can be beneficial to teach their children in the home setting. This could further spread across the nation to training programs as training methods for new Board Certified Behavior Analysts (BCBAs) at University 
programs and practicum supervisors.

\section{Summary}

Identifying effective training standards for staff working with individuals with developmental disabilities is a vital part of any human service organization. To provide effective strategies to clients they serve, agencies must understand the immeasurable value of quality staff training programs. However, closing the research-to-practice gap for staff trainings may be difficult, time consuming, and costly. Training staff effectively requires a substantial amount of time, money, and materials. Additionally, creates unbillable hours and staff are often missing therapy sessions with clients. However, despite initial drawbacks, it is critical for human service organizations to understand the link between effective staff training and improved organization output tied to their mission and vision. This study contributes to the literature by analyzing a cost effective and high quality training method that can be used to teach those working directly with individuals with developmental and intellectual disabilities to implement a free-operant preference assessment. The content of some trainings is simply too complicated and will always require additional hands-on direct staff training in order to be effective. However, current research supports the use of computer based learning alone as being an effective mode to training staff to implement the steps of various direct preference assessments in as little as 30-minutes training time without a trainer present (Rosales et al., 2015; Weldy et al., 2014). 


\section{References}

Bishop, M. R. \& Kenzer, A. L. (2012). Teaching behavioral therapists to conduct brief preference assessments during therapy sessions. Research in Autism Spectrum Disorders, 6, 450-457. doi: 10.1016/j.rasd.2011.07.005

Boyle, M. A., Curtis, K. S., Forck, K. L., Fudge, B. M., Speake, H. N., \& Pauls, B. P. (2019). A replication of the response-restriction preference assessment. Behavioral Interventions, 34, 564 -576. https://doi.org/10. 1002/bin.1683

Brock, M. E. \& Carter, E. W. (2013). Effects of a professional development package to prepare special education paraprofessionals to implement evidence-based practice. The Journal of Special Education. Advance online publication.

http://dx.doi.org/10.1177/0022466913501882

Carr, J. E., Nicolson, A. C., \& Higbee, T. S. (2000). Evaluation of a brief multiple-stimulus preference assessment in a naturalistic context. Journal of Applied Behavior Analysis, 33, 353-357. doi:10.1901/ jaba.2000.33-353.

Cote, C. A., Thompson, R. H., Hanley, G. P., \& McKerchar, P. M. (2007). Teacher report and direct assessment of preferences for identifying reinforcers for young children. Journal of Applied Behavior Analysis, 40, 157-166.

DaFonte, M.A. \& Capizzi, A.M., (2015). A module-based approach: Training paraeducators on evidence-based practices. Physical Disabilities: Education and Related Services, 34(1), 31-54. doi: 10.14434/pders.v34i1.13823

Deliperi, P., Vladescu, J. C., Reeve, K. F., Reeve, S. A., \& DeBar, R. M., (2015). Training staff to implement a paired-stimulus preference assessment using video modeling with voiceover instruction. Behavioral Interventions, 30, 314-332. doi: 10.1002/bin.1421. 
DeLeon, I.G. \& Iwata, B.A. (1996). Evaluation of a multiple-stimulus presentation format for assessing reinforcer preferences. Journal of Applied Behavior Analysis 29, 519-532.

Delli Bovi, G. M., Vladescu, J. C., DeBar, R. M., Carroll, R. A., \& Sarokoff, R. A. (2017). Using video modeling with voice-over instruction to train public school staff to implement a preference assessment. Behavior Analysis in Practice, 10(1), 72-76. http://doi.org/10.1007/s40617-016-0135-y

Egel, A. L. (1981), Reinforcer variation: Implications for motivating developmentally disabled children. Journal of Applied Behavior Analysis, 14, 345-350. doi:10.1901/jaba.1981.14$\underline{345}$

Fazzio, D., Martin, G. L., Arnal, L., \& Yu, D. C. T. (2009). Instructing university students to conduct discrete-trials teaching with children with autism. Research in Autism Spectrum Disorders, 3(1), 57-66. doi:10.1016/j.rasd.2008.04.002

Feldman, E. K. \& Matos, R. (2013). Training paraprofessionals to facilitate social interactions between children with autism and their typically developing peers. Journal of Positive Behavior Interventions, 15(3), 169-179. http://dx.doi.org/10.1177/1098300712457421

Granpeesheh, D., Tarbox, J., Dixon, D. R., Peters, C. A., Thompson, K., \& Kenzer, A. (2010). Evaluation of an eLearning tool for training behavioral therapists in academic knowledge of applied behavior analysis. Research in Autism Spectrum Disorders, 4, 11-17. doi:10.1016/j.rasd.2009.07.004

Gerencser, K. \& Akers, J. \& Becerra, L. \& Higbee, T., \& Sellers, T. (2020). A Review of Asynchronous Trainings for the Implementation of Behavior Analytic Assessments and Interventions. Journal of Behavioral Education. 29, 122-152. 10.1007/s10864-01909332-X. 
Graff, R. B. \& Karsten, A. M. (2012a). Assessing preferences of individuals with developmental disabilities: a survey of current practices. Behavior Analysis in Practice, 5, 37-48. doi:10.1901/ jaba.1992.25-491.

Graff, R. B., \& Karsten, A. M. (2012b). Evaluation of a self-instruction package for conducting stimulus preference assessments. Journal of Applied Behavior Analysis, 45, 69-82.

Johnson, B. M., Miltenberger, R. G., Egemo-Helm, K., Jostad, C. J., Flessner, C., \& Gatheridge, B. (2005). Evaluation of behavioral skills training for teaching abduction-prevention skills to young children. Journal of Applied Behavior Analysis, 38, 67-78.

Kang, S., O'Reilly, M., Lancioni, G., Falcomata, T. S., Sigafoos, J., \& Xu, Z. (2013). Comparison of the predictive validity and consistency among preference assessment procedures: A review of the literature. Research in Developmental Disabilities, 34(4), 1125-1133. http://dx.doi.org/10.1016/j.ridd.2012.12.021

Karsten, A. M., Axe, J. B., \& Mann, C. C. (2015). Review and Discussion of Strategies to Address Low Trainer-to-Staff Ratios. Behavioral Interventions, 30(4), 295-313. DOI: $10.1002 /$ bin. 1420

Kazdin, A. E. (2011). Single-case research designs: Methods for clinical and applied settings. Oxford University Press.

Kodak, T., Fisher, W. W., Kelley, M. E., \& Kisamore, A. (2009). Comparing preference assessments: Selection- versus duration-based preference assessment procedures. Research in Developmental Disabilities, 30, 1068-1077.

Leaf, J. Milne, C., Aljohani, W., Ferguson, J., Cihon, J., Oppenheim-Leaf, M., McEachin, J., \& Leaf, R., (2019). Training change agents how to implement formal preference assessments: A review of the literature. Journal of Developmental and Physical 
Disabilities. 10.1007/s10882-019-09668-2.

Lerman, D. C., Tetreault, A., Hovanetz, A., Strobel, M., \& Garro, J. (2008). Further Evaluation of a Brief, Intensive Teacher-Training Model. Journal of Applied Behavior Analysis, 41(2), 243-248. http://doi.org/10.1901/jaba.2008.41-243

Lipschultz, J. L., Vladescu, J. C., Reeve, K. F., Reeve, S. A., \& Dipsey, C. R. (2015). Using video modeling with voiceover instruction to train staff to conduct stimulus preference assessments. Journal of Developmental and Physical Disabilities, 27, 505-532.

Maffei-Almodovar, L. \& Sturmey, P. (2018). Change agent training in behavior analytic procedures for people with developmental and intellectual disabilities: A meta-analysis. Review Journal of Autism and Developmental Disorders. Advance online publication, 5, 129-141. https://doi.org/10.1007/s40489-018-0128-6.

McCulloch, E. \& Noonan, M. (2013). Impact of online training videos on the implementation of mand training by three elementary school paraprofessionals train staff to implement discrete-trial instruction. Education and Training in Autism and Developmental Disabilities, 48 (1).

Northouse, P. G. (2016). Leadership: Theory and practice (7th ed.). Thousand Oaks, CA: Sage.

Nosik, M. R. \& Williams, W. L. (2011). Component evaluation of a computer based format for teaching discrete trial and backward chaining. Research in Developmental Disabilities, 32, 1694-1702. doi: 10.1016/j.ridd.2011.02.002

Nosik, M. R., Williams, W. L., Garrido, N., \& Lee, S. (2013). Comparison of computer based instruction to behavior skills training for teaching staff implementation of discrete-trial instruction with an adult with autism. Research in Developmental Disabilities, 34, 461468. doi: 10.1016/j.ridd.2012.08.011 
Nottingham, C. L., Vladescu, J. C., Giannakakos, A. R., Schnell, L. K., \& Lipschultz, J. L. (2017). Using video modeling with voiceover instruction plus feedback to train implementation of stimulus preference assessments. Learning and Motivation, 58, 37-47.

Pace, G. M., Ivancic, M. T., Edwards, G. L., Iwata, B. A., \& Page, T. J. (1985). Assessment of stimulus preference and reinforcer value with profoundly retarded individuals. Journal of Applied Behavior Analysis 18, 249-255.

Piazza, C. C., Roane, H. S., \& Karsten, A. (2011). Identifying and enhancing the effectiveness of positive reinforcement. In W. W. Fisher, C. C. Piazza, \& H. S. Roane (Eds.), Handbook of applied behavior analysis (pp. 151-164). New York: Guilford Press.

Pollard, J. S., Higbee, T. S., Akers, J. S. \& Brodhead, M. T. (2014). An evaluation of interactive computer training to teach instructors to implement discrete trials with children with autism. Journal of Applied Behavior Analysis, 47, 765-776. doi:10.1002/jaba.15

Reid D. H. \& Parsons M. B. (2002). Organizational behavior management in human service settings. In: Austin J., Carr J. E., editors. Handbook of applied behavior analysis. Reno, NV: Context Press; pp. 275-294. (Eds.)

Reid, D. H., Rotholz, D. A., Parsons, M. B., Morris, L., Braswell, B. A., Green, C. W., \& Schell, R. M. (2003). Training human service supervisors in aspects of positive behavior support: Evaluation of a state-wide, performance-based program. Journal of Positive Behavior Interventions, 5, 35-46.

Roane, H. S., Vollmer, T. R., Ringdahl, J. E., \& Marcus B. A. (1998). Evaluation of a brief stimulus preference assessment. Journal of Applied Behavior Analysis 31, 605-620. 
Rosales R., Gongola L., \& Homlitas C. (2015). An evaluation of video modeling with embedded instructions to teach implementation of stimulus preference assessments. Journal of Applied Behavior Analysis, 48, 209-214. doi: 10.1002/jaba.174.

Roscoe, E. M. \& Fisher, W. W. (2008). Evaluation of an efficient method for training staff to implement stimulus preference assessments. Journal of Applied Behavior Analysis, 41, $249-254$.

Roscoe, E. M., Fisher, W. W., Glover, A. C., \& Volkert, V. M. (2006). Evaluating the relative effects of feedback and contingent money for staff training of stimulus preference assessments. Journal of Applied Behavior Analysis, 39, 63-77. doi: 10.1901/jaba.2006.705

Vladescu, J. C., Carroll, R., Paden, A., \& Kodak, T. M. (2012). The effects of video modeling with voiceover instruction on accurate implementation of discrete trial instruction. Journal of Applied Behavior Analysis, 45(2), 419-423. http://doi.org/10.1901/jaba.2012.45-419

Vollmer T. R., Marcus B. A., \& LeBlanc L. (1994). Treatment of self-injury and hand mouthing following inconclusive functional analyses. Journal of Applied Behavior Analysis, 27, $331-44$.

Weldy, C. R., Rapp, J. T., \& Capocasa, K. (2014). Training staff to implement brief stimulus preference assessments. Journal of Applied Behavior Analysis, 47, 214-218. 
R4ınning head: EVALUATION OF COMPUTER-BASED TRAINING

\section{SECTION TWO:}

\section{PRACTIONER SETTING}


R5unning head: EVALUATION OF COMPUTER-BASED TRAINING

\section{Introduction}

The setting for this study took place at a for-profit organization, Community Supports. This organization offers three types of services to individuals with varying intellectual or developmental disabilities: (1) independent living services development, (2) customized employment services, and (3) behavior services. The services at Community Supports Program are designed to offer the greatest opportunity for success for the individuals served. Community Supports holds self-reliance at a very high value. They support each person to become more self-sufficient in order to help them achieve their personal goals and live a more full and vibrant life. They also focus on strategies for achievement that are applicable to all aspects of life. The mission of the organization is:

“All people are capable of individual growth when challenged.

All people are capable of earning respect when given the opportunity.

All people deserve the opportunity for inclusion within their community.

Serve the needs of the people inviting us into their lives first, and the needs of our organization will follow.

To go shopping, go to worship, work hard, play hard and continually strive for an improved quality of life is a need we all have.

It is our mission at Community Supports to provide these opportunities."

The goals of the organization are "to provide support to the person in need of services in a meaningful and relevant way that will increase their exposure to friendships, jobs and the community. To always remain person centered in our planning and implementation of our programs, customizing each person's plan to fit their specific needs and goals for their life. To create jobs and meet the needs of the people we serve by fusing the relationship to the 
community of small business owners to provide a customized training for each employee served. To bring community awareness of the productive value that people with disabilities possess. To educate the community, parents/guardians and people with disabilities about advocacy and the nature of disabilities. Continue to develop services for the people served by Community Supports as the need arises with custom supports for our community."

The most common source of funding is from the Department of Mental Health (DMH) through the local Regional Office for individuals who are Medicaid waiver eligible. They also contract with a local parent advisory committee to fund employment services for individuals with Autism Spectrum Disorder (ASD).

Behavior services are offered and focus on promoting a positive change using the principles of Applied Behavior Analysis (ABA) to increase quality of live with all individuals served. The organization provides the highest quality evidence-based training and treatment to best support the individuals and their family. Behavior services include: behavior assessment, development of individualized behavior intervention plans/treatment, training of implementation of treatment and behavior plan strategies, and follow up, monitoring, and modifications to the intervention plan as necessary. Behavioral interventions can focus on functional communication, social skills, independent living skills, community participation skills, etc. For example, if an individual engages in problem behavior during the day program, they may be unable to attend full days in the day program, reducing their access to services. ABA services work in collaboration within the organization to identify necessary behavior supports to enable clients to access all appropriate services.

Individuals receiving services typically attend an onsite program weekly for about six hours daily. While in the day programs are divided into groups and taught a variety of life skills 
based on their level of need and ability (e.g., balancing bank accounts, personal hygiene skills, sorting laundry, etc.). Some of these consumers received applied behavior analysis services during their time at Community Supports.

\section{History of Organization}

The setting was in a rural Midwestern area, across three small towns within a 45-minute driving radius (ranging in population from 40,000 to 15,000 people). The company opened the first center in 2013 with a small handful of employees and clients. Today the organization has three centers, with the newest opening at the end of 2019. The organization serves close to 60 adults with disabilities, ranging in age from 18 to 62 years. Currently, there are about 40 employees working at the facility, with $55 \%$ of these employees providing direct care. The average schooling for direct care staff are high school graduate or GED.

The Applied Behavior Analysis (ABA) program was formed in 2019 with one Board Certified Behavior Analyst (BCBA) and one provisional Behavior Analyst (moving to a BCBA in February 2020). At the beginning of 2020, the organization expanded the program and hired an additional Provisional Behavior Analyst and four Registered Behavior Technicians (RBT). These RBT's were hired within the company and have similar qualifications as the direct care staff.

Funding for all aspects of the programs within this organization is mainly provided by the Department of Mental Health for Developmental Disabilities (DMH/DD), specifically under the Medicaid waiver. Additional state funding for the employment services is used and private pay is an option to receive services. 


\section{Organizational Analysis}

This organization was founded in 2013 by a husband and wife team to meet community need. Having a child with a disability, this family saw firsthand the need in the community and sought to address it. They sought to create an organization to provide quality services for adults with developmental disabilities. This type of adult support is extremely limited and virtually nonexistent, particularly in this rural area. These serves range from working with individual's that may want to enter the job market to those that need to focus on self-help skills. Some individual's live in group home while some live with their families. The range of severity of the disabilities is great and a variety of services are necessary to meet their unique needs. Parents are often told while transitioning from high school that there are little to no supports once they graduate from school. How are families able to work if they cannot leave them at home alone? How do they pay for someone to stay with the individuals in the home? Many are forced to have services that act as babysitters, while the individual goes through each day with little purpose or meaning. All of the progress made in school slowly becomes undone. I have worked with a number of individuals at a younger age and then revisited them once they were adults and observed this occurring. Families are unable to provide the support necessary for the individual, but have nowhere to turn. Their vision was to provide families with a way to "hear voices that needed to be heard, talents that needed to be shared, and opportunities for people to contribute back to their community in the unique way that only they can”.

In order to maintain, improve and grow services, the organization has many individuals in a variety of leadership and administrative roles. Roles focusing on the organizational support include: Executive Director/Owner, Business Director/Owner, Compliance Officer, Financial Director, and Director (over each of the three areas). Leadership/Administrative roles in the 
Independent Living Services Development area include: Community Outreach Coordinator, Assistant Director, Program Manager, and Development Disability Specialist (three individuals working at the three different centers). There are 22 Direct Support Professionals (DSP) that report to the Development Disability Specialist across each location. The Employment Services has one Employment Specialist overseeing four Employment Direct Support Professionals (EDSP). The ABA program has two Board Certified Behavior Analysts (BCBA's) providing supervision and oversight for one provisional Behavior Analyst and four Registered Behavior Technician's (RBT's).

Bolman and Deal (2013) use four frames or lenses for leaders to approach organizational issues. Organization can intermix each of these frames to improve aspects of their organizational structure. Using the human resource and symbolic frames, an analysis of the organization is outlined as follows. The human resource frame emphasizes the needs of the people or employees working within the organization. It emphasizes personal growth and job satisfaction. Bolman and Deal (2013) proposed the use of the human resource frame if commitment and motivation are necessary within the organization. The company has many procedures and structures in place, along with a number of employees that are in charge of a variety of activities throughout the organization. The need for so many different people leading and organizing appears well-thought-out from a structural viewpoint, but it can be tricky when there are so many people directing services. By focusing on the relationship between the organization and the employees, identifying the needs of both the individual and the company, and emphasizing the importance of interpersonal and intrapersonal dynamics, the organization can move together as a family, focusing on both relationships. While employed part time within this organization, I was able to see the owner's focus on staff support and team building. They were readily available to 
meet with staff and continued to maintained hands on relationship within the daily workings of the organization. They often let staff know that it is acceptable to make mistakes, but it is important to take responsibility for any mistakes. They model by example and let staff know that they too make mistakes and are not perfect. This allows staff more freedom to explore different ideas and projects without the fear of management being overly critical and judgmental.

Douglas McGregor also proposed belief systems using motivation as a central element, Theory X and Theory Y (Bolman \& Deal, 2013). Theory X was the predominant philosophy of managers before the 1960 s and identified the need for constant supervision of employees because they were inherently lazy and unmotivated (Bolman \& Deal, 2013). In contrast, Theory Y believed that people typically respond in the manner they are treated in the organization and have the potential to improve, becoming responsible and ethical members of the organization who often go beyond the requirements of their jobs (Bolman \& Deal, 2013). The organization works with the individuals to empower them to go above and beyond their job description by allowing them the freedom to make decisions under a set of guidelines. When people believe that the organization is working for them, they are often willing to go beyond what is required of them (Bolman \& Deal, 2013). For example, research by Burns and DiPaola (2013) showed that principals that conveyed trust and support to their teaching staff resulted in their teachers being willing to work additional hours outside their school day, including tutoring students, while maintaining high job satisfaction. Additional positive results were also related to the performance of their students.

The second frame or lens is symbolic. Culture within a group is easy to recognize but hard to define. The culture of an organization is not as simple as a rulebook of how to interact with others, but rather an understanding of what takes place between individuals on a daily basis 
within the organization. Individuals at this organization contribute to and shape the culture by his or her own individual and collective experiences (Manning, 2013). The owners of the company work hard to maintain a positive work culture for all employees. With the workforce over half direct care staff (e.g., less skilled or entry level employees and close to minimum wage hourly pay) and spread across three sites, there is a concern of high turnovers and difficulty creating team cohesion. Organizational theorist Schein (1993) stresses that the focus on the culture within organizations should be related to the values they have within the organization. Providing the highest quality of services to families and individuals are important values that are emphasized throughout the organization.

\section{Leadership Analysis}

One important aspect of developing culture is through an organization's leadership. It is important to unite a team by leading by example rather than command. Leaders within the company demonstrate great dedication and desire to strive daily to adhere to these values. The owners of this company have a personal story they used to create passion and determination toward the group's vision and goals. The use of stories carries history and values while reinforcing group identity (Bolman \& Deal, 2013). Success stories told by employees can offer hope and reinforce values. This creates cohesion within the team (Levi, 2014). A shared cohesive culture can provide the necessary push for a team to accomplish things that no one individual would be able to do on his or her own.

Ongoing development of effective leadership skills should be a central focus. This does not happen in a vacuum as "leaders need to manage relationships effectively; no leader is an island" (Golman, 1996, p. 20). Operating under the human resource lens will provide clarity and focus in regard to linking the needs of individuals while tapping into their talents and skills to 
grow profits within the organization. It is critical for the organization's leaders to understand the need to build effective teams through effective training. Company leaders must value training employees to competency in the skills they will be using with clients. This can be a hard sale to agencies when trainings are often financially burdensome to the bottom line. Training staff requires time, money, and materials. During the training, staff are missing time spent with clients and trainings are generally unbillable hours. However, it is important for the company's leaders to understand the importance of developing on ongoing effective and systemic training in order to move employees toward the organization's vision. Northouse (2016) describes positive outcomes from organizations with effective teams; they demonstrate greater productivity, effective use of resources, better decisions and problem solving, better products and services, and greater innovation and creativity.

Leaders must nurture a culture in which employees feel valued. Research shows that employees that are happy and feel valued, tend to be more productive, creative, and willing to go above and beyond expectations at work (Bolman \& Deal, 2013). One way the organization could increase trust and sincere conversations with staff is to create ongoing anonymous staff surveys regarding structure, organization, and team building within the organization. Asking staff how improvements could be made in variety of activities within the organization can make staff feel included and a part of the group. This also can be beneficial to obtaining accurate and honest feedback from employees in order to understand what is working well and what needs to be adjusted throughout the organization. This will be particularly important as the organization expands.

Communication is an exchange of information, needs, and feeling between individuals (Bolman \& Deal, 2013). Group members must be open and honest with one another about their 
strengths and weaknesses in order to build a solid group foundation (Lencioni, 2002). If the group cannot trust one another, then they will remain guarded during discussions and never address the important elements that are necessary to work together effectively. The foundation will crumble quickly when conflict and passionate debates occur in important group decisions. Effective communication is how trust begins. Respecting others, listening actively, asking openended questions, and controlling emotions are just a few necessary components that will be beneficial in conversations with team members (Levi, 2014).

Ethics directs a leader's actions and decisions within organizations. Ethical leadership is identified by five key principles that include serving others, ensuring justice, respecting others, encouraging honesty, and building community (Northouse, 2016). Respect focuses on taking into consideration all other viewpoints, not just those that agree with you. A leader must also be open in understanding people's different perspectives in a variety of issues. Preskill and Brookfield (2009) say "openness is the willingness to entrain a variety of alternative perspectives, being receptive to contributions from everyone regardless of previous attainment or current status and create dialogic open spaces - multiple opportunities for diverse voices and opinions to be heard" (p. 21). The company's owners are open, honest, and willing to hear different viewpoints from other's in the group. Their focus continues to be growing the organization in an ethical way that is beneficial to employees and clients as a whole.

\section{Implications for Research in the Practitioner Setting}

Implications for research in applied setting enable staff to receive effective and efficient training to implement procedures related to their daily job expectations. An emerging line of research has begun to focus on maintaining effectiveness but increasing efficiency of trainings by reducing the need for the presence of a trainer throughout the training (Karsten, et al., 2011; 
Nottingham et al., 2017). The content of some trainings are simply too complicated and will always require additional hands-on direct staff training in order to be effective. However, current research supports video modeling training alone as an effective mode to implement the steps of various direct preference assessments in as little as 30-minutes training time without a trainer present (Rosales et al., 2015; Weldy et al., 2014).

\section{Summary}

The individuals within this organization are an amazing group of people dedicated to improving the lives of the individuals receiving services. Identifying efficient and effective training methods with procedures that help staff perform their jobs with increased confidence and accuracy can provide a better work environment for all staff, while increasing productivity and overall happiness in the workplace. The organization is capable of moving as a united front toward their vision and expand quality services for more individuals while maintaining a positive work culture for their employees. 


\section{References}

Bolman, L.G. \& Deal, T.E. (2013). Reframing organizations: Artistry, choice, \& leadership (5 $5^{\text {th }}$ ed.). San Francisco, CA: Jossey-Bass.

Burns, W. \& DiPaola, M. (2013). A study of organizational justice, organizational citizenship behavior, and student achievement in high schools. American Secondary Education, 42(1), 4-21.

Goleman, D. (1996). What makes a leader? In HBR's 10 must reads on leadership (pp. 1-21). Boston, MA: Harvard Business School Publishing Corporation.

Karsten, A. M., Carr, J. E., \& Lepper, T. L. (2011). Description of practitioner model for identifying preferred stimuli with individuals with autism spectrum disorders. Behavior Modification, 35, 347-369.

Lencioni, P. (2002). The five dysfunctions of a team. San Francisco, CA: Jossey-Bass.

Levi, D. J. (2014). Group dynamics for teams (4th ed.). Los Angeles, CA: Sage.

Manning, K (2013). Organizational theory in higher education ( $1^{\text {st }}$ ed.). New York, NY: Routledge.

Northouse, P.G. (2016). Leadership: Theory and practice. $\left(7^{\text {th }}\right.$ ed.). Thousand Oaks, CA: Sage. Nottingham, C.L., Vladescu, J.C., Giannakakos, A.R., Schnell, L.K., \& Lipschultz, J.L. (2017). Using video modeling with voiceover instruction plus feedback to train implementation of stimulus preference assessments. Learning and Motivation, 58, 37-47.

Preskill, S. \& Brookfield, S. D. (2009). Learning as a way of leading: Lessons from the struggle for social justice. San Francisco, CA: Jossey-Bass. 
Rosales R., Gongola L., \& Homlitas C. (2015). An evaluation of video modeling with embedded instructions to teach implementation of stimulus preference assessments. Journal of Applied Behavior Analysis, 48, 209-214. doi: 10.1002/jaba.174.

Schein, E. H. (1993). Organizational culture and leadership. In J.M. Shafritz, J. S. Ott \& Y. S. Jang (Eds.), Classics of organization theory (pp. 360-367). Belmont, CA: Wadsworth Cengage Learning.

Weldy, C. R., Rapp, J. T., \& Capocasa, K. (2014). Training staff to implement brief stimulus preference assessments. Journal of Applied Behavior Analysis, 47, 214-218. 
ÆRZunning head: EVALUATION OF COMPUTER-BASED TRAINING

SECTION THREE:

\section{SCHOLARLY REVIEW}


\$R8mning head: EVALUATION OF COMPUTER-BASED TRAINING

\section{Introduction}

Organizations must understand the immeasurable value of quality training programs for staff to learn the required skills to provide effective strategies to clients they serve. However, this can be challenging to close the research-to-practice gap for staff trainings, as the methods can be time consuming and costly. However, despite initial drawbacks, it is critical for human service organizations to understand the link between effective staff training and improved organization output tied to their mission and vision for the clients served. Hands on trainings provided under the direction of highly skilled professionals are considered an important part of best practice staff training for the development of performance skills (Lerman, et al., 2008; Nottingham, et al., 2017). However, this type of intensive hands-on training is often time consuming and costly, making it difficult to provide the level required to fully support trainees.

Direct services staff in the field of behavior analysis would benefit in learning to accurately identify potential items and activities that can function as reinforcers for the target learner. Reinforcement is an important principle in the practice of Applied Behavior Analysis used to strengthen desired behaviors (Cooper et al., 2007). In order to identify effective reinforcers, one must determine individual's preferences. Preferred stimuli is defined as items that an individual chooses to engage in, that may in turn function as a reinforcer (Graff \& Karsten, 2012a). As a supervisor and Board Certified Behavior Analyst (BCBA), my position requires me to implement preference assessments with clients as well as supervise a number of direct line therapists whom are also implementing preference assessments.

My focus with all of my clients is to provide the highest quality service in order to increase each individual's quality of life. In order to effectively work towards this goal, it is important to identify preferences or motivation. Reflect on a task or endeavor you have 
completed or currently engaged in. Consider the underlying motivation for you engaging in this activity. Maybe you are training to run a marathon or finishing a research study. The motivation you have to engage in the activity will be important as effort increases and struggles are present. Running a marathon requires lengthy amounts of time running many many days for very long durations. There will be days you may not feel like running, but you can think about your motivation - why are you running? Maybe the end results is to run the 26 miles to have the personal satisfaction of crossing that finish line. Setting smaller goals as you train could also help provide some additional reinforcement along the way. Despite what your motivation is to complete the activity, engaging in sometimes aversive activities becomes worthwhile.

I am currently training for a fitness competition that requires me to be in the gym six days a week, work out up to two hours daily, and eat a very strict low carb diet. I have identified many motivators within this activity, of course the end result being that I compete in the fitness competition and place first. However, I also find motivation in lifting heavier weights and seeing the changes in my body. I am more motivated to stay on the diet and come to the gym every day, in order to meet my target goal. Most typically developing adults are able to identifying some motivators for engaging in tasks that may something be aversive (e.g., eating healthy, going to the gym, finishing lengthy research paper, going to class, getting up early, etc.), however not everyone is able to identify their own preferences, motivation, or understand the purpose of engaging in a task he or she does not enjoy. For individuals with developmental disabilities, we are challenged to find their motivation to complete tasks that are beneficial for them, but may be aversive (e.g., self-care skills, brushing teeth, following directions, independent living skills). Identifying internal or personal goal or discussing motivation for activities may be too abstract for some individuals with developmental disabilities to understand. 
Therefore, it is up to professionals to help identify these preferences that can be used to motivate individuals, particularly those with developmental disabilities, to engage in tasks that can increase their quality of life and independence. Determining preferences of individuals with development disabilities can often be challenging due to communication deficits, inflexible and repetitive behavior patterns, and/or restricted interests (Roane, et al., 1998). In many cases, a simple interview with an individual or with family members will reveal a list of preferred activities. Possibly observing the clients in the natural setting and noting activities they chose during their unstructured time can also be an effective means of identifying preferences. However, for many individuals with developmental disabilities we work with, additional methods must be used, including directly assessing the individual's preferences.

Another issue is that delaying reinforcement (across hours, days, or weeks) too much could decrease motivation for some clients. In fact, some clients may initially require reinforcement to be delivered after each trial within a task. This requires having a number of different preferred items available for the client to access (e.g., playing games, listening to music, YouTube videos, going on walks, drawing, etc.). Furthermore, clients may have communicate deficits which prevent them from expressing their wants and needs and discuss their motivation. This can be related to difficulties communicating, understanding spoken language, difficulties answering questions, and engaging in back and forth communications. So, we must develop alternative methods to understand what motivates the individuals we serve. One option that comes to mind would be to ask those most familiar with the individual, such as a parent or caregiver. However, research has shown low correlations between caregiver reports and observational measures of actual preference for individuals (Graff \& Karsten, 2012a; Cote, et al., 2007; Roane et al., 1998). 
Conducting direct preference assessments increases the likelihood of identifying the most potent reinforcers and is recommended in best practice guidelines (Cote, et al., 2007; Leaf, et al., 2020). In fact, previous studies have demonstrated empirically derived reinforcers, from preference assessments, are more effective than arbitrarily selected reinforcers across a variety of behavior programs (Kodak, et al., 2009; Vollmer, et al., 1994). One direct preference assessment is the free-operant (FO) preference assessment (Roane, et al., 1998). This type of preference assessment is simple and quick to implement at only 5-minutes in duration, as compared to other types of preference assessments, which range from 15-30 minutes in length (Kang, et al., 2013). This assessment involves the simultaneous presentation of all stimuli to the individual and allows engagement with all items without withdrawing items at any time. Currently, there are a handful of empirical studies demonstrating positive outcomes when staff training uses technology (e.g., computer based learning or video modeling with voiceover instructions) without any additional training components to teach trainees to accurately implement the steps of direct preference assessments (Deliperi, et al., 2015; Delli Bovi, et al., 2017; Lipschultz, et al., 2015; Rosales, et al., 2015; Weldy, et al., 2014). To date, only two published studies have explored the use of technology unaided by additional supports to train staff to implement the steps specifically for the free-operant preference assessment (Rosales et al., 2015; Weldy et al., 2014).

Research supports the use of direct preference assessments and identifies benefits of doing so with individuals with developmental disabilities, however, these methods are only useful if staff are trained to competency in the implementation of these assessments. More than half of all respondents ( $n=406)$ surveyed by Graff and Karsten (2012a) reported that they were never trained to conduct direct preference assessments. Individuals that did report receiving training indicated it was from independently reading published studies or training manuals 
(27\%), in-services training (19\%), and $12 \%$ attended a workshop on conducting direct preference assessments. This appears much lower than the recommended training guidelines for best practice (Graff \& Karsten, 2012a). Furthermore, survey results revealed that $50 \%$ of all respondents cited lack of knowledge of preference assessment procedures as a barrier to implementing them with clients (Graff \& Karsten, 2012a). Given the importance of identifying effective reinforcers when working with individuals with developmental disabilities combined with the self-reported lack of training and knowledge of preference assessments, an essential research path needs to be explored regarding the development of effective and efficient training programs to teach staff to implement the steps of direct preference assessments (Graff \& Karsten, 2012a; Vollmer, et al., 1994).

\section{Overview}

This quantitative single subject design study will be used to is used to navigate relevant topics connected to the current research questions that include (a) research on direct preference assessments, focusing on free-operant preference assessment, (b) behavior skills training and current research identifying more effective and efficient use of technology and (d) current research using technology without a trainer present to conduct staff trainings teaching the steps of direct preference assessments.

\section{Conceptual Framework}

The goal of science is to achieve a thorough understanding of the specific phenomena under study. In applied behavior analysis, the focal points are socially important behaviors. The United States Surgeon General (1999) concluded, "Thirty years of research demonstrated the efficacy of applied behavioral methods in reducing inappropriate behavior and increasing 
communication, learning, and appropriate social behavior." Applied behavior analysis (ABA) is the application of learning principles focused on improving behaviors of social significance and determining if the observed changes are a function to the applied procedures (Baer, Wolf, \& Risley, 1968). Newman (1992) states that ABA is a systematic approach based on "reliable data deriving from ongoing recording and evaluation of performance" (p. 4). Common features in the application of ABA-based treatment and interventions are: (1) objective measurement of behavior, (2) procedures are based on scientifically established principles of behavior, and (3) focus on controlling the environment in order to effectively evaluate the outcomes (Hagopian, Hardesty, \& Gregory, 2015).

Positive reinforcement occurs when "a behavior is followed immediately by the presentation of a stimulus that increases the future frequency of the behavior in similar conditions" (Cooper, Heron, \& Heward, 2007 p. 561). A reinforcer is defined as any object, condition, or event that when presented immediately following a behavior, increases the frequency of that behavior (Cooper, et al., 2007). The effectiveness of skill acquisition and behavior reduction interventions depend largely on the successful identification and implementation of effective reinforcers (Kodak, et al., 2009).

Direct care staff often struggle to identify effective reinforcers for individuals with developmental disabilities. This can be linked to the individual's communication deficits, fixed or restricted interests, and/or limited leisure skills. To further complicate, individuals with severe developmental disabilities may not respond to typical reinforcers used for other clients such as social praise (i.e., high fives and verbal praise) or intrinsic motivation (e.g., enjoying the activity itself). Research identifies direct preference assessments as the most effective way to use preferred stimuli to identify potential reinforcers for individuals with development 
disabilities (Kang, et al., 2013).

Interventions must have a strong evidence base that also applies to the experimental designs used to generate empirical evidence to study these various interventions and analyze their outcomes (Hitchcock, et al., 2015; Horner et al., 2005). Research studies in the field of behavior analysis often use single subject experimental design, in that, the subject serves as their own control rather than another group or individual. Single subject designs are used to evaluate the effect of a number of different interventions in applied research and are used in the fields of psychology, education, and human behavior. Hitchcock et al., (2015) describe single subject designs as "experimental methods consisting of various designs involving repeated measures of a specific behavior or skill under different conditions to evaluate the effectiveness of a treatment for an individual or small group of individuals that serve as their own control” (p. 460).

Single subject experimental designs involve repeated, systematic measurement of the dependent variable before (baseline), during (treatment/intervention), and after treatment (generalization/maintenance) through manipulation of the independent variable (Kazdin, 2011). The focus of single subject designs are to emphasize the individual organisms' differences rather than group designs which focuses group averages. Identifying the effects of treatment at the individual level is helpful, especially in the clinical and educational context. This design breaks down the effects of treatment at an individual level.

Single subject design research analysis relies heavily on collecting and graphically displaying data. "Behavior analysts employ a systematic form of examination known as visual analysis to interpret graphically displayed data" (Cooper, et al., 2007, p. 149). Visual analysis is particularly important within single subject designs, as two or more conditions are compared. For example, the baseline (before treatment) and intervention (once treatment is applied) are 
used to establish cause and effect relationships between the dependent and independent variable. Cooper, et al., (2007) outline six advantages to graphic displays of behavior data (a) provides an immediate visual record of data, (b) allows one to explore behavioral variations of data in real time, (c) serves as judgement aides that help interpret intervention results, (d) allows for visual analysis, (e) unbiased, independent judgements may be made from graphs, and (f) serves as an effective tool for client feedback.

Data paths across all conditions is interpreted by examining these three characteristics: level, trend, and variability (Horner et al., 2005). Level is defined as the average rate of performance during a phase. This is specifically where the data points are as related to the vertical ( $\mathrm{x}$ ) axis and viewed as low, moderate, or high. Trend relates to the overall direction of the data path on a graph. Trends can be increasing, decreasing, or zero. For example, if the intervention is successful for increasing a target behavior, the graph would want to show the data in an upward trend. Variability is referred to as the range of data points around the mean. When interpreting variability, one would report data being "stable" or "variable". High variability suggests lack of experimental control and decreases the ability to predict future patterns.

Important parts typically included within single subject design graphs include a baseline. The baseline condition (i.e., pretest condition) establishes a point of reference for other conditions to be compared. At baseline, measurement is taken of the dependent variable prior to administering the independent variable or treatment. Certain qualities in the data are required during this phase in order to establish an appropriate comparison. The data at baseline must be stable with limited variability and lack any trend of improvement (Horner et al., 2005). If baseline data is improving before the intervention, this can compromise the ability to determine 
treatment effect once the intervention begins. Kazdin (2011) recommends a minimum of three baseline data point in order to establish stability in data.

There are different applications within the single subject designs including A-B-A-B design, multi-element design, and multiple baseline design. Multiple baseline design can be measured across multiple individuals, behaviors, or settings. This current study uses the multiple baseline across participants design. Similar to the A-B-A-B design, the multiple baseline design starts in baseline and then proceeds to the intervention. However, it is not necessary to return to baseline using the multiple baseline design in order to demonstrate treatment effect (Cooper et al., 2007). This is useful when the treatment cannot be withdrawn or the intervention is irreversible due to learning effects (i.e., cannot stop reading once the subject learns to read).

Using a multiple baseline across participants, the treatment is applied to one of the participants until a stable baseline has been established while the other participants remain in the baseline condition (Horner et al., 2005). This begins with measurement at baseline of two or more participants (Cooper et al., 2007). Then, the treatment is applied in sequential manner to each of the other participants in the design. Experimental control is demonstrated if the target behavior change for each participant shows similar changes only when the treatment variable is introduced (Cooper et al., 2007). In summary, the multiple baseline across participants approach demonstrates experimental control as the dependent variable is measured across multiple participants and the treatment effects are replicated across those multiple participants.

\section{A Review of the Literature}

\section{Direct Preference Assessments}

One direct preference assessment is the free-operant (FO) preference assessment. This type of preference assessment is simple and quick to implement at only 5-minutes in duration, as 
compared to other types of preference assessments, which range from 15-30 minutes in length (Kang, et al., 2013). This assessment involves the simultaneous presentation of all stimuli to the individual and allows engagement with all items without withdrawing items at any time. Graff and Karsten (2012a) reported that $81.4 \%$ of surveyed professionals cited lack of time as a barrier to using preference assessment on a regular basis. Because of the ease of implementation and short duration, free-operant preference assessments can be used daily to reveal shifts in preferences (Egel, 1981).

A large body of empirical studies effectively demonstrates direct preference assessment's capacity to identify items that may function as effective reinforcers when provided contingently after desired behavior for individuals with developmental disabilities (Carr, Nicolson, \& Higbee, 2000; DeLeon \& Iwata, 1996; Kang, et al., 2013; Northup, et al., 1996; Pace, et al., 1985; Roane, et al., 1998). Additionally, research also suggests that highly preferred items are more effective reinforcers than low to moderately preferred items for skill acquisition (Carr et al., 2000; DeLeon \& Iwata, 1996; Fisher, et al., 1992; Northup et al., 1996; Roane et al., 1998). Preferred stimuli is defined as items that an individual chooses to engage in, that may in turn function as a reinforcer (Graff \& Karsten, 2012a). Both indirect (i.e., parent/caregiver interview or survey) and direct (i.e., systematic presentation of stimuli in various methods) measures can be used to pinpoint preferred items and activities. Indirect methods can include parent, caregiver, and staff interviews. Adults familiar with the individual can also complete checklists and surveys (e.g., Reinforcer Assessment for Individuals with Disabilities (RAIDS), Fisher, et al., 1992; Piazza et al., 2011). Research has shown low correlations between caregiver reports and observational measures of actual preference for individuals (Cote, et al., 2007; Graff \& Karsten, 2012a; Roane et al., 1998). However, indirect methods can be used to identify a range 
of items to be used within direct preference assessments (Graff \& Karsten, 2012a; Fisher, et al., 1996). Numerous studies have demonstrated empirically derived reinforcers are more effective than arbitrarily selected reinforcers across a variety of behavior programs (Kodak, et al., 2009; Vollmer, et al., 1994). Conducting direct assessment in addition to indirect means increases the likelihood of identifying the most potent reinforcers (Cote et al., 2007; Graff \& Karsten, 2012a).

Direct assessments include six different methods staff can use the single-stimulus (SS; Pace, et al., 1985), single-stimulus engagement (SSE; DeLeon, et al., 1999), paired-stimulus (PS; et al., 1992), (4) multiple-stimulus (MS; Windsor, et al., 1994), multiple-stimulus without replacement (MSWO; DeLeon \& Iwata, 1996), and (6) free-operant (FO; Roane, et al., 1998). Each method can be further classified into two different categories of (a) approach-based or (b) engagement-based procedures (Hagopian et al., 2004). Four of the preference assessment methods (single stimulus, paired-stimulus, multiple stimulus with replacement, and multiplestimulus without replacement assessments) are approach-based procedures in which responses are measured as touching the stimuli (Hagopian, et al., 2004). The dependent variable is reported as a percentage of trials chosen. Two of the preference assessment methods (freeoperant and single-stimulus engagement) are considered engagement-based in which responses are measured as choice responses according to the duration of engagement/play with specific stimuli (Hagopian, et al., 2004; Ortiz \& Carr, 2000; Roane et al., 1998). The dependent variable is reported as a percentage of intervals of stimulus engagement. The focus of this review will be the free-operant preference assessment that will be used in the study.

\section{Free-operant Preference Assessments}

Free-operant (FO) preference assessments involve the simultaneous presentation of multiple stimuli and allow unrestricted access to all items (Roane et al., 1998). The duration of 
the assessment is typically only five minutes, making it quick and easy to implement. The dependent measure of the assessment is the time allocated in the engagement of each item. Observers can score item engagement using 10-s partial interval scoring or momentary time sampling (Boyle et al., 2019; Verriden \& Roscoe, 2016; Weldy, et al., 2014). Data is then summarized as percentage of engagement, which then can be converted to a rank.

Roane, et al. (1998) compared the free-operant preference to a paired stimulus preference assessment across 17 individuals with developmental disabilities. Four dependent measures were collected during this study that included: (a) outcome of each preference assessment, (b) duration of each preference assessment, and (c) occurrences of inappropriate behavior, and (d) attempt to escape from each assessment (Roane, et al., 1998). During the free-operant assessment, 10 items were made available to each participant with unrestricted access to these items for 5-minutes. The items were placed on in a circle on the table. Prior to the session, a therapist conducted a brief initial sampling of each item with the client (e.g., placing each item in the client's hand or modeling the appropriate manipulation of each item). The dependent measure was the percentage of intervals the individuals engaged with each item using a 10-s partial interval recording procedure. Interobserver agreement (IOA) was collected for 53.2\% of all sessions and average $91.1 \%$ for all dependent measures. Interobserver agreement for percentage-of-intervals measured was calculated by dividing each session into 10 -s intervals and dividing the total number of intervals with agreement by the sum of intervals with agreements plus disagreements.

Roane, et al. (1998) results demonstrated that the free-operant preference assessment was comparable to paired stimulus preference assessment in identifying stimuli that functioned as reinforcers during simple operant responding trials. Furthermore, the free-operant presentation 
was associated with fewer problem behaviors as compared to paired stimulus preference assessment. Of the 13 individuals that engaged in problem behavior, 11 (85.6\%) engaged in problem behavior more frequently in PS assessment. Finally, the free-operant preference assessment required less time to complete than the paired stimulus preference assessment (5 minutes as compared to average of 21.67 minutes).

Ortiz and Carr (2000) extended the work of Roane et al. (1998) by comparing two multiple-stimulus preference assessment methods: free-operant and multiple stimulus without replacement (MSWO) with three children with developmental disabilities. Both preference assessments included seven to eight toys identified through indirect methods by relevant adults as believed to be highly preferred by the participants. The MSWO assessment was implemented five times during each session, with five assessments conducted across a one-week period. The free-operant assessment was implemented for five separate five-minute sessions across a oneweek period. The dependent measure of the FO assessment was collected using a stopwatch to record the duration of engagement with all items during each 5-minute session (Ortiz \& Carr, 2000). Data was calculated by the total sum of the duration of engagement with each item across sessions. Interobserver agreement was collected for $40 \%$ of the sessions and defined as both observers (e.g., primary and secondary) recording the same cumulative duration, within 10-s, for each of the items during the 5-minute session. IOA was reported as averaging $88 \%, 92 \%$, and $100 \%$ for each participant using a point-to-point method. The results indicated that both preference assessments produced similar results, except that the FO assessment identified only the most preferred stimuli, rather than a hierarchy of preferred items (like the MSWO). During this research study, the duration was not reported for the MSWO and FO preference assessment was 5-minutes. 


\section{Benefits to Using Free-operant Preference Assessments}

Graff and Karsten (2012a) reported that $81.4 \%$ of surveyed professionals cited lack of time as a barrier to using preference assessment on a regular basis. These quick assessments allow one to quickly identify preferred items to use during sessions and allow greater allocation of time spent during sessions to be directed at targeting skill acquisition or behavior reduction strategies with clients. Free-operants preference assessments are quick to implement (generally about 5-minutes in duration) and can be used daily to reveal shifts in preferences (Egel, 1981; Roane et al., 1998). Previous research has demonstrated that preferences change often and vary over time (Fisher, et al., 1997; Hanley, et al., 2006; Kang et al., 2013). As a result, it is likely that the reinforcing effects of identified preferred stimuli are likely to vary over time. Therefore, frequent and quick assessment of preferences is important in identifying effective reinforcers and is allowing more time to be spent focusing on other behavior implementation strategies with clients (Graff \& Karsten, 2012a; Kang, et al., 2013; Roane et al., 1998). All other preference assessments (e.g., MSWO, PS, SS, MS) require a duration averaging between 15-30 minutes to complete (Kang et al., 2013; Graff \& Karsten, 2012a). For example, the paired stimulus preferred assessment involves presenting two items or activities simultaneously and requiring the individual to "pick one" and averages 31.5 minutes in duration (Fisher, et al., 1992; Kang et al., 2013; Pace et al., 1985; Paclawskyj \& Vollmer, 1995).

Studies have demonstrated free-operant preference assessment to be associated with low to zero levels of problem behaviors as compared to other types of preference assessments (Chazin \& Ledford, 2016; Roane et al., 1998; Verriden \& Roscoe, 2016)). Roane et al. (1998) suggest that the unrestricted presentation of stimuli the free-operant may prevent the occurrence of problem behavior. Study results from Roane, Vollmer, Ringdahl, and Marcus (1998) indicate 
less problem behavior during FO assessment procedures as compared to PS assessments.

Additional research studies identify the duration of the assessments with certain individuals can lead to increased likelihood of the occurrence of problem behavior that is maintained by access to tangible stimuli (e.g., escape; Kang, et al., 2011; Rush, et al., 2010). Kang, et al., (2011) cite one disadvantage of the MSWO format as it is likely to evoke challenging behavior in that access to the preferred item must be interrupted throughout the assessment.

The free-operant preference assessment is also beneficial in that simultaneous engagement with multiple items are allowed during the preference assessment. Some other assessment only allow engagement with one item at a time (e.g., MSWO; PS; SS). For some individuals, engagement with multiple items (e.g., pushing a car through the blocks) may allow for wider range of preferred activities.

\section{Limitations of Using Free-operant Preference Assessments}

A limitation of the free-operant preference assessment is that they are less likely to generate a hierarchy of most to least preferred items as compared to other preference assessment like the paired stimulus and MSWO (Boyle, et al., 2019; Kang et al., 2013; Verriden \& Roscoe, 2016). This is because the individual may allocate all of his or her time during the assessment toward only one or two items (Roane et al., 1998). Boyle, et al. (2019) suggest based on their research that the free-operant preference assessment may be the best option when only single or two to three highly preferred stimuli need to be identified. Research has suggested that this limitation may be circumvented with the ability to frequently update preferences on a daily basis due to the quick and easy presentation (Kang et al., 2013). 


\section{Summary of Free-operant Preference Assessments}

The free-operant preference assessment may be the best option for practitioners who have a fixed and limited period of time in which to conduct preference assessments (Boyle et al., 2019). Given that the survey results from Graff and Karsten (2012a) indicate that $60 \%$ of respondents (and $81 \%$ of certified behavior analyst) cite lack of time as a main obstacle in implementing preference assessments. Using the free-operant assessment appears to address this specific challenge. These assessments are also beneficial in circumstances when only a small number (e.g., between 1 and 3) of highly preferred items needs to be identified, rather than a complete hierarchy. Data collection methods for the FO assessment include calculating total duration across engagement of the items within the assessment and during partial interval or momentary time sample recording procedures to calculate percentage of engagement across intervals.

\section{Evidence Based Staff Training}

The foundation of applied behavior analysis centers on implementing evidence based behavioral procedures with individuals with developmental disabilities. This also applies to the training methods used to teach staff. Training professionals on procedures to conduct preference assessments would be beneficial to those implementing behavior interventions and strategies (Roscoe \& Fisher, 2008). Conducting direct preference assessments increases the likelihood of identifying the most potent reinforcers and is recommended in best practice guidelines (Cote, et al., 2007; Leaf, et al., 2020). However, these methods are only useful if staff are specifically trained to implement the necessary steps of the procedure.

Trainings used to teach staff to work with individuals with developmental disabilities area often lacking in opportunities for hands on practice and implementation of these strategies. 
Developing training using video and online capabilities can be one solution to overcoming the barriers associated with the development of effective and efficient trainings. Successful application of evidence-based strategies must first begin with effective high quality training for individuals applying these techniques. One hallmark feature of excellent training is focus on treatment integrity or the degree to which an intervention is implemented as intended. Training staff to implement procedures with high levels of treatment integrity, under the direction of highly skilled professional, leads to increased positive outcomes for those being served (DaFonte \& Capizzi, 2015).

Two different objectives often guide trainings: enhancing knowledge base or increasing performance skills. These trainings result in different outcomes and require different approaches or procedures. Trainings designed to enhance knowledge provide the necessary information to answer questions and develop a foundation of understanding about the topic (often in lecture type teaching method). Trainings designed to increase the performance skills result in staff being provided with the necessary skills to perform work duties that he or she was previously unable to complete before the target instruction. Many staff training programs rely on only verbal-skill strategies (e.g., lectures, presentation of written and visual material), but these trainings fail to teach the learners to perform newly targeted job skills to competency (Parsons, et al., 2011). Previous research shows these trainings are ineffective in yielding positive results on the job performance of human service staff (Alavosius \& Sulzer-Azaroff, 1990; Karsten et al., 2015; Parsons, et al., 2011; Petscher \& Bailey, 2006; Phillips, 1998). Reid and Parsons (2002) furthermore emphasized correct and accurate implementation of techniques by stating "if support personnel do not implement treatment plan proficiently, then in essences there is not treatment for challenging behavior" (p. 6). 
Evidence based staff training must include both performance and competency-based strategies (Parsons, et al., 2011; Reid, et al., 2003). Competency is defined as one being able to perform a target skill to a specific mastery criterion. This means that the training includes the trainee practicing the skill until he or she is able to completely demonstrate the skill. One proven research method to effectively teach targeted job skills is to employ behavior skills training (BST) (Hogan, et al., 2015; Miles \& Wilder, 2009; Parson, et al., 2012; Nigro-Bruzzi \& Sturmey, 2010; Sarokoff \& Sturmey, 2004).

\section{Evidence Based Implementation of the Steps in Behavior Skills Training Utilizing Technology}

Behavior skills training (BST) is a proven way to teach a number of behavior analytic techniques in a variety of ways to staff and parents (Gianoumis, et al., 2012; Homlitas, et al, 2014; Iwata, et al., 2000; Lafasakis \& Sturmey, 2007; Lavie \& Sturmey, 2002; Miles \& Wilder, 2009; Nigro-Bruzzi \& Sturmey, 2010; Rosales, et al., 2009; Sarokoff \& Sturmey, 2004; Wallace, et al., 2004; Seiverling, et al., 2012; Van Vonderen, et al., 2012). Miltenberger (2008) describes the four basic teaching components for BST to include (1) instructions, (2) modeling, (3) rehearsal, and (4) feedback. Parsons, et al., (2012) provides further outline of a basic protocol for conducting a BST session in the following six steps (1) describe the target skill, (2) provide a written description of the skill, (3) demonstrate the target skill, (4) require trainee to practice the target skill, (5) provide feedback during the practice, and (6) repeat steps four and five to mastery.

Performance and competency-based staff training is vital, particularly surrounding the implementation of evidence based procedures. Unfortunately, incorporating all of the steps in BST trainings can be time consuming and costly. While the benefits often outweigh the negatives, it is advantageous to explore the different modalities technology has to offer that can 
enhance trainings and increase efficiency. Emerging technologies have provided the opportunity to enhance training and increase efficiency. Access to computers and internet have offered new ways to acquire training and education. Web-based instructions and Microsoft PowerPoint ${ }^{\mathrm{TM}}$ slides have been shown to be effective while decreasing cost and expand training delivery (DaFonte \& Capizzi, 2015; Brock \& Carter, 2013; Feldman \& Matos, 2013; McCulloch \& Noonan, 2013).

The following information breaks down the steps for BST procedure based on previous research identifying the most important components and presentation that lead to effectively training staff to competency. A mastery criterion should be established to identify what is considered competency in the target skills (90-100\% accuracy of the target steps completed correctly over a certain number of consecutive rehearsal trials). Additional research related to best practice and recommendations for the use of technology across each BST step is also discussed.

Instructions. When describing the target skill, one must be sure to provide a rationale for the importance of the skill, describe all behaviors that are involved in performing the skill and behaviorally define the target skill. Step two provides a written description of these target skills, that can be in the form of a performance checklist or written summary of the steps involved in performing the skill (Miltenberger, 2008; Parsons, et al., 2011). These steps should be a summary broken down into simple, easy to quickly read and interpret, and it is not recommended to provide a lengthy document for this training purpose.

Use of Technology Best Practice with Instructions Component. Use of Microsoft PowerPoint $^{\mathrm{TM}}$ slides with a voice over component enables the training to describe the target skill in both vocal and written format. Information, in both forms, should include the rationale for the 
importance of the skill followed by description of the target behaviors. Breaking down a skill into smaller steps (task analysis) and providing a table of these steps would be beneficial (Miltenberger, 2008; Parsons, et al., 2011). Highlighting important concepts during the video can be accomplished during the voice over component and on-screen text. This makes it more noticeable to trainees. Written content and voice-over instruction is often included to increase the saliency of certain aspects of the video, and several recent studies have evaluated the use of video modeling with voiceover to train staff to implement direct preference assessment (Deliperi, et al., 2015; Lipschultz, et al., 2015).

Modeling. The second step demonstrates, or models, the target skill for the trainee. The trainee observes another person completing the target steps. Modeling activities often include using two trainers completing the target steps in that one trainee plays the role of the client and the other trainee completes the role of the staff member. If two trainers are not available, there is the option to use a trainee, although recommendations identify two trainers as the preferred method (Graff \& Karsten, 2012a).

Use of Technology Best Practice with Modeling Component. Developing trainings that offer research proven training strategies in a video format can be one solution to overcoming the barriers associated with the development of evidence based professional training (Vismara, Young, Stahmer, Griffith, \& Rogers, 2009). Using video modeling also ensures consistency of implementation across multiple staff to ensure the training events cover the same topics and implement the steps correctly without additional trainer resources. Video modeling has been used in a number of different BST research studies (Catania, et al., 2009; Nosik, et al., 2013; Rosales, et al., 2015; Vladescu, et al., 2012). 
Video modeling (VM) involves showing a video demonstrating a skill or target behavior with the expectation that the viewers will imitate the demonstrated behavior. One benefit of using a video model rather than live model is the time requirement of the two trainers, one to play the role of the client and one to model implementing the intervention steps. If the video model includes voice over instruction (typically written instruction on the presentation slides too), it does not require the presence of a trainer while trainees view the training. Videos are helpful in that they provide the opportunity to pause the video at crucial points to describe key actions (Parsons et al., 2011). Miltenberger (2008) follows recommendations regarding guidance to increase effectiveness of the modeling step (using videos included): (a) model in real situations or activities, (b) repeat as often as necessary, (c) enhance generalization by modeling in a variety of different ways and situations, and (d) provide an opportunity to rehearse the behavior as soon as possible after trainee observes the model.

Karsten, et al., (2015) summarized research on evidence-based training, focusing on four innovations used during eight specific research studies, one of those innovations included video modeling. Their research identified specific considerations to using video modeling during trainings: (1) the length of the videos, (2) the number of steps should be included in the video, (3) identifying specific features that increase efficacy of video models, and (4) the length of time between viewing the videos and implementing the steps of the procedure. Based eight studies in the review, the range duration of videos was three minutes to 10 minutes (Karsten et al., 2015). The consensus was that the videos needed to be long enough to depict all of the skills necessary to implement the procedure. Furthermore, it was helpful in some research studies to model in the video how to respond to client errors and other variations in performance, since most staff errors occurred when the simulated or real clients made errors (Karsten et al., 2015). The number of 
steps for procedures in the Karsten et al. (2015) study involved a range of 8-12 steps but averaged seven steps. Other features that were found useful in many studies were a voice over component, on screen text, and reducing all distractions while explaining descriptions of the steps. Karsten, Axe, and Mann (2015) reviewed eight studies and half of those studies demonstrated video modeling along improved staff implementation of behavioral procedures (Catania et al., 2009; Collins, et al., 2009; Moore \& Fisher, 2007; Vladescu et al., 2012).

Gerencser et al. (2020) defined a variety of staff training using technology into different methods, including computer based instructions and video modeling with voiceover instructions. Video modeling with voiceover instructions targets using videos of one or more people implementing the steps of the target skill for the trainee to view. Computer training typically employs video modeling, however, it also utilizes additional multiple training elements such as competency questions, narrated slides, self-guided practice, and/or mastery assessments. The training used during this study is identified as computer-based training and includes video examples, competency questions, embedded instructions for each slide, slide-guided practice implementing all steps, and pre/post written tests.

Rehearsal. Graff and Karsten (2012a) identify rehearsal to include role play with a simulated client (adult playing the role of the client) or in-vivo with an actual client. Role play includes the trainee completing the target steps with another person (often the trainee). The role play can also include a client or another trainee. This is one step that trainings may mistakenly leave out, due to this taking up a large bulk of training time, but research identifies it as a critical feature related to the success of BST on mastery of the skill (Parsons, et al., 2011; Rosales et al., 2009). 
Use of Technology Best Practice with Rehearsal Component. Karsten et al. (2015) summarized that the latency between watching the videos and demonstration of the skill was between $10 \mathrm{~min}$ to one hour for eight studies reviewed. It appears that it is helpful for trainees to watch the videos just before implementing the procedures. In addition, some studies allowed trainees to view the videos on multiple occasions. Pollard et al. (2014) demonstrated that interactive computer training increased trainees' implementation of discrete trial instruction (DTI) with children with autism. The three participants had no prior professional training or specific training in this skill. The results of this study show that only one participant required a feedback session and all other participant's increased fidelity to target steps after instructions, modeling, and role play with an adult simulated client. These participants increased from a baseline average of $25 \%$ to an average of $93 \%$ correct implementation of target steps. The results of this study were impressive in that the interactive computer training (e.g., information and modeling) alone increased trainees' fidelity to mastery criterion.

Feedback. The final component in the process is to provide specific feedback to the trainee, often combined with the rehearsal step. The feedback includes communicating to each individual trainee the aspects of the skill that were performed correctly and corrective feedback identifying steps that were incorrect. This can also include providing additional instructions on how to perform it correctly. The feedback is generally delivered at the conclusion of the practice (rather than interrupting the practice).

In previous research, if modeling the target behavior does not result in mastery of the skill, with addition of the performance feedback component is added. For example, Karsten, Axe, and Mann (2015) review identified two studies found that video modeling alone resulted in $80 \%$ procedural accuracy, but with the addition of performance feedback, it increased to $100 \%$ 
procedural integrity (DiGennaro-Reed, et al., 2010; Nosik \& Williams, 2011). Nosik and Williams (2011) used interactive computer training (ICT) to train four undergraduate students to implement discrete trial training and backward chaining procedures with adults with developmental disabilities. The training components included three components: instructions using video models of correct and incorrect implementation of the skills, written and observed feedback. Implementation of the target steps increased to $100 \%$ integrity for one participant receiving the instruction and written feedback alone, while the remaining three participants required all three components before reaching $95 \%$ to $100 \%$ integrity. Generalization sessions with clients during eight-week follow up showed three of four participants maintained high levels of integrity.

Use of Technology Best Practice with Feedback Component. Catania, et al., (2009) evaluated the effects of video modeling on staff implementation of discrete trial training steps. This study's findings demonstrated the effectiveness of video modeling on increasing performance levels of staff that maintained across time. Vladescu, et al., (2012), used video modeling techniques to successfully increase staff performance on skill acquisition of children receiving early intervention.

\section{Evidence Based Implementation of Staff Training on Preference Assessments Utilizing}

\section{Technology}

Gerencser, et al. (2020) reviewed 22 studies using asynchronous trainings for behavior analytic assessments and interventions. These trainings were divided into four asynchronous modalities, including video modeling with voiceover instruction and computer-based instructions. The main differences between these modalities were the computer based instructions utilized multiple features from other training formats such as video examples, 
competency questions, narrated slides, self-guided practice, and/or mastery assessments. Four of the computer-based studies used pre/posttests either inserted in the modules or presented before and after the training (Higbee, et al., 2016; McCulloch \& Noonan, 2013; Pollard et al., 2014; Wainer \& Ingersoll, 2013). Mastery was required on the post test for each of these studies before moving to the next step in the training (or new training module). A summary of the results of these studies indicate that $69.55 \%$ (16 out of 22$)$ participants met performance criterion that was set by each individual research study at the end of the training. Performance dropped below criterion during maintenance and/or generalization phases for some participants in three of the studies (Higbee et al., 2016; Pollard et al., 2014; Wainer \& Ingersoll, 2013). Performance feedback was added to each of these studies during these phases to achieve mastery criterion.

Five studies are reviewed below in their evaluation of the use of technology (specifically video modeling with voice over instruction) to train staff to implement the steps of preference assessments (Deliperi, et al., 2015; Delli Bovi, et al., 2017; Lipschultz, et al., 2015; Rosales, et al., 2015; Weldy, et al., 2014). The specific preference assessment taught during these training included multiple stimulus without replacement only ( $n=2$; Dell Bovi et al., 2016), multiple stimulus without replacement and free-operant ( $\mathrm{n}=9$; Weldy et al., 2014), multiple stimulus without replacement, free-operant, and paired stimulus assessments ( $\mathrm{n}=3$; Rosales, et al., 2015), multiple stimulus without replacement, paired stimulus, and single stimulus assessments ( $\mathrm{n}=4$; Lipschultz et al., 2015), and paired stimulus (n=3; Deliperi et al., 2015).

Weldy, et al., (2014) used video model and voice over to train nine staff in a group setting to implement MSWO and FO preference assessment procedures. Each preference assessment was taught using separate 30-minute PowerPoint presentations in a group format with no supervisor present. A noncurrent multiple probe design across preference assessments was 
used to evaluate the results of the video training among staff members. A seven step tasks analysis was used to outline the steps for the MSWO preference assessment (described by Roscoe \& Fisher, 2008) and an 11-step task analysis was used for the FO preference assessment steps described by Roane et al. (1998). Interobserver agreement was collected for $54 \%$ and $20 \%$ of the sessions for the two groups on a step-by-step basis for each participant (dividing the number of agreements by the number of disagreement and agreements and converting to a percentage). The mean agreement scores for the assessments were $91 \%$ and $95 \%$. The trainees in the study all held bachelor's degrees in the field of behavior analysis and were experienced in implementing behavior interventions and data collection. The video training was on a PowerPoint presentation that was viewed by the entire group. Each slide contained detailed audio instructions with video modeling examples of the steps in the preference assessments. Within one day of the training, trainees were asked to complete an assessment with a designated client. Criterion for mastery was $90 \%$ accuracy across two assessments with clients. A booster training that included watching the video again was added if the participant did not perform at $90 \%$ accuracy after the first video viewing. Results demonstrated staff were successfully trained to implement both preference assessments with clients in generalization probes. Only two participants did not perform to mastery criterion after the first viewing of the video trainings. The total training time for all other participants was 60 minutes, while the other two training times were 90 minutes. This research added to the literature by demonstrating the training in a group format, no rehearse/role play of the skill was used, and no additional training steps were added (e.g., performance feedback) during the study. Limitations of this study are that all participants had at least one year of behavior analytic studies, implementation of behavior analytic interventions, and data collection. This may not be an adequate training method for 
individuals with less experience or education in the field, such as newly hired line therapists (e.g., registered behavior technicians or behavior implementers).

Rosales, et al., (2015) used a multiple baseline design across participants to evaluate staff training using video modeling and voice over instructions to implement three preference assessments (FO, PS, and MSWO) with three teachers. The primary dependent measure was the number of correctly performed responses within each preference assessment. Interobserver agreement was completed during $44 \%$ to $70 \%$ of all sessions. It was calculated using trial-bytrial method (number of agreements divided by number of agreements plus disagreements and converting to a percentage). Mean agreement was $96 \%$ across all sessions. The format of the training consisted of training one assessment at a time. The videos demonstrated correct implementation of each step and included written instructions. No feedback was provided during the role play. Mastery criterion was $90 \%$ correct responses across two consecutive sessions with a simulated client adult. Probes with a student were conducted in the natural setting one week after the last training session for each assessment. Two weeks to one month after the last training session, generalization probes were completed with a different student for each participant across the assessments. The average percentage of correct responding at baseline and after the interventions for the free-operant preference assessment was $30 \%$ during baseline and 99\% accuracy after training. Performance feedback was an extra step that was added for one participant that did not meet mastery criteria after the fourth training session. Limitations of this study included not using a script for the simulated clients during the role play sessions (Rosales et al., 2015; Roscoe \& Fisher, 2008). Second, performance increases during the training was suggested to be possibly related to reviewing the video again before completing the assessment and that could serve as feedback. 
Delli Bovi, et al. (2017) demonstrated the effectiveness of video modeling with voice over instructions to train two public school staff to correctly implement a multiple-stimulus without replacement (MSWO). Baseline, training, maintenance, and generalization phases were included in the study. Simulated data was provided to allow the participants to calculate the results (three different data calculation sheets were provided depicting results from three mock MSWO sessions). Assessment scripts were used when a simulated client (first author) completed typical and atypical responses during the baseline and training phase. A concurrent multiple baseline across participants was the single subject experimental design. The dependent variable was the percentage of opportunities implemented correctly for trainees using a 13-step task analysis. The percentage was calculated for each session by dividing the number of correct responses by the number of total opportunities to engage in a correct response and multiplying by 100 . Trial by trial interobserver agreement (IOA) was collected and the mean interobserver agreement scores ranged from 92 to $100 \%$ ). During the training, the trainees viewed the 17 minute instructional video showing the steps necessary to conduct the MSWO assessment. The first part of the video was filmed third person point-of-view showed the experimenter modeling each step in the assessment. Voiceover instruction was added to include detailed description of each step. The final part of the video was playing a full MSWO session of eight trials with a simulated client (no voice over instruction used during this portion). The second part of the video, filmed from first person point-of-view with voice-over instruction, showed the instructor completing the steps to calculate the percentage for each item creating a rank-order list of items. Each participant completed the role play step after viewing the video. The criterion for mastery in role play was $90 \%$ correct responding for two consecutive sessions. No feedback was provided. 
The role play training portion consisted of using simulated clients, the generalization phase used actual clients in the natural setting (students in the special education classroom), and the maintenance portion was completed eight weeks after intervention. The results of the study demonstrated that this was an effective mode in training staff to implement the steps of the preference assessment. The training produced generalized responding, maintenance, and high social validity ratings among the trainees. This study collected procedural integrity data in that a trained observer viewed video of the experimental steps for $100 \%$ of the sessions. The data was collected on the following steps: the experimenter presented the training video in its entirety, provided the trainees with all materials to conduct a session, and provided no other training components prior to or following the staff trainee's viewing of the video. Mean procedural integrity was $100 \%$ for both trainees based on the total number of implemented steps divided by the total number of steps and multiplied by 100 . Social validity data used the modified Treatment Acceptability Rating Form Revised (TARF-R; Reimers \& Wacker, 1988) questionnaire that consisted of ten statements.

The results of Delli Bovi et al. (2017) indicated that the two participants met the mastery criterion in two training sessions and also demonstrated close to $100 \%$ accuracy during generalization probes with an actual client. The social validity survey indicated the trainees were satisfied with the training, would recommend the training to others, and enjoyed the training. They reported they believed they could accurately conduct a MSWO preference assessment after the video modeling and voice over training and believed it was effective training mode to learn a new skill (Delli Bovi, et al., 2017).

Lipschultz, et al. (2015) evaluated the effectiveness of video modeling with voiceover instruction (VMVO) to train clinic staff to implement the steps of three direct preference 
assessments (single-stimulus, paired stimulus, and multiple stimulus without replacement). This study used a concurrent multiple baseline across participant's design and mastery criteria was $90 \%$ accuracy on completion of each direct preference assessment across two sessions. The study included teaching trainees to (a) select the most appropriate direct preference assessment to implement based on client characteristics, (b) select appropriate stimuli based on client indirect survey results, (c) implement the target steps of each preference assessment, and (d) score and interpret data collected during the assessment. Results demonstrated that VMVO training was effective and staff was able to generalize implementation of the direct preference assessments with high levels of treatment integrity. Trainees provided positive ratings of the training.

\section{Summary}

It is important to continue to explore identifying effective staff training methods as evidence based in order to reduce the research-to-practice gap. Teaching performance skills (i.e., skills staff will perform in their work duties that they previously could not perform prior to training), targets improving implementation of target skill sets, in addition to acquiring a knowledge-based understanding of the target skills. Understanding that effective staff training is tied directly to improved organization output must occur in the human service field. However, this type of intensive hands-on training is often time-consuming and costly, making it difficult to provide at the level required to fully support trainees. Exploring the contribution cach component of behavior skills training (BST) and if it is necessary for all components to be present in order to make training effective would be one was to increase efficiency of trainings. Can technology be used to reduce the need for a trainer to be present, still provide the necessary components of behavior skills training and maintain effective training for staff to complete the target task to competency? An emerging line of research has begun to focus on maintaining 
effectiveness but increasing efficiency of behavior-based performance staff trainings by reducing the need for the presence of a trainer and identifying which steps require hands-on support (Gerencser et al., 2020; Karsten, et al., 2011; Nottingham et al., 2017). It is important to continue to push the boundaries in the areas of effectiveness, efficiency, and acceptability in order to continue to provide the highest quality training (Parsons, Rollyson, \& Reid, 2011). Considerations must be explored in minimizing the demands on staff time while maintaining the quality and effective training components. Developing effective and efficient staff training packages is an important research path that requires further examination for individuals working with individuals with developmental disabilities. 


\section{References}

Alavosius M. P. \& Sulzer-Azaroff, B. (1990). Acquisition and maintenance of health-care routines as a function of feedback density. Journal of Applied Behavior Analysis, 23, $151-162$.

Baer, D., Wolf, M., \& Risley, T. (1968). Some current dimensions of applied behavior analysis. Journal of Applied Behavior Analysis, 1, 91-97.

Boyle, M. A., Curtis, K. S., Forck, K. L., Fudge, B. M., Speake, H. N., \& Pauls, B. P. (2019). A replication of the response-restriction preference assessment. Behavioral Interventions, 34, 564 -576. https://doi.org/10. 1002/bin.1683

Brock, M. E., \& Carter, E. W. (2013). Effects of a professional development package to prepare special education paraprofessionals to implement evidence-based practice. The Journal of Special Education. Advance online publication. http://dx.doi.org/10.1177/0022466913501882

Carr, J. E., Nicolson, A. C., \& Higbee, T. S. (2000). Evaluation of a brief multiple-stimulus preference assessment in a naturalistic context. Journal of Applied Behavior Analysis, 33, 353-357. doi:10.1901/ jaba.2000.33-353.

Catania, C. N., Almeida, D., Liu-Constant, B., \& DiGennaro-Reed, F. D. (2009). Video modeling to train staff to implement discrete-trial instruction. Journal of Applied Behavior Analysis, 42, 387-392. doi:10.1901/jaba.2009.42-387.

Chazin, K. T. \& Ledford, J. R. (2016). Free-operant observation. In Evidence-based instructional practices for young children with autism and other disabilities. Retrieved from http://vkc.mc.vanderbilt.edu/ebip/free-operant 
Collins, S., Higbee, T. S., \& Salzberg, C. L. (2009). The effects of video modeling on staff implementation of a problem-solving intervention with adults with developmental disabilities. Journal of Applied Behavior Analysis, 42, 849-854. doi:10.1901/jaba.2009.42-849.

Cooper, J. O., Heron, T. E., \& Heward, W. L. (2007). Applied behavior analysis (2nd ed.). Upper Saddle River, NJ: Pearson.

Cote, C. A., Thompson, R. H., Hanley, G. P., \& McKerchar, P. M. (2007). Teacher report and direct assessment of preferences for identifying reinforcers for young children. Journal of Applied Behavior Analysis, 40, 157-166.

DaFonte, M.A. \& Capizzi, A.M., (2015). A module-based approach: Training paraeducators on evidence-based practices. Physical Disabilities: Education and Related Services, 34(1), 31-54. doi: 10.14434/pders.v34i1.13823

Deliperi, P., Vladescu, J. C., Reeve, K. F., Reeve, S. A., \& DeBar, R. M., (2015). Training staff to implement a paired-stimulus preference assessment using video modeling with voiceover instruction. Behavioral Interventions, 30, 314-332. doi: 10.1002/bin.1421.

DeLeon, I.G. \& Iwata, B.A. (1996). Evaluation of a multiple-stimulus presentation format for assessing reinforcer preferences. Journal of Applied Behavior Analysis 29, 519-532.

DeLeon, I. G., Iwata, B. A., Conners, J., \& Wallace, M. D. (1999). Examination of ambiguous stimulus preferences with duration-based measures. Journal of Applied Behavior Analysis, 32, 111-114.

Delli Bovi, G. M., Vladescu, J. C., DeBar, R. M., Carroll, R. A., \& Sarokoff, R. A. (2017). Using video modeling with voice-over instruction to train public school staff to implement a 
preference assessment. Behavior Analysis in Practice, 10(1), 72-76.

http://doi.org/10.1007/s40617-016-0135-y

DiGennaro-Reed, F. D., Codding, R., Catania, C. N., \& Maguire, H. (2010). Effects of video modeling on treatment integrity of behavioral interventions. Journal of Applied Behavior Analysis, 43, 291-295. doi:10.1901/jaba.2010.43-291.

Egel, A. L. (1981), Reinforcer variation: Implications for motivating developmentally disabled children. Journal of Applied Behavior Analysis, 14, 345-350. doi:10.1901/jaba.1981.14$\underline{345}$

Feldman, E. K., \& Matos, R. (2013). Training paraprofessionals to facilitate social interactions between children with autism and their typically developing peers. Journal of Positive Behavior Interventions, 15(3), 169-179. http://dx.doi.org/10.1177/1098300712457421

Fisher, W. W., Piazza, C. C., Bowman, L. G., \& Amari, A. (1996). Integrating caregiver report with a systematic choice assessment to enhance reinforcer identification. American Journal on Mental Retardation, 101, 15-25.

Fisher, W., Piazza, C.C., Bowman, L.G., Hagopian, L.P., Owens, J.C., \& Slevin, I. (1992). A comparison of two approaches for identifying reinforcers for persons with severe and profound disabilities. Journal of Applied Behavior Analysis 25, 491-498.

Fisher, W. W., Thompson, R. H., Piazza, C. C., Crosland, K., \& Gotjen, D. (1997). On the relative reinforcing effects of choice and differential consequences. Journal of Applied Behavior Analysis, 30, 423-438.

Gerencser, K. \& Akers, J. \& Becerra, L. \& Higbee, T., \& Sellers, T. (2020). A Review of Asynchronous Trainings for the Implementation of Behavior Analytic Assessments and Interventions. Journal of Behavioral Education. 29, 122-152. 10.1007/s10864-019- 
09332-x.

Gianoumis, S., Seiverling, L., \& Sturmey, P. (2012). The effects of behavior skills training on correct teacher implementation of natural language paradigm teaching skills and child behavior. Behavioral Interventions. 27, 57-74. DOI: 10.1002/bin.1334

Graff, R. B., \& Karsten, A. M. (2012a). Assessing preferences of individuals with developmental disabilities: a survey of current practices. Behavior Analysis in Practice, 5, 37-48. doi:10.1901/ jaba.1992.25-491.

Graff, R. B., \& Karsten, A. M. (2012b). Evaluation of a self-instruction package for conducting stimulus preference assessments. Journal of Applied Behavior Analysis, 45, 69-82.

Hagopian, L.P., Hardesty, S.L., \& Gregory, M., (2015). Overview and summary of scientific support for applied behavior analysis https://www.kennedykrieger.org/sites/default/files/patient-care-files/aba-scientificsupport-9-2015.pdf

Hagopian, L., Long, E., \& Rush, K. (2004). Preference assessment procedures for individuals with developmental disabilities. Behavior Modification, 28, 668-677.

Hanley, G. P., Iwata, B. A., \& Roscoe, E. M. (2006). Some determinants of changes in preference over time. Journal of Applied Behavior Analysis, 39, 189-202.

Higbee, T. S., Aporta, A. P., Resende, A., Nogueira, M., Goyos, C., \& Pollard, J. S. (2016). Interactive computer training to teach discrete trial instruction to undergraduates and special educators in Brazil. Journal of Applied Behavior Analysis. Advance online publication. doi:10.1002/jaba.329. 
Hitchcock, J.H., Kratochwill, T.T., \& Chezan, L.C. (2015). What works clearinghouse standards and generalization of single-case design evidence. Journal of Behavioral Education, 24, 459-469.

Hogan, A., Knez, N, \& Kahng, S. (2015). Evaluating the use of behavior skills training to improve school staffs' implementation of behavior intervention plans. Journal of Behavioral Education, 24, 242-254.

Homlitas, C., Rosales, R., \& Candel, L. (2014). A further evaluation of behavior skills training for implementation of the picture exchange communication system. Journal of Applied Behavior Analysis. 47(1), 1-6.

Horner, R. H., Carr, E. G., Halle, J., McGee, G., Odom, S., \& Wolery, M. (2005). The use of single subject research to identify evidence-based practice in special education. Exceptional Children, 71,165-179.

Iwata, B. A., Wallace, M. D., Kahng S. W., Lindberg, J. S., Roscoe, E. M., Conners, J., Hanley, G. P., Thompson, R. H., \& Worsdell, A. S. (2000). Skill acquisition in the implementation of functional analysis methodology. Journal of Applied Behavior Analysis, 33(2), 181-194.

Kang, S., O'Reilly, M., Lancioni, G., Falcomata, T. S., Sigafoos, J., \& Xu, Z. (2013). Comparison of the predictive validity and consistency among preference assessment procedures: A review of the literature. Research in Developmental Disabilities, 34(4), 1125-1133. http://dx.doi.org/10.1016/j.ridd.2012.12.021

Kang, S., O’Reilly, M., Fragale, C., Aguilar, J., Rispoli, M., \& Lang, R. (2011). Evaluation of the rate of problem behavior maintained by different reinforcers across preference assessments. Journal of Applied Behavior Analysis, 44, 835-846. 
Karsten, A. M., Axe, J. B., \& Mann, C. C. (2015). Review and Discussion of Strategies to Address Low Trainer-to-Staff Ratios. Behavioral Interventions, 30(4), 295-313. DOI: $10.1002 /$ bin. 1420

Kazdin, A. E. (2011). Single-case research designs: Methods for clinical and applied settings. Oxford University Press.

Kodak, T., Fisher, W. W., Kelley, M. E., \& Kisamore, A. (2009). Comparing preference assessments: Selection- versus duration-based preference assessment procedures. Research in Developmental Disabilities, 30, 1068-1077.

Kratochwill, T. R., Hitchcock, J., Horner, R. H., Levin, J. R., Odom, S. L., Rindskopf, D. M. \& Shadish, W. R. (2010). Single-case designs technical documentation. From the What Works Clearinghouse.

Lafasakis, M. \& Sturmey, P. (2007). Training parent implementation of discrete-trial teaching: Effects on generalization of parent teaching and child correct responding. Journal of Applied Behavior Analysis, 40, 685-689.

Lavie, T. \& Sturmey, P. (2002). Training staff to conduct a paired-stimulus preference assessment. Journal of Applied Behavior Analysis. 35(2), 209-211.

Lerman, D. C., Tetreault, A., Hovanetz, A., Strobel, M., \& Garro, J. (2008). Further Evaluation of a Brief, Intensive Teacher-Training Model. Journal of Applied Behavior Analysis, 41(2), 243-248. http://doi.org/10.1901/jaba.2008.41-243

Lipschultz, J.L., Vladescu, J.C., Reeve, K.F., Reeve, S.A., \& Dipsey, C.R. (2015). Using video modeling with voiceover instruction to train staff to conduct stimulus preference assessments. Journal of Developmental and Physical Disabilities, 27, 505-532. 
Maffei-Almodovar, L., \& Sturmey, P. (2018). Change agent training in behavior analytic procedures for people with developmental and intellectual disabilities: A meta-analysis. Review Journal of Autism and Developmental Disorders. Advance online publication, 5, 129-141. https://doi.org/10.1007/s40489- 018-0128-6.

McCulloch, E. \& Noonan, M. (2013). Impact of online training videos on the implementation of mand training by three elementary school paraprofessionals train staff to implement discrete-trial instruction. Education and Training in Autism and Developmental Disabilities, 48 (1).

Miles, N. I. \& Wilder, D. A. (2009). Effects of behavioral skills training on caregiver implementation of guided compliance. Journal of Applied Behavior Analysis. 42(2), 405410. DOI: $10.1901 /$ jaba.2009.42-405

Miltenberger, R. (2008). Behavior Modification: principals and procedure ( $3^{\text {rd }}$ ed.) Belmont, CA. Wadsworth Publishing.

Moore, J. M. \& Fisher, W. W. (2007). The effects of videotape modeling on staff acquisition of functional analysis methodology. Journal of Applied Behavior Analysis, 40, 197-202. doi:10.1901/ jaba.2007.24-06.

Newman, B. (1992). The reluctant alliance: Behaviorism and humanism. Buffalo, NY: Prometheus.

Nigro-Bruzzi, D. \& Sturmey, P. (2010). The effects of behavioral skills training on mand training by staff and unprompted vocal mands by children. Journal of Applied Behavior Analysis, 43(4), 757-761.

Northup, J., George, T., Jones, K., Broussard, C., \& Vollmer, T. R. (1996). A comparison of reinforcer assessment methods: the utility of verbal and pictorial choice 
procedures. Journal of Applied Behavior Analysis, 29(2), 201-212.

https://doi.org/10.1901/jaba.1996.29-201

Nosik, M. R., \& Williams, W. L. (2011). Component evaluation of a computer based format for teaching discrete trial and backward chaining. Research in Developmental Disabilities, 32, 1694-1702. doi: 10.1016/j.ridd.2011.02.002

Nosik, M. R., Williams, W. L., Garrido, N., \& Lee, S. (2013). Comparison of computer based instruction to behavior skills training for teaching staff implementation of discrete-trial instruction with an adult with autism. Research in Developmental Disabilities, 34, 461468. doi: 10.1016/j.ridd.2012.08.011

Nottingham, C.L., Vladescu, J.C., Giannakakos, A.R., Schnell, L.K., \& Lipschultz, J.L. (2017). Using video modeling with voiceover instruction plus feedback to train implementation of stimulus preference assessments. Learning and Motivation, 58, 37-47.

Ortiz, K. \& Carr, J. E. (2000). Multiple-stimulus preference assessments: A comparison of freeoperant and restricted-operant formats. Behavioral Interventions, 15, 345-353.

Paclawskyj, T. R., \& Vollmer, T. R. (1995). Reinforcer assessment for children with developmental disabilities and visual impairments. Journal of Applied Behavior Analysis, $28,219-224$.

Pace, G. M., Ivancic, M. T., Edwards, G. L., Iwata, B. A., \& Page, T. J. (1985). Assessment of stimulus preference and reinforcer value with profoundly retarded individuals. Journal of Applied Behavior Analysis 18, 249-255.

Parsons, M. B., Rollyson, J. H., \& Reid, D. H. (2011). Evidence-based staff training: A guide for practitioners. Behavior Analysis in Practice. 5(2), 2-11.

Petscher, E. S. \& Bailey, J. S. (2006). Effects of training, prompting, and self-monitoring on staff 
behavior in a classroom for students with disabilities. Journal of Applied Behavior Analysis, 39, 215-226. doi:10.1901/jaba.2006.02-05.

Phillips, J. F. (1998). Applications and contributions of organizational behavior management in schools and day treatment settings. Journal of Organizational Behavior Management, 18,103-129. doi: 10.1300/J075v18n02_06

Piazza, C. C., Roane, H. S., \& Karsten, A. (2011). Identifying and enhancing the effectiveness of positive reinforcement. In W. W. Fisher, C. C. Piazza, \& H. S. Roane (Eds.), Handbook of applied behavior analysis (pp. 151-164). New York: Guilford Press.

Pollard, J. S., Higbee, T. S., Akers, J. S. \& Brodhead, M. T. (2014). An evaluation of interactive computer training to teach instructors to implement discrete trials with children with autism. Journal of Applied Behavior Analysis, 47, 765-776. doi:10.1002/jaba.15

Reid D. H. \& Parsons M. B. (2002). Organizational behavior management in human service settings. In: Austin J., Carr J. E., editors. Handbook of applied behavior analysis. Reno, NV: Context Press; pp. 275-294. (Eds.)

Reid D. H., Rotholz D. A., Parsons M. B., Morris L., Braswell B. A., Green C. W., \& Schell R. M. (2003). Training human service supervisors in aspects of positive behavior support: Evaluation of a state-wide, performance-based program. Journal of Positive Behavior Interventions, 5, 35-46.

Reimers, T. M. \& Wacker, D. P. (1988). Parents' rating of the acceptability of behavioral treatment recommendation made in an outpatient clinic: A preliminary analysis of the influence of treatment effectiveness. Behavioral Disorders, 14, 7-15.

Roane, H. S., Vollmer, T. R., Ringdahl, J. E., \& Marcus B. A. (1998). Evaluation of a brief stimulus preference assessment. Journal of Applied Behavior Analysis 31, 605-620. 
Rosales R., Gongola L., \& Homlitas C. (2015). An evaluation of video modeling with embedded instructions to teach implementation of stimulus preference assessments. Journal of Applied Behavior Analysis, 48, 209-214. doi: 10.1002/jaba.174.

Rosales R., Stone, K., \& Rehfeldt, R. A. (2009). The effects of behavioral skills training on implementation of the picture exchange communication system. Journal of Applied Behavior Analysis, 42(3), 541-549.

Roscoe, E. M. \& Fisher, W. W. (2008). Evaluation of an efficient method for training staff to implement stimulus preference assessments. Journal of Applied Behavior Analysis, 41, $249-254$.

Sarokoff, R. A. \& Sturmey, P. (2004). The effects of behavioral skills training on staff implementation of discrete-trial teaching. Journal of Applied Behavior Analysis, 37, 535538.

Seiverling, L., Williams, K., Sturmey, P., \& Hart, S., (2012) Effects of behavioral skills training on parental treatment of children's food selectivity. Journal of Applied Behavior Analysis, 45(1), 197-203.

United States Surgeon General (1999). Mental health: A report of the Surgeon General. Washington, DC: Author.

Van Vonderen, A., Didden, R., \& Beeking, F. (2012). Effectiveness of instruction and video feedback on staff's trainer behavior during one-to-one training with children with severe intellectual disability. Research in Developmental Disabilities, 33, 283-290.

Verriden, A. L. \& Roscoe, E. M. (2016). A comparison of preference-assessment methods. Journal of Applied Behavior Analysis, 49, 265-285. https://doi.org/10.1002/jaba.30

Vismara, L. A., Young, G. S., Stahmer, A. C., Griffith, E. M., \& Rogers, S. J. (2009). 
Dissemination of Evidence-Based Practice: Can We Train Therapists from a Distance? Journal of Autism and Developmental Disorders, 39(12), 1636-1651. http://doi.org/10.1007/s10803-009-0796-2

Vladescu, J. C., Carroll, R., Paden, A., \& Kodak, T. M. (2012). The effects of video modeling with voiceover instruction on accurate implementation of discrete trial instruction. Journal of Applied Behavior Analysis, 45(2), 419-423. http://doi.org/10.1901/jaba.2012.45-419

Vollmer T. R., Marcus B. A., \& LeBlanc L. (1994). Treatment of self-injury and hand mouthing following inconclusive functional analyses. Journal of Applied Behavior Analysis, 27, $331-44$.

Wainer, A. L., \& Ingersoll, B. R. (2013). Disseminating ASD interventions: A pilot study of a distance learning program for parents and professionals. Journal of Autism and Developmental Disorders, 43, 11-24. doi:10.1007/s10803-012-1538-4

Wallace, M. D., Doney, J. K., Mintz-Resudek, C. M., \& Tarbox, R. S. F. (2004). Training educators to implement functional analyses. Journal of Applied Behavior Analysis, 37(1), 89-92. https://doi.org/10.1901/jaba.2004.37-89

Weldy, C. R., Rapp, J. T., \& Capocasa, K. (2014). Training staff to implement brief stimulus preference assessments. Journal of Applied Behavior Analysis, 47, 214-218.

Windsor, J., Piche', L. M., \& Locke, P. A. (1994). Preference testing: A comparison of two presentation methods. Research in Developmental Disabilities, 15, 439-455. 
Rounning head: EVALUATION OF COMPUTER-BASED TRAINING

SECTION FOUR:

CONTRIBUTION TO PRACTICE 


\section{White Paper for Staff Training Best Practices \\ Presented to Community Supports Organization}

Identifying effective training standards for staff working with individuals with developmental disabilities is a vital part of any human service organization. To provide effective strategies to consumers served, it is important agencies must understand the immeasurable value of quality staff training programs. However, closing the research-to-practice gap for staff trainings may be difficult, time consuming, and costly. Training staff effectively requires a substantial amount of time, money, and materials. Additionally, creates unbillable hours and staff are often missing therapy sessions with consumers. However, despite initial drawbacks, it is critical for human service organizations to understand the link between effective staff training and improved organization output tied to their mission and vision.

Reid and Parsons (2002) described two outcomes effective staff training should produce: staff skill acquisition and "enhanced consumer welfare" (p. 53). Training staff to implement procedures with high levels of treatment integrity leads to increased positive outcomes for those being served and contributes to developing effective teams (DaFonte \& Capizzi, 2015). Human service organizations build strong teams through effective training. Northouse (2016) describes positive outcomes from organizations with effective teams in that they demonstrate greater productivity, display effective use of resources, make better decisions, solve complex problems, create better products and services, and foster greater innovation and creativity. Computer and video technology emerging over the last few years provide more opportunities for organizations to deliver quality trainings to their employees while increasing efficiency and reducing costs associated with trainings (Gerencser, et al., 2020). 
Staff training that focused on teaching performance skills not only improves knowledge of the subject matter, but specifically targets improving staff's ability to implement target skill sets. Hands on trainings provided under the direction of highly skilled professionals are considered an important part of best practice staff training for the development of performance skills (Lerman, et al., 2008; Nottingham, et al., 2017). However, this type of intensive hands-on training is often time consuming and costly, making it difficult to provide the level required to fully support trainees.

Direct services staff in the field of behavior analysis would benefit in learning to accurately identify potential items and activities that can function as reinforcers for the target learner. By identifying the individual's preferred items, it is presumed that the preferred items are more likely to function as reinforcers that can be used in behavior analytic interventions. However, determining preferences of individuals with development disabilities can often be challenging due to communication deficits, inflexible and repetitive behavior patterns, and/or restricted interests (Roane, et al., 1998). Conducting direct preference assessments increases the likelihood of identifying the most potent reinforcers and is recommended in best practice guidelines (Cote, et al., 2007; Leaf, et al., 2020).

Research supports the use of direct preference assessments and identifies benefits of doing so with individuals with developmental disabilities, however, these methods are only useful if staff are trained to competency in the implementation of these assessments. Graff and Karsten (2012a) surveyed 406 professionals regarding current practices related to assessing preferences of individuals with developmental disabilities and more than half of all respondents reported that they were never directly trained to conduct direct preference assessments. Individuals that did report receiving training indicated it was from independently reading 
published studies or training manuals (27\%), in-services training (19\%), and $12 \%$ attended a workshop on conducting direct preference assessments. Furthermore, survey results revealed that $50 \%$ of all respondents cited lack of knowledge of preference assessment procedures as a barrier to implementing them with consumers (Graff \& Karsten, 2012a). Given the importance of identifying effective reinforcers when working with individuals with developmental disabilities combined with the self-reported lack of training and knowledge of preference assessments, an essential research path needs to be explored regarding the development of effective and efficient training programs to teach staff the steps of implementing preference assessments (Graff \& Karsten, 2012a; Vollmer, et al., 1994).

One direct preference assessment is the free-operant (FO) preference assessment. This type of preference assessment is simple and quick to implement at only 5-minutes in duration, as compared to other types of preference assessments, which range from 15-30 minutes in length (Kang, et al., 2013). This assessment involves the simultaneous presentation of all stimuli to the individual and allows engagement with all items without withdrawing items at any time. Graff and Karsten (2012a) reported that $81.4 \%$ of surveyed professionals cited lack of time as a barrier to using preference assessment on a regular basis. Because of the ease of implementation and short duration, free-operant preference assessments can be used daily to reveal shifts in preferences (Egel, 1981).

Computer based instruction is one viable instructional method current research has highlighted that can offer a way to train staff effectively and efficiently. An emerging line of research has begun to focus on maintaining effectiveness but increasing efficiency of behavior based performance staff trainings by reducing the need for the presence of a trainer throughout the training (Gerencser et al., 2020; Nottingham et al., 2017). Using technology in the form of 
videos and computer training has been shown to be an effective teaching modality for numerous applied behavior analytic technologies while decreasing cost and expanding training delivery (Boyle et al., 2019; Brock \& Carter, 2013; DaFonte \& Capizzi, 2015; Feldman \& Matos, 2013; McCulloch \& Noonan, 2013). Current research supports computer-based training alone, without a trainer present, as an effective mode of teaching the implementation of direct preference assessments in as little as 30-minutes training time (Deliperi, et al., 2015; Delli Bovi, et al., 2017; Lipschultz, et al., 2015; Rosales, et al., 2015; Weldy, et al., 2014).

One direct preference assessment is the free-operant (FO) preference assessment. This type of preference assessment is simple and quick to implement at only 5-minutes in duration, as compared to other types of preference assessments, which range from 15-30 minutes in length (Kang, et al., 2013). This assessment involves the simultaneous presentation of all stimuli to the individual and allows engagement with all items without withdrawing items at any time. The dependent measure of the assessment is the time allocated in the engagement of each item. Observers can score item engagement using 10-s partial interval scoring or momentary time sampling (Boyle et al., 2019; Verriden \& Roscoe, 2016; Weldy, et al., 2014). Data is then summarized as percentage of engagement, which then can be converted to a rank. Graff and Karsten (2012a) reported that $81.4 \%$ of surveyed professionals cited lack of time as a barrier to using preference assessment on a regular basis. These quick assessments allow one to quickly identify preferred items to use during sessions and allow greater allocation of time spent during sessions to be directed at targeting skill acquisition or behavior reduction strategies with clients. Free-operants preference assessments are quick to implement (generally about 5-minutes in duration) and can be used daily to reveal shifts in preferences (Egel, 1981; Roane et al., 1998). 
Training these direct line staff to conduct direct preference assessments can lead to increased effectiveness of skill acquisition and behavior reduction programs for consumers by staff able to better identify potential reinforcers that can be used within these interventions. The use of technology to provide training and reduce the number of direct training hours with professionals while continuing to provide an effective training will offer benefits across professionals, parents, and schools.

\section{Conceptual/Theoretical Framework}

Applied behavior analysis (ABA) is the application of learning principles focused on improving behaviors of social significance and determining if the observed changes are a function to the applied procedures (Baer, Wolf, \& Risley, 1968). Reinforcement is an important principle in the practice of Applied Behavior Analysis used to strengthen desired behaviors (Cooper et al., 2007).

The effectiveness of skill acquisition and behavior reduction interventions depend largely on the successful identification and implementation of effective reinforcers (Kodak, et al., 2009). Direct care staff often struggle to identify effective reinforcers for individuals with developmental disabilities. Research identifies direct preference assessments as the most effective way to use preferred stimuli to identify potential reinforcers for individuals with development disabilities (Kang, et al., 2013).

\section{Review of Literature}

\section{Direct Preference Assessments}

A large body of empirical studies effectively demonstrates direct preference assessment's capacity to identify items that may function as effective reinforcers when provided contingently after desired behavior for individuals with developmental disabilities (Carr, Nicolson, \& Higbee, 
2000; DeLeon \& Iwata, 1996; Kang, et al., 2013; Northup, et al., 1996; Pace, et al., 1985;

Roane, et al., 1998). Additionally, research also suggests that highly preferred items are more effective reinforcers than low to moderately preferred items for skill acquisition (Carr et al., 2000; DeLeon \& Iwata, 1996; Fisher, et al., 1992; Northup et al., 1996; Roane et al., 1998). Preferred stimuli is defined as items that an individual chooses to engage in, that may in turn function as a reinforcer (Graff \& Karsten, 2012a).

Both indirect (i.e., parent/caregiver interview or survey) and direct (i.e., systematic presentation of stimuli in various methods) measures can be used to pinpoint preferred items and activities. However, indirect methods can be used to identify a range of items to be used within direct preference assessments (Graff \& Karsten, 2012a; Fisher, et al., 1996). Numerous studies have demonstrated empirically derived reinforcers are more effective than arbitrarily selected reinforcers across a variety of behavior programs (Kodak, et al., 2009; Vollmer, et al., 1994). Conducting direct assessment in addition to indirect means increases the likelihood of identifying the most potent reinforcers (Cote et al., 2007; Graff \& Karsten, 2012a).

\section{Evidence Based Staff Training}

Research emphasizes the importance of implementing evidence based behavioral procedures with individuals with developmental disabilities. One hallmark feature of excellent training is focus on treatment integrity or the degree to which an intervention is implemented as intended. Training staff to implement procedures with high levels of treatment integrity, under the direction of highly skilled professional, leads to increased positive outcomes for those being served (DaFonte \& Capizzi, 2015). Research shows that many staff training programs relying on verbal-skill strategies (e.g., lectures, presentation of written and visual material) are effective for enhancing targeted information, but often are ineffective for teaching learners to perform newly 
targeted job skills (Parsons, Rollyson, \& Reid, 2011). Previous research shows these trainings are ineffective in yielding positive results on the job performance of human service staff (Alavosius \& Sulzer-Azaroff, 1990; Karsten et al., 2015; Parsons, et al., 2011; Petscher \& Bailey, 2006; Phillips, 1998). Evidence based staff training must include both performance and competency-based strategies (Parsons, et al., 2011; Reid, et al., 2003). Competency is defined as one being able to perform a target skill to a specific mastery criterion. This means that the training includes the trainee practicing the skill until he or she is able to completely demonstrate the skill. One proven research method to effectively teach targeted job skills is to employ behavior skills training (BST) (Hogan, Knez, \& Kahng, 2015; Miles \& Wilder, 2009; Parson, et al., 2012; Nigro-Bruzzi \& Sturmey, 2010; Sarokoff \& Sturmey, 2004).

Miltenberger (2008) describes the four basic teaching components for BST to include (1) instructions, (2) modeling, (3) rehearsal, and (4) feedback. Performance and competency-based staff training is vital, particularly surrounding the implementation of evidence-based procedures. Unfortunately, incorporating all of the steps in BST trainings can be time consuming and costly. While the benefits often outweigh the negatives, it is advantageous to explore the different modalities technology has to offer that can enhance trainings and increase efficiency. The following is a summary of the behavior skills training (BST) components regarding review best practice guideline for the use of technology.

- Instructions: Use of Microsoft PowerPoint ${ }^{\mathrm{TM}}$ slides with a voice over component enables the training to describe the target skill in both vocal and written format. Information, in both forms, should include the rationale for the importance of the skill followed by description of the target behaviors. Breaking down a skill into smaller steps (task analysis) and providing a table of these steps would be beneficial 
(Miltenberger, 2008; Parsons, et al., 2011). Highlighting important concepts during the video can be accomplished during the voice over component and on-screen text. This makes it more noticeable to trainees. Written content and voice-over instruction is often included to increase the saliency of certain aspects of the video, and several recent studies have evaluated the use of video modeling with voiceover to train staff to implement direct preference assessment (Deliperi, et al., 2015; Lipschultz, et al., 2015).

- Modeling: Video modeling (VM) involves showing a video demonstrating a skill or target behavior with the expectation that the viewers will imitate the demonstrated behavior. One benefit of using a video model rather than live model is the time requirement of the two trainers, one to play the role of the client and one to model implementing the intervention steps. Using video modeling also ensures consistency of implementation across multiple staff to ensure the training events cover the same topics and implement the steps correctly without additional trainer resources. Video modeling has been used in a number of different BST research studies (Catania, et al., 2009; Nosik, et al., 2013; Rosales, et al., 2015; Vladescu, et al., 2012). Videos are also helpful in that they provide the opportunity to pause the video at crucial points to describe key actions (Parsons et al., 2011).

- Rehearsal. It appears that it is helpful for trainees to watch the videos just before implementing the procedures. In addition, some studies allowed trainees to view the videos on multiple occasions. Rehearsals can be with adults playing the role of consumers.

- Feedback. The final component in the process is to provide specific feedback to the trainee, often combined with the rehearsal step. The feedback includes communicating 
to each individual trainee the aspects of the skill that were performed correctly and corrective feedback identifying steps that were incorrect. This can also include providing additional instructions on how to perform it correctly. The feedback is generally delivered at the conclusion of the practice (rather than interrupting the practice). In previous research, if modeling the target behavior does not result in mastery of the skill, with addition of the performance feedback component is added (DiGennaro-Reed, et al., 2010; Nosik \& Williams, 2011). For example, Karsten, Axe, and Mann (2015) review identified two studies found that video modeling alone resulted in $80 \%$ procedural accuracy, but with the addition of performance feedback, it increased to $100 \%$ procedural integrity (DiGennaro-Reed, et al., 2010; Nosik \& Williams, 2011).

\section{Research Design}

This study used a single subject research design, using a noncurrent multiple baseline across participants. This design was used to evaluate the effect of computer-based training on trainee's correct implementation of the steps of the free-operant preference assessment. The independent variable was the computer-based training for each trainee. The dependent variable was the percent of correct implementation of the 11-step task analysis by the trainees (similar to those described by Weldy et al., 2014). A baseline was established for the dependent variable for each participant (like a control condition). During the FO preference assessment, trainees were required to (a) implement the preference assessment, (b) collect and summarize the data, (c) rank items based on calculated percentage of selection. After the computer training, staff members conducted the preference assessment with a behavior team staff member acting as a consumer. The next step, the staff participant's completing the preference assessment with a 
consumer during a behavior session. Finally, maintenance data was collected about 2-3 weeks after the training during behavior sessions with a consumer. Maintenance is to identify if the training steps were maintained across time.

\section{Results}

During baseline, each of the participants demonstrated low to moderate levels of correct responding within the steps of the FO preference assessment with an average mean of 53.56\%; range 22 to $73 \%$ ). After the computer training, performance of the target steps improved immediately across all participants and the percentage of correct responding across the participants averaged $96.63 \%$ (range $91 \%-100 \%$ ). Each of the four participants met mastery criterion after two consecutive sessions above $90 \%$ with the simulated clients. A generalization probe was conducted within one week after the training, in which each participant was observed completing at least two preference assessment during client's behavior sessions. During generalization phase with clients, the percentage of correct responding across the participants mean average was 96\% (range 81\%-100\%). Performance feedback, both written and verbal, was provided to one participant during a generalization session with a consumer. Incorrect responses occurred when she did not show each item to the consumer at the start of the assessment and did not collect engagement data correctly on the data sheet when the client held two items in his hand for 2 minutes of the assessment (i.e., engagement was defined as the client touching any item during the specific time period). Performance feedback was provided to Madison after this session by the primary investigator. Maintenance probes followed at least 1-2 weeks after generalization sessions for three of the four participants. These probes were $100 \%$ across the participants ability to complete the target steps. 


\section{Discussion}

Trainings used to teach staff to work with individuals with developmental disabilities area often lacking in opportunities for hands on practice and implementation of these strategies. Incorporating all of the steps in BST trainings can be time consuming and costly. Developing training using video and online capabilities can be one solution to overcoming the barriers associated with the development of effective and efficient trainings. By utilizing computerbased training to enhance training opportunities and increase efficiency, the participants were given the same type of training opportunities used in evidence based training, but without the trainer presence. This provide lower cost of utilizing professionals to complete trainings that can be completed using a computer-based training. The use of professionals and supervisors can be focused on areas and activities that require their expertise. Outcomes of the current study support the results of previous studies teaching staff the steps of preference assessments through the use of technology without a trainer present (Deliperi, et al., 2015; Delli Bovi, et al., 2017; Lipschultz, et al., 2015; Rosales, et al., 2015; Weldy, et al., 2014).

This training used both performance and competency-based strategies, both necessary for evidence based staff training (Parsons, et al., 2011; Reid, et al., 2003). Competency based training in the form of practicing the skill was used until he or she is able to completely demonstrate the skill by utilizing behavior skills training steps of (1) instructions, (2) modeling, (3) rehearsal, and (4) feedback. By using simulated clients, this allowed the participant to perform the 11 steps of the preference assessment until a mastery criterion of $90 \%$ accurate implementation of the steps were achieved. All four participants in this study achieved mastery of the target steps in two sessions with simulated clients. 
This allowed for maintaining effectiveness and quality of the training while decreasing cost. Baseline sessions average mean was $53.6 \%$ across the four participants and after the computer training, the ability for staff to implement the 11 steps of the preference assessment correctly increased to a mean average of $96.6 \%$. All participants achieved mastery of the target skills within two sessions with simulated clients. The average duration of the training across participants was about 40 minutes in duration. This time included completing the written pre and posttests, completing baseline trial, the computer training, and implementing at least two sessions with simulated client.

There was a concern in previous research that this type of training might not be an adequate training method for individuals with less experience or education in the field, such as direct line therapists. However, all four entry level direct line therapists were able to complete the steps of the assessment and maintained mastery levels into maintenance. This type of training would be beneficial to use with other training topics for staff within this agency. Future computer-based trainings could be beneficial in group training as well. Additionally, some trainings could be viewed individually by staff members on their own computer and then demonstrate the skill with supervisors to ensure competency. Identifying effective training standards for staff working with individuals with developmental disabilities is a vital part of any human service organization. This study was beneficial to organizations that are interested in having highly trained staff members and quality training programs, by analyzing a cost effective and high quality training method that can be used to teach those working directly with individuals with developmental and intellectual disabilities to implement a free-operant preference assessment. 


\section{References}

Alavosius M. P. \& Sulzer-Azaroff, B. (1990). Acquisition and maintenance of health-care routines as a function of feedback density. Journal of Applied Behavior Analysis, 23, $151-162$.

Baer, D., Wolf, M., \& Risley, T. (1968). Some current dimensions of applied behavior analysis. Journal of Applied Behavior Analysis, 1, 91-97.

Boyle, M. A., Curtis, K. S., Forck, K. L., Fudge, B. M., Speake, H. N., \& Pauls, B. P. (2019). A replication of the response-restriction preference assessment. Behavioral Interventions, 34, 564 -576. https://doi.org/10. 1002/bin.1683

Brock, M. E., \& Carter, E. W. (2013). Effects of a professional development package to prepare special education paraprofessionals to implement evidence-based practice. The Journal of Special Education. Advance online publication.

http://dx.doi.org/10.1177/0022466913501882

Carr, J.E., Nicolson, A.C., \& Higbee, T.S. (2000). Evaluation of a brief multiple-stimulus preference assessment in a naturalistic context. Journal of Applied Behavior Analysis, 33, 353-357. doi:10.1901/ jaba.2000.33-353.

Catania, C. N., Almeida, D., Liu-Constant, B., \& DiGennaro-Reed, F. D. (2009). Video modeling to train staff to implement discrete-trial instruction. Journal of Applied Behavior Analysis, 42, 387-392. doi:10.1901/jaba.2009.42-387.

Cote, C. A., Thompson, R. H., Hanley, G. P., \& McKerchar, P. M. (2007). Teacher report and direct assessment of preferences for identifying reinforcers for young children. Journal of Applied Behavior Analysis, 40, 157-166. 
Cooper, J. O., Heron, T. E., \& Heward, W. L. (2007). Applied behavior analysis (2nd ed.). Upper Saddle River, NJ: Pearson.

DaFonte, M. A. \& Capizzi, A. M., (2015). A module-based approach: Training paraeducators on evidence-based practices. Physical Disabilities: Education and Related Services, 34(1), 31-54. doi: 10.14434/pders.v34i1.13823

Deliperi, P., Vladescu, J. C., Reeve, K. F., Reeve, S. A., \& DeBar, R. M., (2015). Training staff to implement a paired-stimulus preference assessment using video modeling with voiceover instruction. Behavioral Interventions, 30, 314-332. doi: 10.1002/bin.1421.

DeLeon, I. G. \& Iwata, B. A. (1996). Evaluation of a multiple-stimulus presentation format for assessing reinforcer preferences. Journal of Applied Behavior Analysis 29, 519-532.

Delli Bovi, G. M., Vladescu, J. C., DeBar, R. M., Carroll, R. A., \& Sarokoff, R. A. (2017). Using video modeling with voice-over instruction to train public school staff to implement a preference assessment. Behavior Analysis in Practice, 10(1), 72-76. http://doi.org/10.1007/s40617-016-0135-y

DiGennaro-Reed, F. D., Codding, R., Catania, C. N., \& Maguire, H. (2010). Effects of video modeling on treatment integrity of behavioral interventions. Journal of Applied Behavior Analysis, 43, 291-295. doi:10.1901/jaba.2010.43-291.

Egel, A. L. (1981). Reinforcer variation: Implications for motivating developmentally disabled children. Journal of Applied Behavior Analysis, 14, 345-350. doi:10.1901/jaba.1981.14$\underline{345}$

Fisher, W. W., Piazza, C. C., Bowman, L. G., \& Amari, A. (1996). Integrating caregiver report with a systematic choice assessment to enhance reinforcer identification. American Journal on Mental Retardation, 101, 15-25. 
Fisher, W., Piazza, C.C., Bowman, L.G., Hagopian, L.P., Owens, J.C., \& Slevin, I. (1992). A comparison of two approaches for identifying reinforcers for persons with severe and profound disabilities. Journal of Applied Behavior Analysis 25, 491-498.

Feldman, E. K., \& Matos, R. (2013). Training paraprofessionals to facilitate social interactions between children with autism and their typically developing peers. Journal of Positive Behavior Interventions, 15(3), 169-179. http://dx.doi.org/10.1177/1098300712457421

Gerencser, K. \& Akers, J. \& Becerra, L. \& Higbee, T., \& Sellers, T. (2020). A Review of Asynchronous Trainings for the Implementation of Behavior Analytic Assessments and Interventions. Journal of Behavioral Education. 29, 122-152. 10.1007/s10864-01909332-x.

Graff, R. B., \& Karsten, A. M. (2012a). Assessing preferences of individuals with developmental disabilities: a survey of current practices. Behavior Analysis in Practice, 5, 37-48. doi:10.1901/ jaba.1992.25-491.

Hitchcock, J.H., Kratochwill, T.T., \& Chezan, L.C. (2015). What works clearinghouse standards and generalization of single-case design evidence. Journal of Behavioral Education, 24, 459-469.

Hogan, A., Knez, N., \& Kahng, S. (2015). Evaluating the use of behavior skills training to improve school staffs' implementation of behavior intervention plans. Journal of Behavioral Education, 24, 242-254.

Horner, R. H., Carr, E. G., Halle, J., McGee, G., Odom, S., \& Wolery, M. (2005). The use of single subject research to identify evidence-based practice in special education. Exceptional Children, 71,165-179.

Kang, S., O'Reilly, M., Lancioni, G., Falcomata, T. S., Sigafoos, J., \& Xu, Z. (2013). 
Comparison of the predictive validity and consistency among preference assessment procedures: A review of the literature. Research in Developmental Disabilities, 34(4), 1125-1133. http://dx.doi.org/10.1016/j.ridd.2012.12.021

Karsten, A. M., Axe, J. B., \& Mann, C. C. (2015). Review and Discussion of Strategies to Address Low Trainer-to-Staff Ratios. Behavioral Interventions, 30(4), 295-313. DOI: $10.1002 /$ bin. 1420

Kazdin, A. E. (2011). Single-case research designs: Methods for clinical and applied settings. Oxford University Press.

Kodak, T., Fisher, W. W., Kelley, M. E., \& Kisamore, A. (2009). Comparing preference assessments: Selection- versus duration-based preference assessment procedures. Research in Developmental Disabilities, 30, 1068-1077.

Leaf, J., Milne, C., Aljohani, W., Ferguson, J., Cihon, J., Oppenheim-Leaf, M., McEachin, J., \& Leaf, R., (2019). Training change agents how to implement formal preference assessments: A Review of the Literature. Journal of Developmental and Physical Disabilities. 10.1007/s10882-019-09668-2.

Lerman, D. C., Tetreault, A., Hovanetz, A., Strobel, M., \& Garro, J. (2008). Further Evaluation of a Brief, Intensive Teacher-Training Model. Journal of Applied Behavior Analysis, 41(2), 243-248. http://doi.org/10.1901/jaba.2008.41-243

Lipschultz, J. L., Vladescu, J. C., Reeve, K. F., Reeve, S. A., \& Dipsey, C. R. (2015). Using video modeling with voiceover instruction to train staff to conduct stimulus preference assessments. Journal of Developmental and Physical Disabilities, 27, 505-532.

McCulloch, E. \& Noonan, M. (2013). Impact of online training videos on the implementation of mand training by three elementary school paraprofessionals train staff to implement 
discrete-trial instruction. Education and Training in Autism and Developmental Disabilities, 48 (1).

Miles, N. I. \& Wilder, D. A. (2009). Effects of behavioral skills training on caregiver implementation of guided compliance. Journal of Applied Behavior Analysis. 42(2), 405410. DOI: $10.1901 /$ jaba.2009.42-405

Miltenberger, R. (2008). Behavior Modification: Principals and Procedure ( ${ }^{\text {rd }}$ ed.) Belmont, CA. Wadsworth Publishing.

Nigro-Bruzzi, D. \& Sturmey, P. (2010). The effects of behavioral skills training on mand training by staff and unprompted vocal mands by children. Journal of Applied Behavior Analysis, 43(4), 757-761.

Northouse, P. G. (2016). Leadership: Theory and practice (7th ed.). Thousand Oaks, CA: Sage.

Northup, J., George, T., Jones, K., Broussard, C., \& Vollmer, T. R. (1996). A comparison of reinforcer assessment methods: the utility of verbal and pictorial choice procedures. Journal of Applied Behavior Analysis, 29(2), 201-212. https://doi.org/10.1901/jaba.1996.29-201

Nosik, M. R., \& Williams, W. L. (2011). Component evaluation of a computer based format for teaching discrete trial and backward chaining. Research in Developmental Disabilities, 32, 1694-1702. doi: 10.1016/j.ridd.2011.02.002

Nosik, M. R., Williams, W. L., Garrido, N., \& Lee, S. (2013). Comparison of computer based instruction to behavior skills training for teaching staff implementation of discrete-trial instruction with an adult with autism. Research in Developmental Disabilities, 34, 461468. doi: 10.1016/j.ridd.2012.08.011 
Nottingham, C. L., Vladescu, J. C., Giannakakos, A. R., Schnell, L. K., \& Lipschultz, J. L. (2017). Using video modeling with voiceover instruction plus feedback to train implementation of stimulus preference assessments. Learning and Motivation, 58, 37-47.

Pace, G. M., Ivancic, M. T., Edwards, G. L., Iwata, B. A., Page, T. J. (1985). Assessment of stimulus preference and reinforcer value with profoundly retarded individuals. Journal of Applied Behavior Analysis 18, 249-255.

Parsons, M. B., Rollyson, J. H., \& Reid, D. H. (2011). Evidence-based staff training: A guide for practitioners. Behavior Analysis in Practice. 5(2), 2-11.

Petscher, E. S. \& Bailey, J. S. (2006). Effects of training, prompting, and self-monitoring on staff behavior in a classroom for students with disabilities. Journal of Applied Behavior Analysis, 39, 215-226. doi:10.1901/jaba.2006.02-05.

Phillips, J. F. (1998). Applications and contributions of organizational behavior management in schools and day treatment settings. Journal of Organizational Behavior Management, 18,103-129. doi: 10.1300/J075v18n02_06

Reid D. H. \& Parsons M. B. (2002). Organizational behavior management in human service settings. In: Austin J., Carr J. E., editors. Handbook of applied behavior analysis. Reno, NV: Context Press; pp. 275-294. (Eds.)

Reid, D. H., Rotholz, D. A., Parsons, M. B., Morris, L., Braswell, B. A., Green, C. W., \& Schell, R. M. (2003). Training human service supervisors in aspects of positive behavior support: Evaluation of a state-wide, performance-based program. Journal of Positive Behavior Interventions, 5, 35-46.

Roane, H. S., Vollmer, T. R., Ringdahl, J. E., \& Marcus B. A. (1998). Evaluation of a brief stimulus preference assessment. Journal of Applied Behavior Analysis 31, 605-620. 
Rosales R., Gongola L., \& Homlitas C. (2015). An evaluation of video modeling with embedded instructions to teach implementation of stimulus preference assessments. Journal of Applied Behavior Analysis, 48, 209-214. doi: 10.1002/jaba.174.

Roscoe, E. M., \& Fisher, W. W. (2008). Evaluation of an efficient method for training staff to implement stimulus preference assessments. Journal of Applied Behavior Analysis, 41, $249-254$.

Sarokoff, R. A., \& Sturmey, P. (2004). The effects of behavioral skills training on staff implementation of discrete-trial teaching. Journal of Applied Behavior Analysis, 37, 535538.

Verriden, A. L. \& Roscoe, E. M. (2016). A comparison of preference-assessment methods. Journal of Applied Behavior Analysis, 49, 265-285. https://doi.org/10.1002/jaba.30

Vladescu, J. C., Carroll, R., Paden, A., \& Kodak, T. M. (2012). The effects of video modeling with voiceover instruction on accurate implementation of discrete trial instruction. Journal of Applied Behavior Analysis, 45(2), 419-423. http://doi.org/10.1901/jaba.2012.45-419

Vollmer T. R., Marcus B. A., \& LeBlanc L. (1994). Treatment of self-injury and hand mouthing following inconclusive functional analyses. Journal of Applied Behavior Analysis, 27, $331-44$.

Weldy, C. R., Rapp, J. T., \& Capocasa, K. (2014). Training staff to implement brief stimulus preference assessments. Journal of Applied Behavior Analysis, 47, 214-218. 
SECTION FIVE:

CONTRIBUTION TO SCHOLARSHIP 


\section{EVALUATION OF COMPUTER-BASED TRAINING TO TEACH STAFF TO IMPLEMENT

\author{
FREE-OPERANT PREFERENCE ASSESSMENTS
}

Running title: EVALUATION OF COMPUTER-BASED TRAINING

Author: L. Leanne Hopper

This research was conducted by the author in partial fulfillment of a doctoral degree from the University of Missouri-Columbia. Leanne Hopper has her own company working at a behavior analyst in various school districts in southeast Missouri area. Please address correspondence to Leanne Hopper, 2022 Allen Drive, Cape Girardeau, Missouri 63701 (email:

LhopperABA1@gmail.com).

Key terms: free-operant preference assessment, computer-based training or instruction, video modeling, staff training 
There was no funding for this research.

All authors declare no conflicts of interest.

The data that support the findings of this study are available from the author upon request.

This research adhered to all ethical guidelines concerning the treatment of human subjects. The study methods were reviewed and approved by a university's institutional review board, and all participants signed letters confirming their informed consent. 


\begin{abstract}
Current technology provides improved methods to deliver high quality staff trainings that also increases the efficiency of trainings. This study focuses on the impact of utilizing computer instruction, without a trainer present, for entry level staff's competency to (a) implement the target steps of a free-operant preference assessment, (b) score and interpret the results of the data, and (c) maintain competency of skills taught after training is complete. Initial baseline across participants was an average of $53.6 \%$ correct implementation of target steps. After computer instruction training, performance improved to an average of $96.6 \%$ accurate completion of target steps across all participants. During generalization phase, participants average accuracy of completing target steps maintained $96 \%$ accuracy, while maintenance accuracy was $100 \%$ accuracy across three participants. Outcomes of the current study supports the use of computer-based learning alone as being an effective mode to training staff in less than 40 minutes training time.
\end{abstract}




\section{Introduction}

Identifying effective training standards for staff working with individuals with developmental disabilities is a vital part of any human service organization. Training staff to implement procedures with high levels of treatment integrity leads to increased positive outcomes for those being served and contributes to developing effective teams (DaFonte \& Capizzi, 2015). Staff training that focuses on teaching performance skills not only improves knowledge of the subject matter, but specifically targets improving staff's ability to implement target skill sets. Hands on trainings provided under the direction of highly skilled professionals are considered an important part of best practice staff training for the development of performance skills (Lerman et al., 2008; Nottingham et al., 2017). However, training staff using best practice guidelines often requires a substantial amount of time, money, and materials, making it difficult to attain the level required to fully support trainees within some agencies.

An emerging line of research focuses on maintaining effectiveness while also increasing efficiency of behavior based performance staff trainings by reducing the need for the presence of a trainer throughout the training (Gerencser et al., 2020; Karsten, Carr, \& Lepper, 2011; Nottingham et al., 2017). Using technology in the form of videos and computer training has shown to be an effective teaching modality for numerous applied behavior analytic technologies while decreasing cost and expanding training delivery (Boyle et al., 2019; Brock \& Carter, 2013; DaFonte \& Capizzi, 2015; Feldman \& Matos, 2013; McCulloch \& Noonan, 2013). A number of behavior analytic interventions and assessments have demonstrated effective training utilizing technology that include discrete trial training (Pollard, et al., 2014; Fazzio, et al., 2009; Nosik \& Williams, 2011; Nosik, et al., 2013); basic applied behavior analysis (ABA) strategies and principles (DaFonte \& Capizzi, 2015; Granpeesheh, et al., 2010; Vladescu, et al., 2012), safety 
skills for children with autism spectrum disorder (Johnson, et al., 2005); and direct preference assessments (Deliperi, et al., 2015; Delli Bovi, et al., 2016; Lipschultz, et al., 2015; Rosales, et al., 2015; Weldy, et al., 2014). The implementation of some behavior procedures are complicated and will likely always require some aspect of hands on direct staff training in the form of trainer feedback or role play in order to be effective. However, some current research supports computer-based training alone, without a trainer present, particularly as an effective mode of teaching the implementation of direct preference assessments in as little as 30-minutes training time (Deliperi, et al., 2015; Delli Bovi, et al., 2017; Lipschultz, et al., 2015; Rosales, et al., 2015; Weldy, et al., 2014).

The purpose of direct preference assessments is to systematically arrange opportunities to the individual in an attempt to identify preferred and/or nonpreferred stimuli. By identifying the individual's preferred items, it is presumed that the preferred items are more likely to function as reinforcers that can be used in behavior analytic interventions. Research has shown low correlations between caregiver reports and observational measures of actual preference for individuals (Graff \& Karsten, 2012a; Cote, et al., 2007; Roane et al., 1998). Conducting direct preference assessments increases the likelihood of identifying the most potent reinforcers and is recommended in best practice guidelines (Carr, Nicolson, \& Higbee, 2000; Cote, et al., 2007; DeLeon \& Iwata, 1996; Kang, et al., 2013; Leaf, et al., 2020; Pace, et al., 1985; Piazza, Roane, \& Karsten, 2011; Roane, et al., 1998). A meta-analysis review by Maffei-Almodovar and Sturmey (2018) on the effective use of various approaches to training behavior performance skills found only six articles specific to training individuals to implement preference assessments. Currently, there are a handful of empirical studies demonstrating positive outcomes when staff training uses technology (e.g., computer based learning or video modeling with voiceover instructions) 
without any additional training components to teach trainees to accurately implement the steps of direct preference assessments (Deliperi, et al., 2015; Delli Bovi, et al., 2017; Lipschultz, et al., 2015; Rosales, et al., 2015; Weldy, et al., 2014). To date, only two published studies have explored the use of technology alone to train staff to implement the steps for the free-operant (FO) preference assessment (Rosales et al., 2015; Weldy et al., 2014).

This study used computer-based training as the mode to present the information to direct line staff members. The distinction between video modeling and computer training was outlined in Gerencser et al. (2020), as they divided staff training using technology into different methods, including computer-based instructions and video modeling with voiceover instructions. The main differences between these modalities were the computer based instructions utilized additional features from other training formats such as video examples, competency questions, narrated slides, self-guided practice, and/or mastery assessments. Video modeling with voiceover instructions is identified as videos the trainee watches that includes one or more people modeling the target steps within the training procedures.

The free-operant preference assessment is simple and quick to implement. It is a duration of 5-minutes, taking less time than other type of preference assessments that range from 15-30 minutes in duration (Kang, et al., 2013). This assessment involves the simultaneous presentation of all stimuli to the individual and allows engagement with all items without withdrawing items at any time. Graff and Karsten (2012a) reported that $81.4 \%$ of surveyed professionals cited lack of time as a barrier to using preference assessment on a regular basis. Because of the ease of implementation and short duration, free-operant preference assessments can be used daily to reveal shifts in preferences (Egel, 1981). 
The use of direct preference assessments follows best practice guidelines and is beneficial to use with individuals with developmental disabilities, however, these methods are only useful if staff are trained to competency in the implementation of these assessments (Carr, Nicolson, \& Higbee, 2000; Cote, et al., 2007; DeLeon \& Iwata, 1996; Kang, et al., 2013; Leaf, et al., 2020; Pace, et al., 1985; Piazza, Roane, \& Karsten, 2011; Roane, et al., 1998). Graff and Karsten (2012a) surveyed 406 professionals regarding current practices related to assessing preferences of individuals with developmental disabilities across the disciplines of Applied Behavior Analysis (ABA), Psychology, and Special Education. More than half of all respondents surveyed by Graff and Karsten (2012a) reported that they were never trained to conduct direct preference assessments. Individuals that did report receiving training indicated it was from independently reading published studies or training manuals (27\%), in-services training (19\%), and $12 \%$ attended a workshop on conducting direct preference assessments. This appears much lower than the recommended training guidelines for best practice (Graff \& Karsten, 2012a). Furthermore, survey results revealed that $50 \%$ of all respondents cited lack of knowledge of preference assessment procedures as a barrier to implementing them with clients (Graff \& Karsten, 2012a). Given the importance of identifying effective reinforcers when working with individuals with developmental disabilities combined with the self-reported lack of training and knowledge of preference assessments, an essential research path needs to be explored regarding the development of effective and efficient training programs to teach staff to implement the steps of direct preference assessments (Graff \& Karsten, 2012a; Vollmer, et al., 1994).

This study addressed some of the gaps in the current literature regarding this subject. First, contribution to the body of literature regarding direct preference assessments and staff training related to using technology without additional trainer present would be beneficial. There 
are currently only five published research studies using technology alone to train staff to implement the steps of preference assessments. Only two of those studies are specific to FO preference assessments. It would be advantageous to extend this line of research with additional information on conducting this type of training with this specific preference assessment.

Second, the prior knowledge and experience of the trainee receiving instruction is also an important component. Gerencser et al. (2020) reviewed three studies using video modeling with embedded instructions to train behavior therapists (Lipschultz et al., 2014; Rosales, et al., 2015; Weldy et al., 2014). The participants trained to implement the preference assessment steps had more prior work experience than in in the other studies using different methods. It was suggested that this could attribute to the success of the participant's training results. To date, no published research study has evaluated the use of computer or video training to train entry level clinical staff (i.e., Registered Behavior Technicians) to conduct the FO preference assessment.

Third, staff must be able to use the information obtained within the preference assessment. The overall goal of preference assessments is to identify stimuli that will go on to function as reinforcers. It is important for staff to be able to accurately score and interpret assessment results. If preference assessments are incorrectly scored or interpreted, this could lead to decreased effective instructional opportunities. Only six research studies published to date have included training staff to summarize and/or interpret preference assessment data (Bishop \& Kenzer, 2012; Graff \& Karsten, 2012b; Deliperi et al., 2015; Roscoe \& Fisher, 2008; Roscoe, et al., 2006; Weldy et al., 2014). But only one of those studies included accurate scoring and interpretation of the FO preference assessment (Weldy et al., 2014). This study will analyze the trainee's ability to score and rank the items used within the preference assessment. 
The purpose of the current study is to extend previous research by evaluating the effectiveness of computer-based training to teach direct line therapists to conduct a free-operant preference assessment to use with adults with developmental disabilities. Computer based instruction is one viable instructional method current research has highlighted that can offer a way to train staff effectively and efficiently. Training these front line implementers to conduct direct preference assessments can lead to increased effectiveness of skill acquisition and behavior reduction programs for clients by staff able to better identify potential reinforcers that can be used within these interventions. The use of technology to provide training and reduce the number of direct training hours with professionals while continuing to provide best practice staff training.

\section{Method}

\section{Participants}

Participants were four female staff members ranging in age from 27 to 42 years. At the beginning of the training, Rose, Madison, Layne, and Ashley had 0, 0, 12, and 0 months, respectively, of experience providing behavior-analytic services to individuals with developmental disabilities. Informed consent was obtained prior to participation. Each of the participants were certified at Registered Behavior Technician ${ }^{\mathrm{TM}}\left(\mathrm{RBT}^{\circledR}\right)$ or in process of obtaining this national certification from the Behavior Analysis Certification Board (BACB). Three of the participants at the start of this research had completed this 40 hour training using online modules (outside of the current organization), but were not certified as RBT. The fourth trainee, Ashley, was certified as an RBT before beginning this study. At the completion of this study, three of the four participants were certified as RBTs. 
All trainee's average level of education was high school graduate or GED (Tests of General Education Development). These staff members previously worked in the position of direct care staff an adult day program at least six months. Participants reported knowledge of direct preference assessments from the RBT training modules, but were not familiar with the terms "FO preference assessment". In addition, the participants reported no hands on training implementing any direct preference assessment. The trainee, Layne, did report 12 months experience implementing behavior analytic programming with one child with autism spectrum disorder (ASD). She implemented these programs under the direction of a BCBA. This experience ended 18 months prior to the start of this research study. Layne reported that no training or implementation of preference assessment occurred during this time.

Participation in the study was voluntary and not a requirement for their employment. Staff participants were excluded from the research study if they met any of the following criteria: (a) score $80 \%$ or above on the written pre-test of the preference assessment training, (b) verbal report of prior experience or hands on training by a board certified behavior analyst regarding implementation of direct preference assessment methods, or (c) demonstrate above $80 \%$ accuracy of implementation of direct preference assessment components during baseline sessions. All participants were able to participate in the study and did not meet any exclusionary standards.

Pre- and posttests composed of 14-multiple choice questions about the specific steps of the preference assessment was provided to each trainee and completed before (pretest) and at the end (posttest) of the computer-based training (see Appendix). This was used to gather basic knowledge of free operant preference assessment for each trainee at baseline and after the computer training was provided. Participants must score below $80 \%$ on the written pretest in 
order to participate in the study. Posttest mastery criterion of $80 \%$ or higher was necessary in order to begin sessions with a simulated client. Percent accuracy for each participant's pre and post test results are provided in table 1.

Table 1

Percentage correct for written pretest and posttest for each trainee

\begin{tabular}{lll}
\hline Trainee & Pretest & Posttest \\
\hline Rose & & \\
Madison & 71 & 100 \\
Layne & 57 & 93 \\
Ashley & 71 & 100 \\
\hline
\end{tabular}

Note. This table provides a summary of the percentage correct for the written pretest and posttest after the computer training for FO preference assessments.

\section{Setting and Materials}

The practitioner setting for this study was a for-profit agency setting in a rural southeast Missouri city. The first author is employed part time within this agency. The computer training portion of the study took place in a small office with a desk and computer. Each participant completed the computer-based training individually in the small office at a desk. They were provided with a copy of the presentation slides, a pencil, a timer, a sample of a completed data sheet on the preference assessment data collection form, three copies of blank preference assessment data collection forms to use for practice during the video training, and one copy of the steps of the assessment (11 step task analysis). The computer was set up to start automatically and the participants were instructed briefly by the first author to return to the conference room after the video ended and also how to pause the training if needed. Once the video began playing, the first author left the room. The participant completed the computerbased training in the room alone. The computer video training was 15 -min in duration and 
played on a MacBook Air computer. The slides were created in PowerPoint with embedded videos.

The sessions with a simulated client (adult playing the role of a client) took place in a larger conference room with a long table and chairs. The trainee and adult simulated client sat across the table from each other. The materials necessary to conduct the assessment were placed in a container on the table. Fifteen different items were alternated during the preference assessments. Five items were placed in the container, along with a timer, clipboard with FO preference assessment data sheet, and pencil at the start of each assessment. The participant was told that these five items were identified as preferred by the simulated client for the purposes of the assessments.

During generalization and maintenance sessions with clients, the supervisors generated a list of 15-20 different preferred items specific to each client that the participant could choose from for each preference assessment. Generalization and maintenance sessions took place during a typical behavior session conducted by the participant with the client in the session room at the agency. This room contained two to four small tables and six chairs. Two additional staff members and three to four other clients not participating in the study were present during these generalization and maintenance sessions. Materials used during these phases included at least five items identified as preferred by the specific client at the table, a timer, pencil, and clipboard with copy of the data collection form to be completed during the assessment.

The data collection form created and used by the participants during all phases of the study, was the primary focus of the training for the computer training portion of this study. This form using 10-s momentary time sample data collection method for a duration of five minutes. 


\section{Design and Measurement}

A concurrent multiple baseline across participants design was used to evaluate the effectiveness of computer based instruction on train entry level behavior staff to implement a FO preference assessment. Data for each session were collected by observers using data sheets created for the current study. The independent variable was the computer-based training for each trainee. The dependent variable was the percent of steps implemented correctly by staff participants based on the 11-step task analysis. For each session, the percentage of opportunities implemented correctly was divided by the total number of steps completed and multiplied by 100.

The task analyses was created similar to those steps described by Weldy et al., 2014. The 11 steps are as follows: (1) prepares materials in location where preference assessment will be conducted (e.g., data sheet, pencil, timer, assessment items), (2) removes distractors from location where assessment is conducted, (3) writes the names of each stimuli in the appropriate area on the data sheet, (4) directs client to area and presents each item separately for approximately 20-seconds for each (or client stops manipulating), (5) places all items in arched array on the table or floor in front of the client, (6) verbal statement to instruct the client to engage with any items in array, (7) press "start" on the timer to begin the session, (8) records data using the 10-s MTS method for 5 minutes (90\% or greater accuracy), (9) presses stop on timer once 5 minutes has elapsed and ends the session, (10) correctly calculated the percentage of intervals each item is manipulated, (11) identifies the correct rank for each item.

The data collection form used by participants during the assessment was divided into 30 intervals (10-second intervals across five minutes), using momentary time sampling method to collect data at the end of each 10-second interval based on the client's interaction with the target 
stimuli used in the preference assessment. Data was collected by placing an " $\mathrm{X}$ " on the correct column for each item the client interacted with at the end of each 10-s interval. Operational definition of "interaction with item" was defined for the participant's body is in contact with the stimuli. The interval was left blank if the client was not interacting with any items at the end of that specific interval. If multiple items were in contact with the client, all items were recorded with a " $\mathrm{X}$ " on the form. At the end of the five-minutes, the total number of intervals the individuals interacted with each item was reported as a percentage of engagement (number of intervals interacted with item divided by the total number of intervals during the assessment and multiplied by 100). Finally, the total percentage of engagement for each stimuli was also used to rank the items based on percentage from one to five, with "one" being the stimuli with the highest percentage (most preferred) from "five" being the stimuli with the lowest percentage (least preferred).

\section{Interobserver agreement}

A secondary independent observer collected data during $38.4 \%$ of sessions. It is recommended that IOA be collected for at least $25 \%$ of all research sessions. Data was collected using the 11 steps task analysis data collection form. Data were compared for each step with the primary observer's data. An agreement was defined as the primary and secondary data collector scoring the same step identically. A disagreement was defined as the primary and secondary data collector scoring the same step differently. IOA was calculated by dividing the number of agreements by the number of agreements plus disagreements and converting the result to a percentage. Mean IOA scores were 99.6\% (range, 91\%-100\%), 100\%, 100\%, 98.2\%, and 100\% (range, 99.2\%-100\%) for Rose, Madison, Layne, and Ashley respectively.

Additional IOA was collected regarding the accuracy of participants data collected during 
preference assessment (i.e., step 8: Records data using the 10-s MTS method for 5 minutes (90\% or greater accuracy). Interval-by-interval IOA was collected using the script data during intervention and baseline trials. An agreement was defined as the secondary data collector scoring the same step identically as what was written on the script (and completed by the simulated client) or performed by the client during generalization and maintenance sessions. A disagreement was defined as the primary and secondary data collector scoring the same step differently during maintenance or generalization phases, or the secondary data collector scoring the same step different from the script for baseline and simulated client phases. IOA was calculated by dividing the number of agreements by the number of agreements plus disagreements and converting the result to a percentage. Mean IOA scores for implementing the FO preference assessment data collection form were $98.68 \%$ (range, 93\%-100\%), 100\%, 96.5\%, 99\%, and 99.2\% (range, 96.5\%-100\%) for Rose, Madison, Layne, and Ashley respectively.

\section{Procedural integrity}

Procedural integrity data were collected across $20 \%$ of training sessions for all participant's sessions. A checklist of steps implemented by investigator(s) were used to record "yes" (if the step was completed correctly) or "no" (if the step was completed incorrectly or skipped) by a secondary observer. The percentage of steps implemented corrected was calculated by dividing the number of correct steps completed by the investigator by the total number of steps and multiplying by 100 . Procedural integrity was $100 \%, 90 \%, 100 \%$, and $90 \%$ for Rose, Madison, Layne, and Ashley respectively. 


\section{Procedure}

\section{Baseline}

The participant entered the conference room and the primary investigator directed the staff to the assessment materials on the table. The investigator oriented the participant to the materials and FO data collection sheet on the clipboard. The researcher instructed the participant by stating, "You can have up to five minutes to review this information. Please let me know when you are finished." A simulated client was present, sitting on the opposite side of the table from the staff. The primary investigator asked the participant to "implement a FO preference assessment as best as you can with the information provided. I cannot answer any questions or provide any feedback. Please let me know when you are finished."

The primary investigator collected data using the 11 step task analysis form, while the participant attempted to implement the steps of the FO assessment with a simulated client. The simulated client used a script to manipulate various items on the assessment table by touching them and engaging with them (e.g., picking up the slinky and opening and closing it). Seven different scripts were randomly alternated by the simulated client regarding engagement of specific items throughout the intervals within the session. Once baseline sessions were complete, the participant was given access to the training portion of this study.

\section{Computer-based training}

The computer-based training used a PowerPoint ${ }^{\mathrm{TM}}$ presentation with modeling examples and narrated slides (e.g., written text and voice over instructions) regarding the specific steps of the FO preference assessment. The video clips during the training were paused with additional voiceover and written information throughout to highlight some important steps. Competency questions were embedded throughout the training in multiple choice and true or false format to 
check for understanding of content by the participant. Self-guided practice activities were included during the data collection and analysis of results portion of the training. Initially, a one minute excerpt was shown of a preference assessment, and participants were encouraged to practice collecting data during that time. Correct data collection sample followed so the participants could compare the accuracy of the data he or she collected. Another video was shown for two-minutes followed by a check for accuracy. The final video of the training was a full 5-minute assessment with correct responses provided on the screen for the participants to compare their responses, including figuring the percentages of engagement and ranking of the items in the preference assessment. No other interactions or feedback was provided to the participants other than the content of the computer training. Furthermore, no contingencies were in place to require completion of these activities during the training (Fazzio, et al., 2009; Pollard et al., 2014).

The duration of the computer training was 40 -minutes. The participants viewed the video individually, three of the participants viewed the video over the course of one day and the fourth participant on a separate day. The video clips during the training were paused with additional voiceover information throughout to highlight some important steps.

\section{Simulated client sessions}

After completing the written posttest with $80 \%$ accuracy or higher, the participants completed the next phase in which they were asked to implement the steps of the FO preference assessment with a simulated client. This step occurred within 15 minutes of completion of the computer training and written posttest. Procedures and materials available to the participant during this phase mirrored the baseline sessions. The simulated client used a script to manipulate various items on the assessment table by touching them and engaging with them (e.g., picking up 
the slinky and opening and closing it). Seven different scripts were randomly alternated by the simulated client regarding engagement of specific items throughout the intervals within the session. Each participant was observed completing each of the target steps of the preference assessment. Criterion for mastery was $90 \%$ accuracy within the steps of the assessment across two consecutive sessions. Booster training session, if necessary, would include viewing the computer training a second time if the participant did not score above $80 \%$ over two sessions. However, these booster sessions were not necessary during for any participant in this study.

\section{Generalization sessions}

Following successful completion with a simulated client, the participants were asked to implement the FO preference assessment with a client during a typical behavior session. Implementation of these preference assessments were part of the behavior services provided during sessions with all clients. Procedures and materials available to the participant during this phase was the same as in baseline and training sessions. Each participant was observed completing at least two different FO preference assessments with a client across different session days. The criterion for mastery was $90 \%$ accuracy within the steps of the assessment across two consecutive sessions. Booster training session that included verbal performance feedback would be added if the participant did not score above $80 \%$ during any sessions. This was necessary for one participant, Madison, during this study.

\section{Maintenance Probes}

Follow up probe observations was completed at least two weeks after the completion of the initial client sessions. Maintenance probes were completed by the participants demonstrating the steps of the preference assessment with a client in a natural setting (similar to generalization sessions). Booster training session that included verbal performance feedback would be added if 
the participant did not score above $80 \%$ during one session. This was not necessary for any participants during this study.

\section{Results}

Figure 3 displays the results by the percentage of correctly implemented steps performed by each of the four participants throughout all sessions. During baseline, each of the participants demonstrated low to moderate levels of correct responding within the steps of the FO preference assessment (average mean 53.56\%; range 22 to $73 \%$ ). Responding was stable during baseline for all participants. At baseline, Rose's average baseline was 29\% (range 22\% to 33\%). Madison's average baseline was $66.25 \%$ with a range of $55 \%$ to $73 \%$. The third participant, Layne, average baseline was $62 \%$ (range $45 \%$ to $73 \%$ ). Her baseline percentages improved, but the last two trials were each $73 \%$. The final participant, Ashley, average her baseline at 50.3\% across six sessions, with a range of $22 \%$ to $55 \%$. Her baseline was stable at $55 \%$ for five of the six sessions.

After the computer training, performance of the target steps improved immediately across all participants. During intervention with simulated clients, the percentage of correct responding across the participants averaged $96.63 \%$ (range $91 \%-100 \%$ ), 91\%, 95.5\%, 100\%, and 100\% for Rose, Madison, and Layne respectively. Each of the four participants met mastery criterion after two consecutive sessions above $90 \%$ with the simulated clients.

Within one week of completing the simulated client phase, a generalization probe was conducted in which each participant was observed completing at least two preference assessment during client's behavior sessions. During generalization phase with clients, the percentage of correct responding across the participants mean average was 96\% (range $81 \%-100 \%$ ), 91\%, 
94\%, 100\%, and 100\% for Rose, Madison, Layne, and Ashley respectively. Three of the four participants obtained $90 \%$ accuracy regarding the 11 steps of the assessment for two consecutive sessions. The fourth participant, Madison dropped to $81 \%$ during the first session with a client.

Figure 3. Percentage of correctly performed steps of the 11-step task analysis for conducting the FO preference assessment 


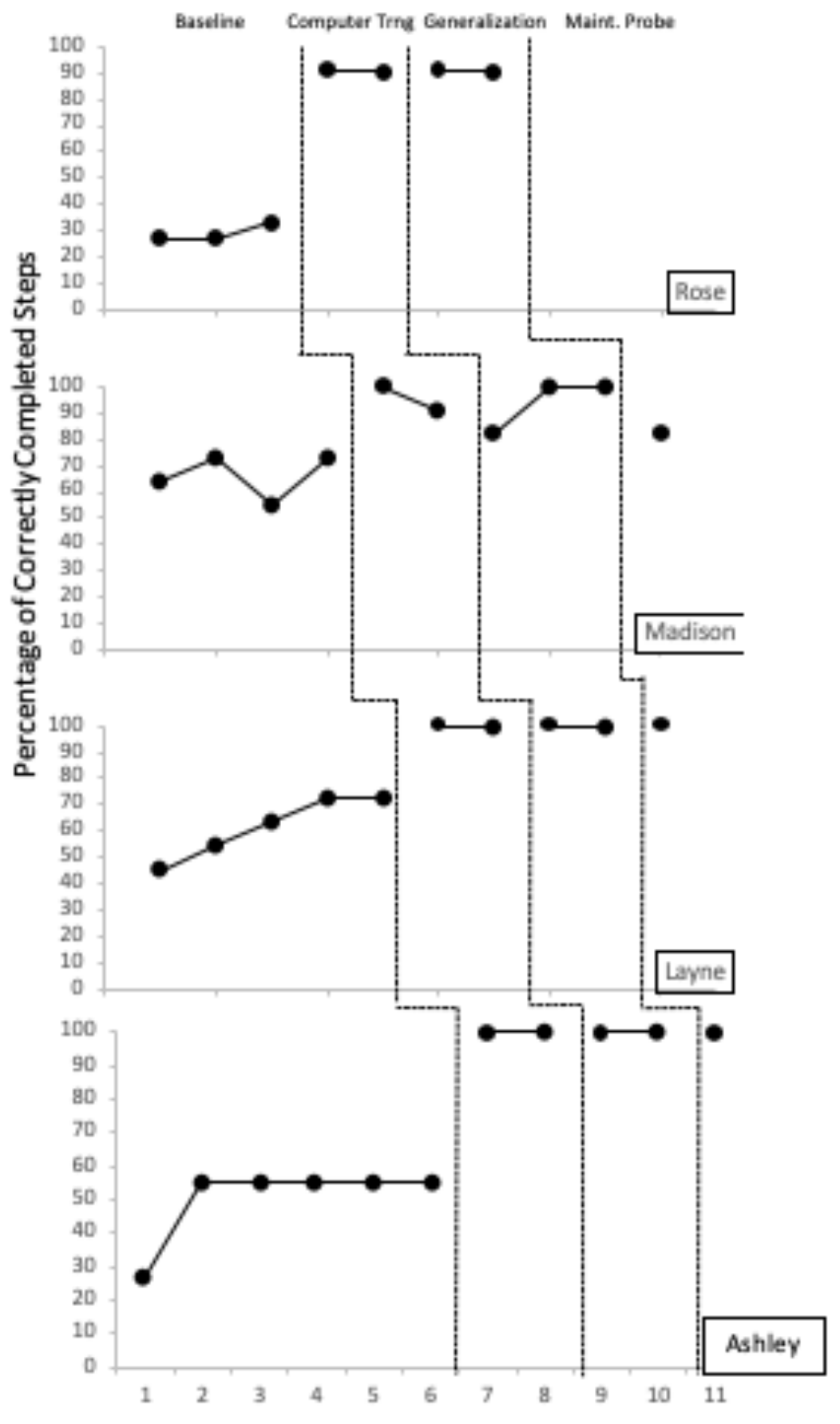

Sessions

Incorrect responses occurred when she did not show each item to the client before starting the assessment (first step of the preference assessment) and did not collect engagement 
data correctly on the data sheet when the client held two items in his hand for 2 minutes of the assessment (i.e., engagement was defined as the client touching any item during the specific time period). Performance feedback was provided to Madison after this session by the primary investigator. This feedback consisted of reviewing the 11 steps of the task analysis data collected by the primary investigator and reviewing the operational definition of "engagement". It was determined that performance feedback during this step would be the best option, in that it took less than 2-minutes to review this information with the participant (watching the video would require an additional 15-minutes). She was able to complete two additional generalization sessions with $100 \%$ correct responding after this feedback session.

Maintenance probes followed at least 2 weeks after generalization sessions for three of the four participants. One participant, Rose, did not transition to the behavior department on the timeline anticipated and continued working at direct care staff over these weeks. During that time, she was unable to complete any preference assessments. It was decided to not include her in the maintenance sessions. Maintenance probes for the remaining three participants was $100 \%$ for all participants.

This study also collected data on the participant's ability to score and rank the items used within the preference assessment. Baseline data across participants indicated that all participants were able to complete this step without additional training necessary, using the data collection form instructions provided at baseline and throughout the training.

\section{Discussion}

Trainings used to teach staff to work with individuals with developmental disabilities area often lacking in opportunities for hands on practice and implementation of these strategies. Developing training using video and online capabilities can be one solution to overcoming the 
barriers associated with the development of effective and efficient trainings. Previous research demonstrates staff training programs relying on only verbal-skill strategies alone (e.g., lectures, presentation of written and visual material) can enhance targeted information, but often are ineffective for teaching learners to perform newly targeted job skills (Parsons, Rollyson, \& Reid, 2011). Outcomes of the current study support the results of previous studies teaching staff the steps of preference assessments through the use of technology without a trainer present (Deliperi, et al., 2015; Delli Bovi, et al., 2017; Lipschultz, et al., 2015; Rosales, et al., 2015; Weldy, et al., 2014).

This training used both performance and competency-based strategies, both necessary for evidence based staff training (Parsons, et al., 2011; Reid, et al., 2003). This study provided competency based training in the form of practicing the skill until he or she is able to completely demonstrate the skill by utilizing behavior skills training steps of (1) instructions, (2) modeling, (3) rehearsal, and (4) feedback. By using simulated clients, this allowed the participant to perform the 11 steps of the preference assessment until a mastery criterion of $90 \%$ accurate implementation of the steps were achieved. All four participants in this study achieved mastery of the target steps in two sessions with simulated clients.

By utilizing computer-based training to enhance training opportunities and increase efficiency, the participants were given the same type of training opportunities used in evidence based training, but without the need for a live trainer. This allowed for maintaining the effectiveness and quality of the training while decreasing cost. Baseline sessions average mean was $53.6 \%$ across the four participants and after the computer training, the ability for staff to implement the 11 steps of the preference assessment correctly increased to a mean average of 96.6\%. All participants achieved mastery of the target skills within two sessions with simulated 
clients. The average duration of the training across participants was about 40 minutes in duration.

This study also addressed the limitation of Weldy et al. (2014) in regard to training staff with little experience in implementation of behavior analytic strategies or intervention. Weldy et al. (2014) participants had at least one year of behavior analytic studies, implementation of behavior analytic interventions, and data collection. There was a concern that this type of training might not be an adequate training method for individuals with less experience or education in the field, such as newly hired line therapists (e.g., registered behavior technicians or behavior implementers). The four participants were all in process of obtaining their RBT certification and three out of four participants had no experience implementing any behavior interventions. One participant had some previous experience implementing ABA procedures, but no experience implementing preference assessments. All four entry level participants were able to complete the steps of the assessment and maintained mastery levels into maintenance.

One participant from this study did require the addition of a performance feedback component. This was also similar to other studies using technology for staff training. A summary of the results of a group of studies outlined by Gerencser (2020) indicate that $69.55 \%$ (16 out of 22) participants met performance criterion that was set by each individual research study at the end of the training. Performance dropped below criterion during maintenance and/or generalization phases for some participants in three of the studies (Higbee et al., 2016; Pollard et al., 2014; Wainer \& Ingersoll, 2013). Performance feedback was added to each of these studies during these phases to achieve mastery criterion. Pollard et al. (2014) used computer-based training to increase implementation of the steps of an intervention for discrete trial instruction. One of their participants also required a feedback session during the intervention phase. This 
study also used participants that had no prior experience or training with the intervention being taught. Rosales et al. (2015) also required performance feedback as an extra step for one participant who did not meet mastery criteria after the fourth training session. This seems to indicate that it would be important to continue to monitor staff implementing new procedures with clients and collecting procedural integrity data to ensure consistent and accurate implementation of the targeted steps. Providing performance feedback is common and often typical with behavior staff working under the supervision of a behavior analyst. Working in the educational setting with teacher or paraprofessionals or home setting with families would be important to ensure that ongoing monitoring is established by the supervisor.

\section{Limitations and future research}

Previous research identifies that a limitation of the free-operant preference assessment is that they are less likely to generate a hierarchy of most to least preferred items as compared to other preference assessment like the paired stimulus and MSWO (Boyle, et al., 2019; Kang et al., 2013; Verriden \& Roscoe, 2016). This is because the individual may allocate all of his or her time during the assessment toward only one or two items (Roane et al., 1998). This was observed during the generalization and maintenance phases of this study with actual clients. Two of the clients during two assessments allocated over $80 \%$ of their time interacting with one item from the assessment. Boyle et al. (2019) has suggested that this limitation may be circumvented with the ability to frequently update preferences on a daily basis due to the quick and easy presentation (Kang et al., 2013).

There were some limitations to this study that could be helpful to future research. For example, during the computer training, the participants were in the office with the computer without anyone present. During that time, data was not collected on if they participated in the 
activities during the training (e.g., completing sample data and practice activities). Although all participants met mastery criteria on the post test, it would be beneficial to identify if all of the activities during the training were necessary. Future research could use permanent product measures to identify completion of most of these activities.

Another limitation was the need to provide performance feedback to one participant. For the purpose of research, it may have been a better option for the participant to view the video again to have the training be only computer based. However, it is also believed that supervisors will be monitoring this training with clients, particularly in the beginning, to ensure consistent and accurate implementation. Supervisors should present and collecting treatment fidelity to review with the trainees on a regular basis as part of their training.

Third, maintenance of preference assessment was only completed with three of the four participants in this study. The fourth participant, Rose, did not transition to the behavior department on the timeline anticipated and continued working in the role of direct care staff over these weeks. Because this participant did not have the opportunity to use her skills in implementing preference assessments with clients during sessions, it was believed that these results would be unable to capture maintenance of the skills taught. The training will be repeated with this participant before working implementing preference assessments with clients. The other three participants were able to demonstrate $100 \%$ maintenance of target steps during their sessions two weeks after the training with clients.

For future research, it would be beneficial to include additional atypical responses during the initial training to ensure the participants have more opportunities to identify ways to respond when the individual does not respond as anticipated. For example, during one trial with an adult with developmental disabilities, the participant did not continue to collect data correctly when 
the client picked up two items and held them in his hands for most of the assessment. Also, the individual did not sit down at the table and the participant was unsure how to respond initially. Completing a sample video session during the training in various locations and ways (e.g., allowing the client to stand up with items on the table in front of him, placing items on the floor, placing items on large tray with client sitting on couch, etc.) would be beneficial for the participants. Future research should explore using these training methods in a group training for new staff. Many agencies and school districts prefer training in group setting, and increasing the research foundation in this area is recommended. Future research should also explore providing these types of trainings to families and school staff. Providing evidence based training to this population is advantageous in addressing developing performance skills inside the classroom and home setting more effectively and efficient. Finally, social validity was also not collected during this study. Additional information on the views of the participants regarding the training would be recommended for future research.

Identifying effective training standards for staff working with individuals with developmental disabilities is a vital part of any human service organization. This study contributed to the literature by analyzing a cost effective and high quality training method that can be used to teach those working directly with individuals with developmental and intellectual disabilities to implement a free-operant preference assessment. 


\section{References}

Bishop, M. R. \& Kenzer, A. L. (2012). Teaching behavioral therapists to conduct brief preference assessments during therapy sessions. Research in Autism Spectrum Disorders, 6, 450-457. doi: 10.1016/j.rasd.2011.07.005

Boyle, M. A., Curtis, K. S., Forck, K. L., Fudge, B. M., Speake, H. N., \& Pauls, B. P. (2019). A replication of the response-restriction preference assessment. Behavioral Interventions, 34, 564 -576. https://doi.org/10. 1002/bin.1683

Brock, M. E. \& Carter, E. W. (2013). Effects of a professional development package to prepare special education paraprofessionals to implement evidence-based practice. The Journal of Special Education. Advance online publication.

http://dx.doi.org/10.1177/0022466913501882

Carr, J. E., Nicolson, A. C., \& Higbee, T. S. (2000). Evaluation of a brief multiple-stimulus preference assessment in a naturalistic context. Journal of Applied Behavior Analysis, 33, 353-357. doi:10.1901/ jaba.2000.33-353.

Cote, C. A., Thompson, R. H., Hanley, G. P., \& McKerchar, P. M. (2007). Teacher report and direct assessment of preferences for identifying reinforcers for young children. Journal of Applied Behavior Analysis, 40, 157-166.

DaFonte, M.A. \& Capizzi, A.M., (2015). A module-based approach: Training paraeducators on evidence-based practices. Physical Disabilities: Education and Related Services, 34(1), 31-54. doi: 10.14434/pders.v34i1.13823

Deliperi, P., Vladescu, J. C., Reeve, K. F., Reeve, S. A., \& DeBar, R. M., (2015). Training staff to implement a paired-stimulus preference assessment using video modeling with voiceover instruction. Behavioral Interventions, 30, 314-332. doi: 10.1002/bin.1421. 
DeLeon, I.G. \& Iwata, B.A. (1996). Evaluation of a multiple-stimulus presentation format for assessing reinforcer preferences. Journal of Applied Behavior Analysis 29, 519-532.

Delli Bovi, G. M., Vladescu, J. C., DeBar, R. M., Carroll, R. A., \& Sarokoff, R. A. (2017). Using video modeling with voice-over instruction to train public school staff to implement a preference assessment. Behavior Analysis in Practice, 10(1), 72-76. http://doi.org/10.1007/s40617-016-0135-y

Egel, A. L. (1981), Reinforcer variation: Implications for motivating developmentally disabled children. Journal of Applied Behavior Analysis, 14, 345-350. doi:10.1901/jaba.1981.14$\underline{345}$

Fazzio, D., Martin, G. L., Arnal, L., \& Yu, D. C. T. (2009). Instructing university students to conduct discrete-trials teaching with children with autism. Research in Autism Spectrum Disorders, 3(1), 57-66. doi:10.1016/j.rasd.2008.04.002

Feldman, E. K. \& Matos, R. (2013). Training paraprofessionals to facilitate social interactions between children with autism and their typically developing peers. Journal of Positive Behavior Interventions, 15(3), 169-179. http://dx.doi.org/10.1177/1098300712457421

Granpeesheh, D., Tarbox, J., Dixon, D. R., Peters, C. A., Thompson, K., \& Kenzer, A. (2010). Evaluation of an eLearning tool for training behavioral therapists in academic knowledge of applied behavior analysis. Research in Autism Spectrum Disorders, 4, 11-17. doi:10.1016/j.rasd.2009.07.004

Gerencser, K. \& Akers, J. \& Becerra, L. \& Higbee, T., \& Sellers, T. (2020). A Review of Asynchronous Trainings for the Implementation of Behavior Analytic Assessments and Interventions. Journal of Behavioral Education. 29, 122-152. 10.1007/s10864-01909332-x. 
Graff, R. B. \& Karsten, A. M. (2012a). Assessing preferences of individuals with developmental disabilities: a survey of current practices. Behavior Analysis in Practice, 5, 37-48. doi:10.1901/ jaba.1992.25-491.

Graff, R. B., \& Karsten, A. M. (2012b). Evaluation of a self-instruction package for conducting stimulus preference assessments. Journal of Applied Behavior Analysis, 45, 69-82.

Higbee, T. S., Aporta, A. P., Resende, A., Nogueira, M., Goyos, C., \& Pollard, J. S. (2016). Interactive computer training to teach discrete trial instruction to undergraduates and special educators in Brazil. Journal of Applied Behavior Analysis. Advance online publication. doi:10.1002/jaba.329.

Johnson, B. M., Miltenberger, R. G., Egemo-Helm, K., Jostad, C. J., Flessner, C., \& Gatheridge, B. (2005). Evaluation of behavioral skills training for teaching abduction-prevention skills to young children. Journal of Applied Behavior Analysis, 38, 67-78.

Kang, S., O'Reilly, M., Lancioni, G., Falcomata, T. S., Sigafoos, J., \& Xu, Z. (2013). Comparison of the predictive validity and consistency among preference assessment procedures: A review of the literature. Research in Developmental Disabilities, 34(4), 1125-1133. http://dx.doi.org/10.1016/j.ridd.2012.12.021

Karsten, A. M., Axe, J. B., \& Mann, C. C. (2015). Review and Discussion of Strategies to Address Low Trainer-to-Staff Ratios. Behavioral Interventions, 30(4), 295-313. DOI: $10.1002 /$ bin. 1420

Leaf, J. Milne, C., Aljohani, W., Ferguson, J., Cihon, J., Oppenheim-Leaf, M., McEachin, J., \& Leaf, R., (2019). Training change agents how to implement formal preference assessments: A review of the literature. Journal of Developmental and Physical Disabilities. 10.1007/s10882-019-09668-2. 
Lerman, D. C., Tetreault, A., Hovanetz, A., Strobel, M., \& Garro, J. (2008). Further Evaluation of a Brief, Intensive Teacher-Training Model. Journal of Applied Behavior Analysis, 41(2), 243-248. http://doi.org/10.1901/jaba.2008.41-243

Lipschultz, J. L., Vladescu, J. C., Reeve, K. F., Reeve, S. A., \& Dipsey, C. R. (2015). Using video modeling with voiceover instruction to train staff to conduct stimulus preference assessments. Journal of Developmental and Physical Disabilities, 27, 505-532.

Maffei-Almodovar, L. \& Sturmey, P. (2018). Change agent training in behavior analytic procedures for people with developmental and intellectual disabilities: A meta-analysis. Review Journal of Autism and Developmental Disorders. Advance online publication, 5, 129-141. https://doi.org/10.1007/s40489- 018-0128-6.

McCulloch, E. \& Noonan, M. (2013). Impact of online training videos on the implementation of mand training by three elementary school paraprofessionals train staff to implement discrete-trial instruction. Education and Training in Autism and Developmental Disabilities, 48 (1).

Nosik, M. R. \& Williams, W. L. (2011). Component evaluation of a computer based format for teaching discrete trial and backward chaining. Research in Developmental Disabilities, 32, 1694-1702. doi: 10.1016/j.ridd.2011.02.002

Nosik, M. R., Williams, W. L., Garrido, N., \& Lee, S. (2013). Comparison of computer based instruction to behavior skills training for teaching staff implementation of discrete-trial instruction with an adult with autism. Research in Developmental Disabilities, 34, 461468. doi: 10.1016/j.ridd.2012.08.011 
Nottingham, C. L., Vladescu, J. C., Giannakakos, A. R., Schnell, L. K., \& Lipschultz, J. L. (2017). Using video modeling with voiceover instruction plus feedback to train implementation of stimulus preference assessments. Learning and Motivation, 58, 37-47.

Pace, G. M., Ivancic, M. T., Edwards, G. L., Iwata, B. A., \& Page, T. J. (1985). Assessment of stimulus preference and reinforcer value with profoundly retarded individuals. Journal of Applied Behavior Analysis 18, 249-255.

Parsons, M. B., Rollyson, J. H., \& Reid, D. H. (2011). Evidence-based staff training: A guide for practitioners. Behavior Analysis in Practice. 5(2), 2-11.

Piazza, C. C., Roane, H. S., \& Karsten, A. (2011). Identifying and enhancing the effectiveness of positive reinforcement. In W. W. Fisher, C. C. Piazza, \& H. S. Roane (Eds.), Handbook of applied behavior analysis (pp. 151-164). New York: Guilford Press.

Pollard, J. S., Higbee, T. S., Akers, J. S. \& Brodhead, M. T. (2014). An evaluation of interactive computer training to teach instructors to implement discrete trials with children with autism. Journal of Applied Behavior Analysis, 47, 765-776. doi:10.1002/jaba.15

Reid, D. H., Rotholz, D. A., Parsons, M. B., Morris, L., Braswell, B. A., Green, C. W., \& Schell, R. M. (2003). Training human service supervisors in aspects of positive behavior support: Evaluation of a state-wide, performance-based program. Journal of Positive Behavior Interventions, 5, 35-46.

Roane, H. S., Vollmer, T. R., Ringdahl, J. E., \& Marcus B. A. (1998). Evaluation of a brief stimulus preference assessment. Journal of Applied Behavior Analysis 31, 605-620.

Rosales R., Gongola L., \& Homlitas C. (2015). An evaluation of video modeling with embedded instructions to teach implementation of stimulus preference assessments. Journal of Applied Behavior Analysis, 48, 209-214. doi: 10.1002/jaba.174. 
Roscoe, E. M. \& Fisher, W. W. (2008). Evaluation of an efficient method for training staff to implement stimulus preference assessments. Journal of Applied Behavior Analysis, 41, $249-254$.

Roscoe, E. M., Fisher, W. W., Glover, A. C., \& Volkert, V. M. (2006). Evaluating the relative effects of feedback and contingent money for staff training of stimulus preference assessments. Journal of Applied Behavior Analysis, 39, 63-77. doi: 10.1901/jaba.2006.705

Verriden, A. L. \& Roscoe, E. M. (2016). A comparison of preference-assessment methods. Journal of Applied Behavior Analysis, 49, 265-285. https://doi.org/10.1002/jaba.30

Vladescu, J. C., Carroll, R., Paden, A., \& Kodak, T. M. (2012). The effects of video modeling with voiceover instruction on accurate implementation of discrete trial instruction. Journal of Applied Behavior Analysis, 45(2), 419-423. http://doi.org/10.1901/jaba.2012.45-419

Wainer, A. L. \& Ingersoll, B. R. (2013). Disseminating ASD interventions: A pilot study of a distance learning program for parents and professionals. Journal of Autism and Developmental Disorders, 43, 11-24. doi:10.1007/s10803-012-1538-4

Weldy, C. R., Rapp, J. T., \& Capocasa, K. (2014). Training staff to implement brief stimulus preference assessments. Journal of Applied Behavior Analysis, 47, 214-218. 
SECTION SIX:

SCHOLARLY PRACTIONER REFLECTION 
While exploring motivation throughout this dissertation, it takes me full circle regarding my own motivation in beginning this doctoral program. I have a love of learning and enjoying challenging myself by setting goals in all areas of my life. These have stayed a constant presence throughout my life. Working for my doctorate was a natural progression in my professional career. Initially, I planned on completing my doctorate degree to teach at a university level. However, the direction of my career was destined for other paths. In any circumstance, finishing my doctorate stood for being at the top of my field.

As a supervisor, I have many opportunities to be a leader in many different arenas, such as clinics, schools, universities, and with families. I was intrigued by the name "Educational Leadership" upon first exploring the program. As a behavior analyst, I have had the pleasure of working within school settings with teachers, therapists, and principals. Beginning this program, I believed I understood the meaning of leadership and thought of myself as a strong leader. This program provided me with a level of understanding about being a leader in so many different facets that I did not realize I was missing. Not only was I able to learn about all of the leadership theories and take important pieces from each of these areas, I also was able to focus on learning about me and how I approached leadership and how others viewed me as a leader.

I identified with servant leadership in my role as a supervisor in my work. To me, this meant that developing a team of individuals to work alongside, to teach them and allow them to grow as professionals was very important to me. I was able to identify my strengths and focus on increasing them to be a better leader. I also learned that I tend to hide in this servant role when things are tough and when difficult conversations must occur. I realized that I must make myself be in these uncomfortable situations with others in order be an effective leader. Just after completing the coursework of the Educational Leadership program, I accepted a leadership role 
within a new private funded organization after leaving the university. As the Director of Therapy, I thought this was the pinnacle of my career, moving into a leadership role as a director. Everyone encouraged me to move into this position and I thought it was just the next step in my upward professional ascent. However, I quickly found myself in a very difficult position within the organization. My leadership style as a servant leader focuses on building trustworthy relationships, team building, and encouraging an overall sense of each person belonging in the workplace. This takes time to put into place and build the necessary trust and relationships among staff. However, the leadership in the organization was weak and engaged in actions that did not promote team building, but rather each person had to protect themselves. Turnover was very high, staff was distrustful of management, and management did not identify value in taking care of their employees. I had tough discussions with management about staff support, team building, creating trust, developing meaningful training opportunities, however, the focus on the new business was on the bottom line, and staff were simply viewed as an expendable commodity. As I realized I was not a good fit for this organization and their intent was not to change their methods, I left the organization. This was a low point of my career, however when my son expressed his thankfulness that I left the position because "mom was always unhappy", I knew I had made the correct decision. Opportunities for growth as a professional, leader, and person are in many forms. Sometimes, the most difficult, the most gut wrenching action is the most beneficial and provides the best opportunity for personal growth. I am now self-employed and working in school districts as a behavior analyst. I have realized that many people believe achieving more recognition, more status is how one evaluates a successful career. However, I have come to realize, that for me, being a leader and leading a balanced life, full of fun, family, and helping others is my definition of true success. Being a part of this program, I may never 
have stepped outside of trying something different and stayed within a position that I stagnant. It was always my dream to work for myself, but I was too scared to make that leap. Without going through all of the struggles and challenges within that organization, I would likely have not taken the jump to working for myself. Having the knowledge and training from this program provided me with the expertise in navigating through these rough waters. While the result of making this change was not what I had planned nor asked for, I have come out on the other side a much stronger and capable leader that could not ask for a better balance at life both professionally and personally. 
Appendix 1

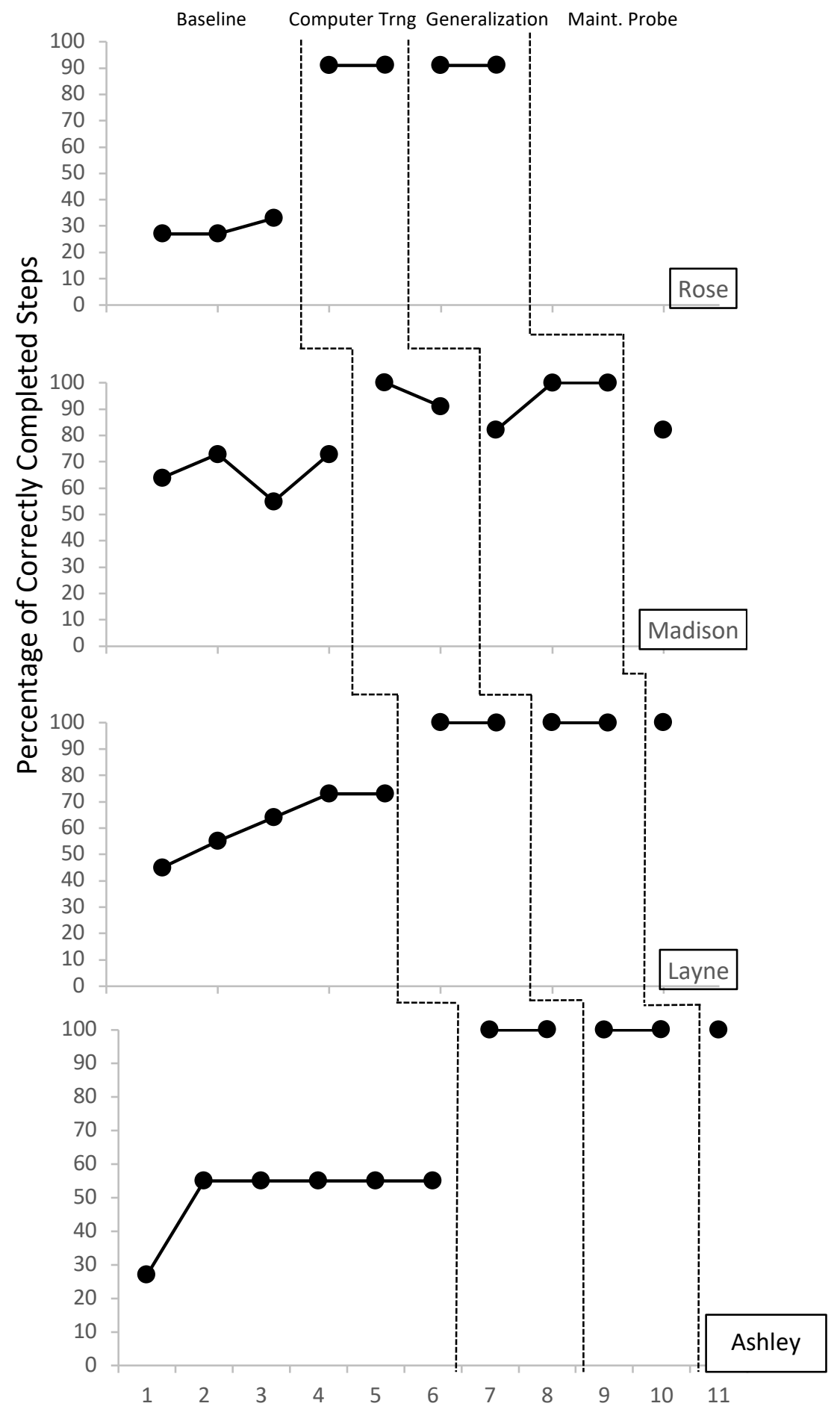

Figure 3. Percentage of correctly performed steps of the 11-step task analysis for conducting the FO preference assessment 
Appendix 2

Free-operant (FO) Preference Assessment Training:

Pre-Test

1. The duration of a FO preference assessment is:
a. Untimed
b. 5-minutes
c. variable, could take between 3-8 minutes
d. 15-minutes

2. An example of an indirect method of identifying preference is:
a. Interviews
b. Checklists
c. Surveys
d. All of the above

3. Research suggest that highly preferred items are more effective as reinforcer for skill acquisition than low and moderately preferred items. TRUE or FALSE

4. What methods are important to identify preference of individuals?
a. Indirect methods only
b. Direct methods only
c. Combination of indirect and direct methods
d. None of the above

5. How long should each item be presented to the client before beginning the preference assessment?
a. 20-seconds
b. 30-seconds
c. This step is not necessary
d. as long as the consumer wants to manipulate the item (but no longer than 5 minutes)

6. How does one best determine what items should be used during preference assessments with consumers you are not familiar with?
a. Pick out items another consumer enjoyed that you worked with previously
b. Use a preference checklist completed by someone familiar with the consumer
c. Use materials from task boxes that the consumer may be familiar with
d. None of the above

7. Data is recorded based on the stimuli being manipulated using what type of data collection method for FO preference assessment?
a. Partial interval recording
b. Whole interval recording
c. Momentary time sampling
d. Trial by trial data 
8. Momentary time sample data is collected in the following manner:

a. You record each item the consumer is touching at any time during the 10 second interval

b. You will watch the timer and every time 10 seconds elapses, you will look up and see which item the consumer is touching and record that item on your data sheet

c. You record each item the consumer is touching during the entire 10 second interval

d. You record every time the consumer touches any item during the 5-minute assessment.

9. If two or more items are manipulated simultaneously, for data collection, you would:

a. Do not record any of the items for that interval (they would cancel themselves out)

b. Record (place a "X") only under one column for the item the consumer manipulated for the longest duration

c. Record (place a "X") in both columns for each item

d. Stop the preference assessment

10. The duration of the assessment is:

a. 5-minutes, regardless of the amount of item manipulation

b. 5-minutes generally, but can stop the assessment if item manipulation does not occur for 3-minutes consecutively

c. Add additional minutes as long as the consumer is engaged with the items

d. 10-minutes

11. At the end of the assessment, the total intervals the slinky was manipulated was 10 intervals out of 30 intervals. What is the $\%$ of interval the slinky was manipulated?
a. $33 \%$
b. $50 \%$
c. $30 \%$
d. you cannot calculate the percentage based on the information provided

12. The following percentages were obtained during a preference assessment for 5 items, use these percentages to rank the items from 1 being the highest percentage to 5 being the lowest percentage.

\begin{tabular}{|l|l|l|l|l|l|}
\hline & $\begin{array}{l}\text { Car } \\
18 \%\end{array}$ & $\begin{array}{l}\text { Play-doh } \\
48 \%\end{array}$ & $\begin{array}{l}\text { Music toy } \\
20 \%\end{array}$ & $\begin{array}{l}\text { Ball } \\
40 \%\end{array}$ & $\begin{array}{l}\text { Cymbals } \\
55 \%\end{array}$ \\
\hline Rank: & & & & & \\
\hline
\end{tabular}

13. Write the total intervals the items were manipulated based on the example below:

a. Squishy ball: 130 
b. Train: 130

14. Write the $\%$ of interval for the squishy ball and train based on the fraction above:
a. Squishy ball: $\%$
b. Train: $\%$

Example (use for question 13 and 14):

\begin{tabular}{|c|c|}
\hline 4 squishy ball & 5.trsin \\
\hline & \\
\hline $\mathbf{X}$ & \\
\hline $\mathbf{X}$ & \\
\hline & \\
\hline & \\
\hline $\mathbf{X}$ & $\mathbf{X}$ \\
\hline $\mathrm{X}$ & \\
\hline $\mathrm{X}$ & \\
\hline & \\
\hline & \\
\hline $\mathbf{X}$ & \\
\hline & \\
\hline & $\mathbf{X}$ \\
\hline & $\mathrm{X}$ \\
\hline & \\
\hline $\mathbf{x}$ & \\
\hline & \\
\hline & $\mathbf{X}$ \\
\hline $\mathbf{X}$ & $\mathbf{X}$ \\
\hline & \\
\hline & \\
\hline & \\
\hline & \\
\hline $\mathrm{X}$ & \\
\hline 130 & $/ 30$ \\
\hline
\end{tabular}


Appendix 3

Free-operant (FO) Preference Assessment Training:

Post-Test

1. The duration of a FO preference assessment is:
a. Untimed
b. 5-minutes
c. variable, could take between 3-8 minutes
d. 15-minutes

2. An example of an indirect method of identifying preference is:
a. Interviews
b. Checklists
c. Surveys
d. All of the above

3. Research suggest that highly preferred items are more effective as reinforcer for skill acquisition than low and moderately preferred items. TRUE or FALSE

4. What methods are important to identify preference of individuals?
a. Indirect methods only
b. Direct methods only
c. Combination of indirect and direct methods
d. None of the above

5. How long should each item be presented to the consumer before beginning the preference assessment?
a. 20-seconds
b. 30-seconds
c. This step is not necessary
d. as long as the consumer wants to manipulate the item (but no longer than 5 minutes)

6. How does one best determine what items should be used during preference assessments with consumers you are not familiar with?
a. Pick out items another consumer enjoyed that you worked with previously
b. Use a preference checklist completed by someone familiar with the consumer
c. Use materials from task boxes that the consumer may be familiar with
d. None of the above

7. Data is recorded based on the stimuli being manipulated using what type of data collection method for FO preference assessment?
a. Partial interval recording
b. Whole interval recording
c. Momentary time sampling
d. Trial by trial data 
8. Momentary time sample data is collected in the following manner:

a. You record each item the consumer is touching at any time during the 10 second interval

b. You will watch the timer and every time 10 seconds elapses, you will look up and see which item the consumer is touching and record that item on your data sheet

c. You record each item the consumer is touching during the entire 10 second interval

d. You record every time the consumer touches any item during the 5-minute assessment.

9. If two or more items are manipulated simultaneously, for data collection, you would:

a. Do not record any of the items for that interval (they would cancel themselves out)

b. Record (place a "X") only under one column for the item the consumer manipulated for the longest duration

c. Record (place a "X") in both columns for each item

d. Stop the preference assessment

10. The duration of the assessment is:

a. 5-minutes, regardless of the amount of item manipulation

b. 5-minutes generally, but can stop the assessment if item manipulation does not occur for 3-minutes consecutively

c. Add additional minutes as long as the consumer is engaged with the items

d. 10-minutes

11. At the end of the assessment, the total intervals the slinky was manipulated was 22 intervals out of 30 intervals. What is the $\%$ of interval the slinky was manipulated?
a. $80 \%$
b. $73 \%$
c. $63 \%$
d. you cannot calculate the percentage based on the information provided

12. The following percentages were obtained during a preference assessment for 5 items, use these percentages to rank the items from 1 being the highest percentage to 5 being the lowest percentage.

\begin{tabular}{|l|l|l|l|l|l|}
\hline & $\begin{array}{l}\text { Car } \\
10 \%\end{array}$ & $\begin{array}{l}\text { Play-doh } \\
60 \%\end{array}$ & $\begin{array}{l}\text { Music toy } \\
40 \%\end{array}$ & $\begin{array}{l}\text { Ball } \\
80 \%\end{array}$ & $\begin{array}{l}\text { Cymbals } \\
19 \%\end{array}$ \\
\hline Rank: & & & & & \\
\hline
\end{tabular}

13. Write the total intervals the items were manipulated based on the example below:

a. Squishy ball: 130 
b. Train: 130

14. Write the $\%$ of interval for the squishy ball and train based on the fraction above:
a. Squishy ball: $\%$
b. Train: $\%$

Example (use for question 13 and 14):

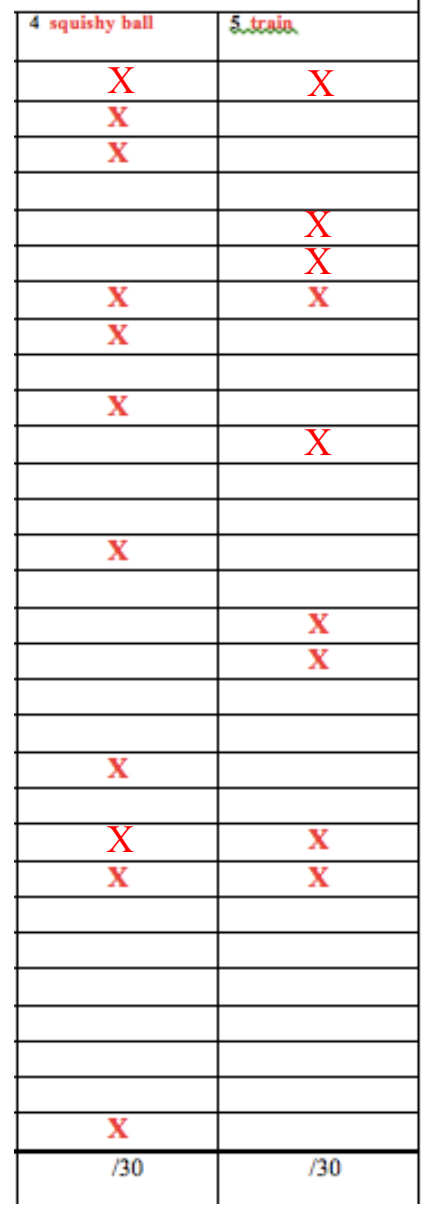




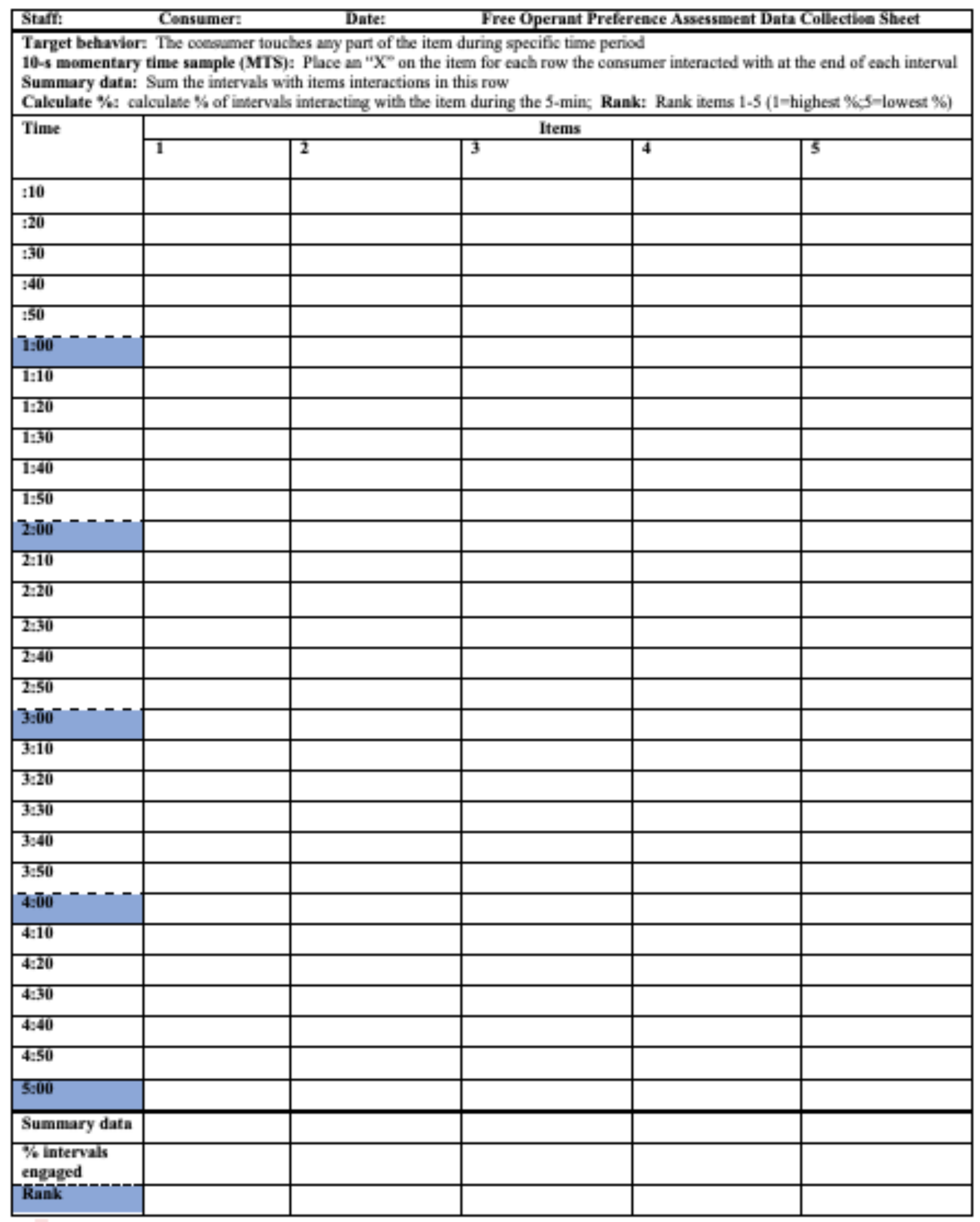




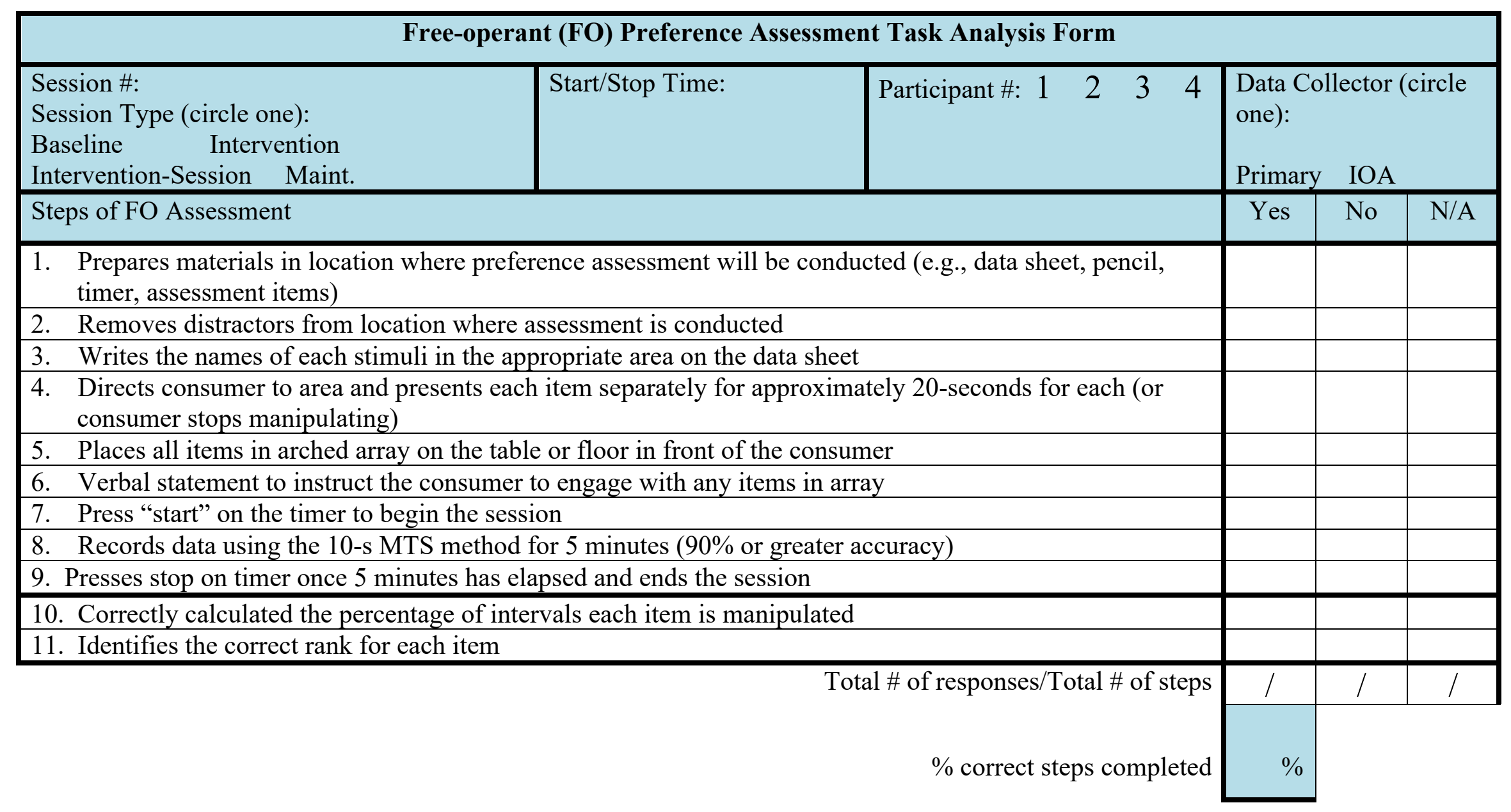

